\title{
(ब(I)
}

AUTARQUIA ASSOCIADA À UNIVERSIDADE DE SÃO PAULO

\section{ESTUDO DA DEPOSIÇÃO ELETROFORÉTICA DE 3YTZP EM TITÂNIO METÁLICO E AVALIAÇÃO DA IRRADIAÇÃO COM LASER}

Gleicy de Lima Xavier

Dissertação apresentada como parte dos
requisitos para obtenção do Grau de
Mestre em Ciências na Área
de Tecnologia Nuclear-Materiais

Orientador:

Prof. Dr. Nelson Batista de Lima 
INSTITUTO DE PESQUISAS ENERGÉTICAS E NUCLEARES AUTARQUIA ASSOCIADA À UNIVERSIDADE DE SÃO PAULO

ESTUDO DA DEPOSIÇÃO ELETROFORÉTICA DE 3YTZP EM TITÂNIO METÁLICO E AVALIAÇÃO DA IRRADIAÇÃO COM LASER

GLEICY DE LIMA XAVIER

Dissertação apresentada como parte dos requisitos para obtenção do Grau de Mestre em Ciências na Área de Tecnologia Nuclear - Materiais.

Orientador:

Dr. Nelson Batista de Lima

SÃO PAULO 


\section{DEDICATÓRIA}

A Deus,

Por sempre ter e dado discernimento para a realização deste trabalho.

Ao meu querido esposo Ramon,

Pelo amor incondicional, companheirismo e paciência. Sem sua constante dedicação e compreensão seria impossível a realização deste trabalho.

Aos meus amados pais, José Idimar e Roseni, Vocês são a minha inspiração de vida. É em vocês que encontro forças para lutar e seguir em frente. Todo amor do mundo encontro em vocês.

À minha querida irmã, Grazielly

Minha melhor amiga, com quem posso contar em qualquer momento para qualquer coisa. Você é meu exemplo de perseverança.

À toda a minha família, avós, tios e primos,

Que sempre entenderam o motivo da minha ausência. E sabem que mesmo estando longe, meu amor por vocês só aumenta. 


\section{AGRADECIMENTOS}

Agradeço a Deus por me ter me dado força e sabedoria para a realização deste trabalho.

Agradeço a querida minha mãe, Roseni, que mesmo estando longe, sempre me motivou mesmo que por telefone. Sempre me amparou nas horas de desânimo e cansaço.

Agradeço ao meu pai, José Idimar, que com todo carinho sempre me fortaleceu, sempre me incentivando a seguir em frente.

A minha irmã Grazielly, que sempre me ouvia, e me incentivava a nunca desanimar, apesar da saudade e da distância.

Ao meu esposo, Ramon, pela compreensão de minhas eventuais ausências, por sempre me incentivar a buscar o melhor, pelo zelo e dedicação, e o aconchego, e por não me deixar desistir quando tudo parecia não dar certo.

Agradeço imensamente ao meu orientador Prof. Dr. Nelson Batista de Lima, pela oportunidade de desenvolvimento deste trabalho e pelo tempo dedicado à minha orientação. Obrigada pelos conselhos, correções, e também pela amizade.

Ao Dr. Valter Ussui, pela amizade, ajuda, ensinamentos e as correções feitas no desenvolver deste trabalho.

Ao Dr. Antônio. A. Couto por todo o apoio dado no desenvolver deste trabalho, e também pela amizade.

Ao Dr. Rene Oliveira, obrigada pela amizade, por toda a assistência dada para a elaboração dessa dissertação, pelas conversas e pelos cafés no laboratório de difração de raios $X$.

Ao Me. Mariano Castagnet pela amizade, pelas conversas e também pela ajuda nas análises realizadas no desenvolvimento dessa dissertação.

Ao Dr. Wagner Rossi pelos ensaios de irradiação feito com o Laser Nd:YAG e por toda a contribuição para a realização dessa dissertação.

Ao laboratório de difração de raios $\mathrm{X}$ do CCTM pelo uso dos equipamentos, assim como de outros laboratórios do CCTM pelo uso de suas instalações para o desenvolvimento deste trabalho. 
Aos técnicos do laboratório de microscopia do CCTM Glauson Machado, Flávia Rodrigues, Nildemar Messias e Celso Vieira, pela amizade e também pelas análises realizadas para a realização dessa dissertação.

Ao técnico do laboratório de microscopia multiusuário do Centro de Laser e Aplicações do IPEN, Marcos Scapin pelas análises realizadas no desenvolvimento deste trabalho.

Aos técnicos João e Takeshi da oficina mecânica do Centro de Química e Meio Ambiente do IPEN pela ajuda na confecção do aparato para deposição eletroforética.

À mestranda Janine Nemeh, obrigada pela amizade, e por todas as contribuições para o desenvolvimento dessa dissertação, principalmente pela ajuda na realização do projeto da peça do aparato de deposição eletroforética.

Aos meus queridos amigos, Aline de Fátima, Rafael Denaldi e Jeferson Matsui que me acompanharam desde a faculdade. Obrigada pelas conversas, pelas ajudinhas, pelas risadas e por todos os momentos bons que passamos juntos no Ipen. Vocês com certeza contribuíram para que essa longa caminhada se tornasse mais divertida.

Aos amigos Mariana Lima, Melissa Martins e Rafael Gitti, Michele Biondo pelas conversas, ajudas nas disciplinas e pela amizade. Obrigada também por toda assistência dada no desenvolver deste trabalho.

À CAPES pelo apoio financeiro, que tornou viável a realização deste trabalho.

Ao IPEN pela oportunidade de realização deste trabalho. 
"A persistência é o menor caminho para o êxito." Charles Chaplin 


\title{
ESTUDO DA DEPOSIÇÃO ELETROFORÉTICA DE 3YTZP EM TITÂNIO METÁLICO E AVALIAÇÃO DA IRRADIAÇÃO COM LASER
}

\author{
Gleicy de Lima Xavier
}

\begin{abstract}
RESUMO
O titânio é amplamente empregado em indústrias químicas, geração de energia, aeroespaciais e biomédicas, pois além de suas boas propriedades mecânicas e resistência à corrosão, apresenta também boa biocompatibilidade. Porém, quando usado, por exemplo, em turbinas a vapor é necessário aumentar ainda mais sua resistência à corrosão em altas temperaturas. Ou quando usado em odontologia a cor acinzentada do metal compromete as reabilitações orais. Sendo assim, torna-se interessante o recobrimento do titânio com uma camada cerâmica, sendo a 3YTZP (zircônia tetragonal policristalina) adequada a tal aplicação, pois além de apresentar resistência mecânica, boa resistência a ciclos térmicos, apresenta boa biocompatibilidade. Neste trabalho foi feito o estudo do recobrimento do titânio com 3YTZP utilizando a técnica da deposição eletroforética além de realizar a irradiação do filme cerâmico utilizando o laser contínuo Nd:YAG com a finalidade de sinterização. O pó de 3YTZP foi obtido pela rota de coprecipitação de óxidos em meio amoniacal e caracterizada por DRX e MEV-FEG. Os resultados de DRX do pó mostraram a presença das fases tetragonal e monoclínica, e pelas micrografias observa-se que as partículas têm estruturas alongadas em formas de bastonetes. Por meio da densificação dos corpos cerâmicos foi possível observar boa sinterabilidade do pó. Como substrato para EPD foram utilizadas chapas de titânio $(15 \mathrm{~mm} \times 15 \mathrm{~mm})$ e foram caracterizadas por DRX, que confirmou apenas a presença da fase a do Ti, indicando assim que são de titânio comercialmente puro. As chapas foram atacadas quimicamente com ácido sulfúrico $50 \%$ em volume por $10 \mathrm{~s}$. A deposição eletroforética foi realizada com as suspensões de $75 \%$ vol.acetona: $25 \%$.vol.etanol a $30 \mathrm{~V}$ por 20,45 e 60 segundos; $50 \%$ vol.acetona: $50 \%$ vol.etanol a $20 \mathrm{~V}$ por 30 , 45 e 60 segundos; $25 \%$ vol.acetilacetona: $75 \%$ vol.etanol a $60 \vee$ por 20,40 e 60 segundos e a $40 \mathrm{~V}$ por 20 segundos; e com acetilacetona pura a $60 \mathrm{~V}$ por 20,40 e 60 segundos e a $40 \mathrm{~V}$ por 20 e 40 segundos. Por meio das microscopias ópticas dos filmes depositados pode-se observar que a melhor condição de deposição foi utilizando a suspensão de acetilacetona a $40 \mathrm{~V}$ por 20 segundos, gerando filmes homogêneos e sem trincas. Foram realizados cinco ensaios de irradiação com lazer a fim de alcançar uma condição ideal de sinterização. As condições fixas para todos os ensaios foram energia de $0,5 \mathrm{~J}$, coeficiente de duração de pulso (Tp) de $10 \mathrm{~ms}$ e coeficiente de repetição de pulso de $10 \mathrm{~Hz}$. No decorrer dos ensaios foi variada a fluência do laser e o número de incidência. As amostras irradiadas foram caracterizadas por microscopia óptica e eletrônica, DRX e Scratch, e verificou-se que a melhor condição de irradiação foi utilizando a fluência de $120 \mathrm{~J} / \mathrm{cm}^{2}$ para o número de incidência do laser de igual a 27 .
\end{abstract}

Palavras chave: Deposição eletroforética, sinterização a laser, titânio. 


\title{
STUDY OF ELECTROPHORETIC DEPOSITION OF 3YTZP IN METALLIC TITANIUM AND EVALUATION OF LASER IRRADIATION
}

\author{
Gleicy de Lima Xavier
}

\begin{abstract}
Titanium is widely used in chemical, power generatin, aerospace and biomedical industries because of you good mechanical properties, corrosion resistance and good biocompatibility. However, when is used, for example, in steam turbines is necessary increase the corrosion resistance at high temperature. Or when is used in dentistry, when the gray color compromisse the aesthetics rehab. In this case, it becomes interesting to coat the titanium with a ceramic layers, and 3YTZP (Yttria-stabilized tetragonal zirconia) is suitable for this application, because it has good mechanical properties, good resistance to thermal cycles and good biocompatibility. In this work it was studied the coating of titanium with 3YTZP using electrophoretic deposition technique in addition irradiation of films using the Nd:YAG continuous laser. The 3YTZP powder was obtained by hydroxide coprecipitation route in ammoniacal medium and characterized by XDR and SEM. The XDR results shower presence os monoclinic and tetragonal phases, and micrographs it can be observed the the particles agglomerates. These particles have elongated structure. Through the densification of the ceramic bodies it was possible to observe good sinterability of the powder. Was used as the substrate to EPD titanium plates (dimension $15 \mathrm{~mm} \times 15 \mathrm{~mm}$ ), and was characterized by XRD, that show presence of $\alpha$-fase, thus indicating that they are commercially pure titanium. The plates were chemically etched with $50 \%$ vol. Sulfuric acid for $10 \mathrm{~s}$. Electrophoretic deposition was performed with suspensions of $75 \%$ vol.acetone: $25 \%$.vol.ethanol at $30 \mathrm{~V}$ for 20,45 e 60 seconds; $50 \%$ vol.acetone: $50 \%$ vol.ethanol at $20 \vee$ for 30,45 e 60 seconds; $25 \%$ vol.acetylacetone: $75 \%$ vol.ethanol at $60 \mathrm{~V}$ for 20,40 e 60 seconds and at 40 $\checkmark$ for 20 seconds; and with pure acetylacetone at $60 \mathrm{~V}$ for 20,40 e 60 seconds and at $40 \mathrm{~V}$ for 20 e 40 seconds. From observation in an optical microscope of the deposited films, we concluded that the best deposition condition was the acetylacetone suspension at $40 \mathrm{~V}$ for 20 seconds, being homogeneous films and free of cracks. Five laser irradiation tests were performed in order to achieve an optimum sintering condition. The fixed conditions for all the tests were energy of $0.5 \mathrm{~J}$, pulse duration coefficient (Tp) of $10 \mathrm{~ms}$ and pulse repetition coefficient of 10 $\mathrm{Hz}$. In the course of the tests, the laser fluency and the laser incidence number were varied. The irradiated samples were characterized by optical and electron microscopy, XRD and Scratch, and it was found that the best irradiation condition was using fluency of $120 \mathrm{~J} / \mathrm{cm}^{2}$ and laser incidence number of 27 .
\end{abstract}

Keywords: Electrophoretic deposition, laser sintering, 3Y-TZP, titanium. 


\section{SUMÁRIO}

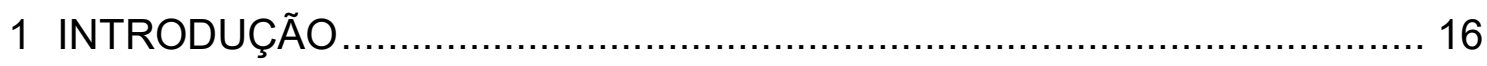

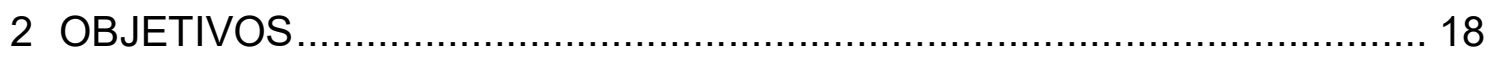

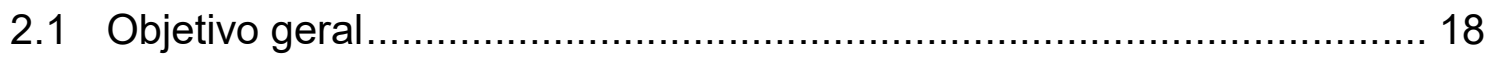

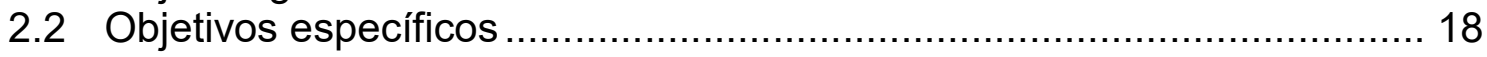

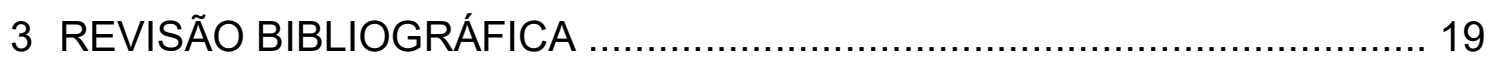

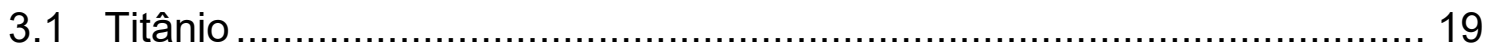

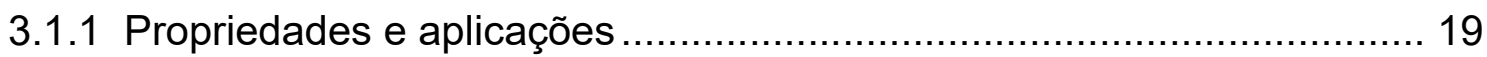

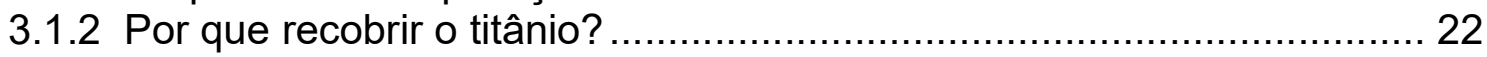

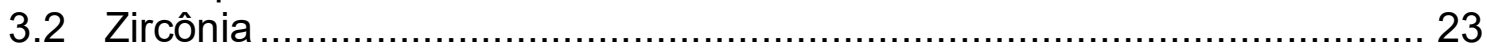

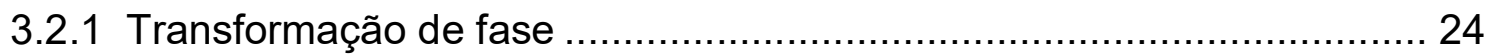

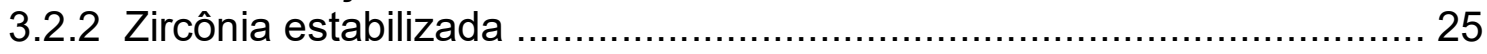

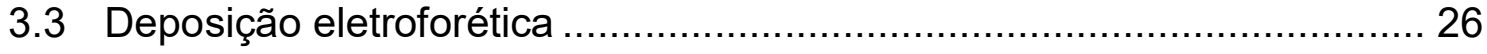

3.3.1 Fatores que influenciam na deposição eletroforética ............................. 28

3.3.1.1 Fatores relacionados à suspensão ............................................... 29

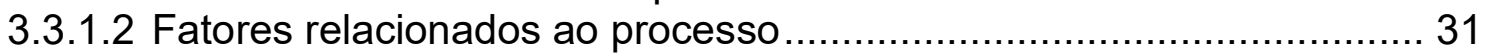

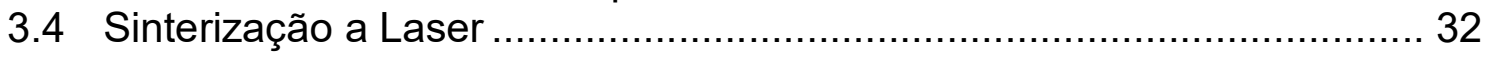

3.4.1 Sinterização a laser de filmes cerâmicos ........................................... 33

3.4.2 Mecanismos de ligação na sinterização a laser ..................................... 33

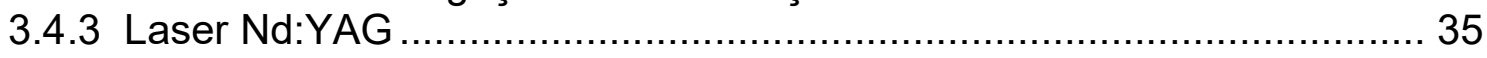

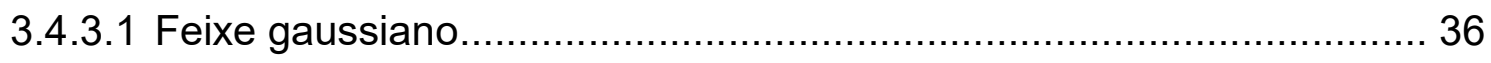

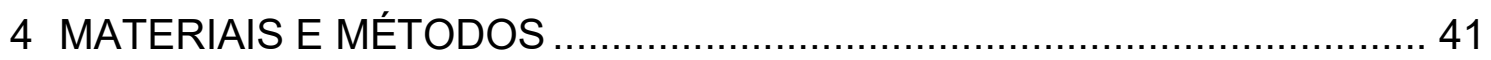

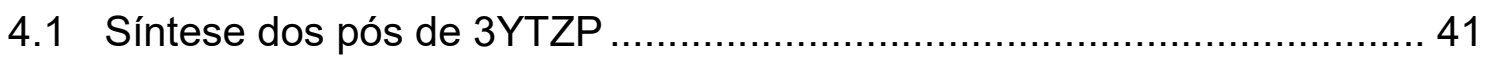

4.1.1 Caracterização do pó de 3YTZP ................................................. 42

4.2 Processamento Cerâmico ................................................................... 43

4.2.1 Caracterização da cerâmica sinterizada ............................................ 44

4.3 Deposição eletroforética .............................................................. 45

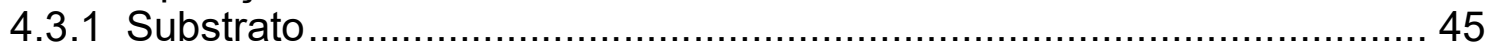

4.3.2 Sistema para deposição eletroforética .............................................. 46

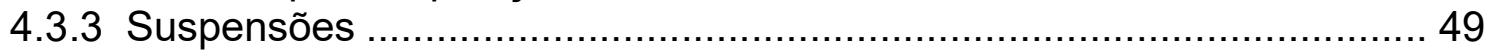

4.3.3.1 Suspensões a base de Acetona …………….............................. 49

4.3.3.2 Suspensões a base de Acetilacetona............................................. 50

4.3.4 Processo de deposição eletroforética …………............................... 51

4.3.5 Caracterização do recobrimento a verde ………............................... 54

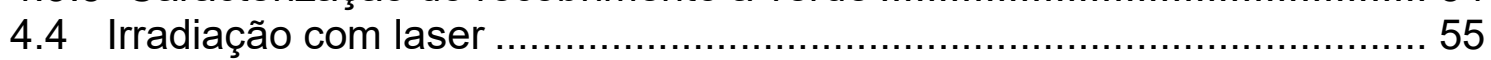

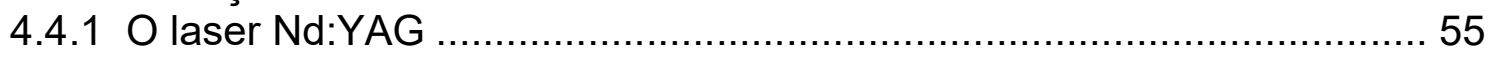

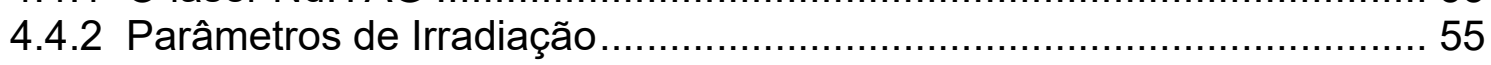

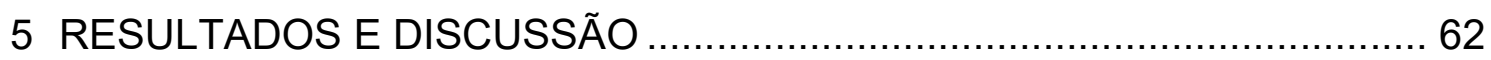


5.1 Caracterização dos pós de 3YTZP

5.2 Caracterização da cerâmica sinterizada de 3YTZP ................................ 63

5.3 Caracterização do substrato para deposição eletroforética ...................... 65

5.4 Suspensões e condições para deposição eletroforética ...........................66

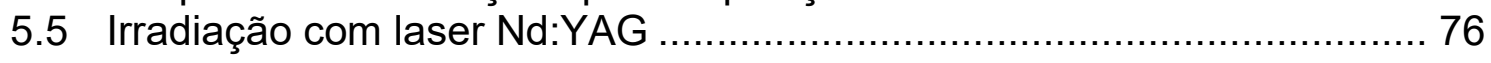

6 CONCLUSÕES

SUGESTÕES PARA TRABALHOS FUTUROS ............................................ 97

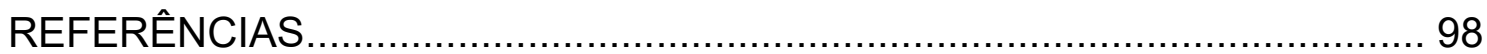




\section{LISTA DE FIGURAS}

Figura 3-1 - Densidade de alguns metais comparada a do titânio [3] 19

Figura 3-2 - Representação esquemática das formas alotrópicas assumidas pelo titânio. (a) estrutura hexagonal compacta - Fase $\alpha$. (b) estrutura cúbica de corpo centrado - Fase $\beta$ [4]. 20

Figura 3-3 - Representação esquemática das três estruturas cristalinas assumidas pela zircônia (a) Cúbica; (b) Tetragonal; (c) Monoclínica [22]........ 24

Figura 3-4 - Representação esquemática do processo de tenacificação da 3YTZP quando submetida a um estado de tensão [21]. 26

Figura 3-5 - Representação esquemática do processo de deposição eletroforética, em que as partículas carregadas negativamente movem-se e depositam-se no eletrodo de carga oposta.

Figura 3-6 - (a) Representação esquemática da dispersão eletrostática das partículas em suspensão. (b) a distorção da dupla camada devido à ação do campo elétrico e (c) arranjo das partículas no eletrodo [28]. 31

Figura 3-7 - Formação do pescoço entre duas partículas de aço obtido com laser $\mathrm{Nd}: Y A G$ [45]. 34

Figura 3-8 - Representação esquemática das etapas da sinterização em fase líquida de uma mistura de pós [46] 35

Figura 3-9 - Raio do feixe gaussiano W (Z) em função da distância $Z$ do feixe de laser relacionando-se a intensidade. (OpenSPIM - Theorical basics. Acessado em 22 de agosto de 2017) [50]. 37

Figura 3-10 - Distribuição do campo elétrico em torno do foco de um feixe gaussiano. (RP Photonics Encyclopedia. Gaussian Beams. Acessado em 22 de agosto de 2017) [51]. 39

Figura 3-11 - Feixe de laser focalizado. (OpenSPIM - Theorical basics. Acessado em 22 de agosto de 2017) [50]. 39

Figura 4-1 - Representação esquemática da síntese dos pós de 3YTZP pela rota de coprecipitação hidróxidos em meio amoniacal. 43

Figura 4-2 - Representação esquemática do processamento cerâmico e caracterização da cerâmica de 3YTZP sinterizada. 45 
Figura 4-3 - Representação esquemática da preparação do substrato de titânio para EPD.

Figura 4-4- Croqui da peça utilizada no sistema de deposição eletroforética. 47

Figura 4-5 - Fotografia do aparato utilizado para o processo de deposição eletroforética. (a) suporte do eletrodo a ser recoberto. (b) suporte para o eletrodo fixo. (c) Sistema para EPD. ........................................................... 48

Figura 4-6 - Fotografia do aparato completo utilizado na EPD....................... 49

Figura 4-7 - Representação esquemática do preparo das suspensões a base de acetona usando etanol como solvente aditivo 50

Figura 4-8 - Representação esquemática do preparo das suspensões a base de acetilacetona.

Figura 4-9 - Representação esquemática das amostras produzidas na série 1 e 2 de EPD. 54

Figura 4-10 - Representação da variação da distância $Z$ ao longo da linha irradiada para o teste 1 para as amostras SA830II e SA830I. 56

Figura 4-11 - Fotografia da amostra SA830II irradiada com laser de Nd:YAG com $Z$ variando de 2 a $5 \mathrm{~mm}$ longo de cada linha.

Figura 4-12 - Amostra SA830I irradiada com laser Nd:YAG com Z variando de 2 a $5 \mathrm{~mm}$ longo de cada linha. 58

Figura 4-13 - Esquema do teste 3 de irradiação 60

Figura 5-1 - Difratograma de raios X do pó de 3YTZP obtido via coprecipitação química e calcinado a $800^{\circ} \mathrm{C}$ por 1 hora. Fase tetragonal (ficha $80-784$ ), fase monoclínica (ficha 70-2491).

Figura 5-2 - MEV-FEG do pó de 3 YTZP calcinado a $800^{\circ} \mathrm{C}$ por 1 hora. 63

Figura 5-3 - Difratograma de raios $X$ da cerâmica de 3YTZP sinterizada a $1500^{\circ} \mathrm{C}$ por 1 hora.

Figura 5-4 - Micrografias da superfície de fratura obtidas por MEV da cerâmica sinterizada a $1500^{\circ} \mathrm{C}$ por 1 hora.

Figura 5-5 - Difratograma de raios $X$ da chapa de titânio utilizada como substrato. 
Figura 5-6 - Micrografias por MEV das amostras produzidas na primeira série de EDP utilizando a suspensão 75Ac. (a) SA830II (30 s, $30 \mathrm{~V}$ ); (b) SA430II (45 s, $30 \mathrm{~V}$ ) e (c) SA130I (60 s, $30 \mathrm{~V}$ ).

Figura 5-7 - Micrografias por MEV das amostras produzidas na primeira série de EPD utilizando a suspensão 50Ac. (a) 1A (30 s, 20 V); (b) 4A (45 s, 20 V) (c) $7 \mathrm{~A}(60 \mathrm{~s}, 20 \mathrm{~V})$.

Figura 5-8 - Micrografias ópticas das amostras produzidas na segunda série de EPD utilizando a suspensão 25Aa. (a) 6E (20 s, 40 V); (b) 6D (20 s, 60 V); (c) $5 \mathrm{D}(40 \mathrm{~s}, 60 \mathrm{~V})$ e (d) 4D (60 s,60 V).

Figura 5-9 - Micrografias ópticas das amostras produzidas na segunda série de EPD com a suspensão 100Aa. (a) 1E (20 s, $40 \mathrm{~V})$; (b) 2E (40 s, $40 \mathrm{~V})$; (c) 3D (20 s, $60 \mathrm{~V})$, (d) 1D (40 s, $60 \mathrm{~V}) ;(\mathrm{e}) 2 \mathrm{D}(60 \mathrm{~s}, 60 \mathrm{~V})$ 71

Figura 5-10 - Micrografias obtidas por MEV das amostras produzidas na série F de deposição usando a suspensão 100Aa (Acetilacetona pura) a $40 \mathrm{~V}$ por 20 S.......

Figura 5-11 - Micrografias das amostras produzidas na série $G$ de deposição com a suspensão 100Aa (Acetilacetona pura) a $40 \mathrm{~V}$ por $20 \mathrm{~s}$.

Figura 5-12 - Distância focal Z relacionada à área do feixe de laser e a fluência.

Figura 5-13 - Micrografias ópticas da amostra SA830II irradiada com laser pulsado Nd:YAG a) primeira e segunda linha de irradiação com velocidade de $450 \mathrm{~mm} / \mathrm{min}$ e $350 \mathrm{~mm} / \mathrm{min}$ e Número de incidência $=1$; b) terceira e quarta linha de irradiação com velocidade de $300 \mathrm{~mm} / \mathrm{min}$ e $250 \mathrm{~mm} / \mathrm{min}$ e Número de incidência $=1$; c) quinta e sexta linha de irradiação com velocidade de 450 $\mathrm{mm} / \mathrm{min}$ e $350 \mathrm{~mm} / \mathrm{min}$ e Número de incidência = 3; d) sétima e oitava linhas de irradiação com velocidade de $300 \mathrm{~mm} / \mathrm{min}$ e $250 \mathrm{~mm} / \mathrm{min}$ e Número de incidência $=3$. 78

Figura 5-14 - Micrografia da amostra irradiada SA830I a) primeira e segunda linha de irradiação com velocidade de $450 \mathrm{~mm} / \mathrm{min}$ e $350 \mathrm{~mm} / \mathrm{min}$ e Número de incidência $=1 ;$ b) terceira e quarta linha de irradiação com velocidade de 300 $\mathrm{mm} / \mathrm{min}$ e $250 \mathrm{~mm} / \mathrm{min}$ e Número de incidência = 1; c) quinta e sexta linha de irradiação com velocidade de $450 \mathrm{~mm} / \mathrm{min}$ e $350 \mathrm{~mm} / \mathrm{min}$ e Número de incidência $=3$; d) sétima e oitava linhas de irradiação com velocidade de 300 $\mathrm{mm} / \mathrm{min}$ e $250 \mathrm{~mm} / \mathrm{min}$ e Número de incidência $=3$. 80

Figura 5-15 - Microscopia eletrônica de varredura da amostra SA430ll Parâmetros de irradiação número de incidência $1, V=375 \mathrm{~mm} / \mathrm{min}$ e fluência de $190 \mathrm{~J} / \mathrm{cm}^{2}$. 
Figura 5-16 - Microscopia eletrônica de varredura da amostra SA430III Parâmetros de irradiação número de incidência $1, V=250 \mathrm{~mm} / \mathrm{min}$ e fluência de $120 \mathrm{~J} / \mathrm{cm}^{2}$.

Figura 5-17 - Microscopia eletrônica de varredura da amostra 3D. Parâmetros de irradiação Fluência de $120 \mathrm{~J} / \mathrm{cm}^{2}, \mathrm{~V}=250 \mathrm{~mm} / \mathrm{min}$ a) Número de incidência 1 e b) número de incidência 2 . 84

Figura 5-18 - Microscopia eletrônica de varreduras da amostra 2F. (a) Região irradiada; parâmetros de irradiação Fluência de $120 \mathrm{~J} / \mathrm{cm}^{2}, \mathrm{~V}=250 \mathrm{~mm} / \mathrm{min}$ e Número de incidência igual a 4. (b) Região não irradiada. 85

Figura 5-19 - Microscopia eletrônica de varreduras da amostra 4F. (a) Região irradiada; parâmetros de irradiação Fluência de $120 \mathrm{~J} / \mathrm{cm}^{2}, \mathrm{~V}=250 \mathrm{~mm} / \mathrm{min}$ e Número de incidência igual a 6 . (b) Região não irradiada. 85

Figura 5-20 - Microscopia eletrônica de varreduras da amostra 5F. (a) Região irradiada; parâmetros de irradiação Fluência de $120 \mathrm{~J} / \mathrm{cm}^{2}, \mathrm{~V}=250 \mathrm{~mm} / \mathrm{min}$ e Número de incidência igual a 8. (b) Região não irradiada. 86

Figura 5-21 - Microscopia eletrônica de varreduras da amostra 8G. (a) Região irradiada; parâmetros de irradiação Fluência de $120 \mathrm{~J} / \mathrm{cm}^{2}, \mathrm{~V}=250 \mathrm{~mm} / \mathrm{min}$ e Número de incidência igual a 15. (b) Região não irradiada.

Figura 5-22 - Microscopia eletrônica de varreduras da amostra 9G. (a) Região irradiada; parâmetros de irradiação Fluência de $120 \mathrm{~J} / \mathrm{cm}^{2}, \mathrm{~V}=250 \mathrm{~mm} / \mathrm{min}$ e Número de incidência igual a 27. (b) Região não irradiada.

Figura 5-23 - Difratograma de raios $x$ das amostras $2 F, 4 F$ e $5 \mathrm{~F}$ irradiadas com laser de $\mathrm{Nd}: \mathrm{YAG}$.

Figura 5-24 - Difratograma de raios $x$ das amostras $2 \mathrm{~F}, 4 \mathrm{~F}$ e $5 \mathrm{~F}$ irradiadas com laser $\mathrm{Nd}$ :YAG comparados ao da cerâmica sinterizada e ao do pó de $\mathrm{ZrO}_{2} \ldots 89$

Figura 5-25 - Difratograma de raios $x$ das amostras $8 G$ e $9 G$ irradiadas com laser de Nd:YAG.

Figura 5-26 - Difratograma de raios $x$ das amostras 8G e 9G irradiadas com laser Nd:YAG comparados ao da cerâmica sinterizada e ao do pó de $\mathrm{ZrO}_{2} \ldots 90$

Figura 5-27 - Micrografia obtida por MEV da amostra não irradiada em que foi realizado o Scratch com pré-carga de $0,5 \mathrm{~N}$, risco de $2 \mathrm{~mm}$ e velocidade de $0,06 \mathrm{~mm} / \mathrm{s}$. (a) e (b) carga variável de $0,5 \mathrm{~N}$ a $3 \mathrm{~N}$; (c) e (d) carga variável de $0,5 \mathrm{~N}$ a $5 \mathrm{~N}$. 92

Figura 5-28 - Micrografia obtida por MEV da 8G irradiada com fluência de 120 $\mathrm{J} / \mathrm{cm}^{2}, \mathrm{~V}=250 \mathrm{~mm} / \mathrm{min}$ e Número de incidência igual a $15 \mathrm{em}$ que foi realizado 
o scratch com pré-carga de $0,5 \mathrm{~N}$ com risco de $2 \mathrm{~mm}$ e velocidade de 0,06 $\mathrm{mm} / \mathrm{s}$ (a) carga variável de $0,5 \mathrm{~N}$ a $2 \mathrm{~N}$ (b) carga variável de $0,5 \mathrm{~N}$ a $3 \mathrm{~N}$ e (c) carga variável de $0,5 \mathrm{~N}$ a $5 \mathrm{~N}$

Figura 5-29 - Micrografia obtida por MEV da 9G irradiada com fluência de 120 $\mathrm{J} / \mathrm{cm}^{2}, \mathrm{~V}=250 \mathrm{~mm} / \mathrm{min}$ e Número de incidência igual a $27 \mathrm{em}$ que foi realizado o scratch com pré-carga de $0,5 \mathrm{~N}$ com risco de $2 \mathrm{~mm}$ e velocidade de 0,06 $\mathrm{mm} / \mathrm{s}$ (a) carga variável de $0,5 \mathrm{~N}$ a $2 \mathrm{~N}$ (b) carga variável de $0,5 \mathrm{~N}$ a $3 \mathrm{~N}$ e (c) carga variável de $0,5 \mathrm{~N}$ a $5 \mathrm{~N}$ 


\section{LISTA DE TABELAS}

Tabela 3-1 - Contaminantes e seus limites máximos para a classificação do Ti puro de acordo com a ASTM F67.

Tabela 4-1 - Codificação das suspensões a base de acetona........................ 50

Tabela 4-2 - Codificação das suspensões a base de acetilacetona................. 51

Tabela 4-3 - Suspensões e parâmetros da série 1 de deposição. ................... 52

Tabela 4-4 - Suspensões e parâmetros da série 2 de deposição. .................. 52

Tabela 4-5 - Parâmetros de Irradiação usando laser Nd:YAG da amostra AS830II.

Tabela 4-6 - Parâmetros de Irradiação usando laser Nd:YAG da amostra AS830I.

Tabela 4-7 - Parâmetros para irradiação das amostras do segundo teste...... 59

Tabela 5-1 - Valores de Rz e Ra para as amostras atacadas. 66

Tabela 5-2 - Valores médios de corrente inicial medidos na EPD para as suspensões utilizadas.

Tabela 5-3 - Espessura aproximada dos filmes obtidos por EPD utilizando as suspensões 75Ac e 50Ac.

Tabela 5-4 - Espessura aproximada dos filmes obtidos por EPD utilizando as suspensões $25 \mathrm{Aa}$ e $100 \mathrm{Aa}$.

Tabela 5-5 - Espessura calculada das amostras produzidas na série F e G de deposição. 


\section{LISTA DE ABREVIATURAS}

100Aa - Suspensão 100\% de Acetilacetona

25Aa - Suspensão 25\% de Acetilacetona e $75 \%$ etanol

3YTZP - Zircônia tetragonal policristalina estabilizada com 3mol\% de ítria

$50 \mathrm{Ac}$ - Suspensão $50 \%$ acetona e $50 \%$ etanol

$75 \mathrm{Ac}$ - Suspensão $75 \%$ acetona e $25 \%$ etanol

ASTM - American Society for Testing and Materials

CSZ - Cubic stabilized zircônia

EPD - Electrophoretic deposition

ICSD - International

MEV-FEG - Microscopia eletrônica de varredura por emissão de campo

Nd:YAG- acrônimo do inglês neodymium-doped yttrium aluminium garnet

$\mathrm{NI}$ - Número de incidência do laser

PSZ - Partially stabilidez zirconia

Tf - Temperatura de fusão

Ti-Cp - Titânio comercialmente puro

Transformação T-M - Transformação tetragonal-monoclínica 


\section{INTRODUÇÃO}

O titânio é um elemento alotrópico, apresentado duas estruturas de acordo coma temperatura sendo forma hexagonal (fase alfa) e cúbica de corpo centrado (fase beta). Tanto sua forma pura quanto suas ligas metálicas apresentam baixa densidade, elevada resistência mecânica e excelente resistência a corrosão que os fazem materiais amplamente utilizados na indústria aeroespacial, química, geração de energia, biomédicas e odontológicas [2, 3].

Entretanto há algumas situações de aplicação do titânio, seja puro ou liga em que se torna interessante recobri-lo com filme cerâmico. Este recobrimento visa aumentar ainda mais a resistência à corrosão, principalmente quando utilizado em altas temperaturas, que é o caso da utilização em turbinas de vapor, na indústria de geração de energia, sendo neste caso utilizado em forma de liga [9, 10], ou ainda aprimorar a utilização do titânio como biomaterial em implantodontia, em que a cor acinzentada do metal compromete o resultado estético das reabilitações orais, sendo que neste caso é utilizado o titânio puro [13].

Neste caso, a zircônia tetragonal policristalina, sendo uma cerâmica com um conjunto de propriedades como elevada resistência a altas temperaturas, resistência ao ataque químico e excelentes propriedades mecânicas, representa uma das melhores alternativas para o recobrimento do titânio, atendendo às necessidade de atuar como barreira térmica, quando usada em altas temperatura, ou atendendo ao requisito de biocompatibilidade quando usada em odontologia $[1,18,19]$

Uma das técnicas que tem se destacado na deposição de filmes cerâmicos em substratos metálicos é a deposição eletroforética (EPD). É um processo que combina a eletroforese, que é a movimentação de partículas carregadas em uma suspensão sob a ação de um campo elétrico, e a deposição, que é a coagulação das partículas em forma densa [28, 29]. É um processo bastante versátil, em que a espessura dos filmes depositados pode variar de 1 a $200 \mu \mathrm{m}$. O campo de aplicação da EPD é bastante amplo, sendo usada como técnica de recobrimento para eletrólito de célula a combustível, obtenção de recobrimento cerâmico em uma variedade de substratos para inúmeras 
aplicações, tais como melhorar a resistência a corrosão, aumentar a resistência ao desgaste, ou atém mesmo recobrimento bioativo para aplicações biomédicas, além de recobrimentos funcionais para aplicação eletrônica. [31, 32, 33, 34].

Para a formação de um filme cerâmico denso e com boas propriedades mecânicas, além de melhor adesão é necessário que seja feita a sinterização do filme. Porém torna-se inviável que sinterização seja feita pelo método convencional, utilizando-se um forno, mesmo que com atmosfera controlada, pois a temperatura de sinterização da zircônia é alta, em tono de $1500^{\circ} \mathrm{C}$, e submeter este conjunto metal/cerâmica a esta temperatura provocaria a degradação do metal. Uma alternativa a este problema é promover a sinterização utilizando a irradiação com laser.

A sinterização a laser passou a ser conhecida quando a prototipagem rápida ganhou o mercado de produção de componentes $3 \mathrm{D}$, em que camadas de algum material, seja ele polímero, cerâmico ou metal, são sucessivamente depositadas e sinterizadas por um feixe de laser de alta potência, até a formação do objeto desejado [41]. É um processo de baixo custo e rápido.

Há poucos relatos na literatura sobre a sinterização a laser de filmes finos, principalmente quando se utiliza o laser Nd:YAG, porém estudos mostram que possível para o Nd:YAG porém com uma janela de processo mais estreita $[42,59]$.

Considerando as necessidades tecnológicas apresentadas, se torna interessante a realização do estudo do recobrimento do titânio com um material cerâmico que atenda às exigências e, além disso, desenvolver um método que possibilite a sinterização do recobrimento cerâmico sem prejudicar o conjunto metal-cerâmica. 


\section{OBJETIVOS}

\subsection{Objetivo geral}

O objetivo geral deste trabalho foi realizar a deposição eletroforética de 3YTZP (zircônia tetragonal policristalina estabilizada por ítria) em titânio comercialmente puro e fazer os estudos da irradiação a laser utilizando o laser pulsado Nd:YAG.

\subsection{Objetivos específicos}

Para desenvolvimento desta dissertação foram determinados os seguintes objetivos específicos:

- Sintetizar o pó de 3YTZP via coprecipitação de óxidos em meio amoniacal e caracterizá-los, avaliando a sua viabilidade no uso na EPD.

- Fazer um estudo da deposição eletroforética utilizando, em uma primeira parte, suspensões a base da mistura álcool etílico / acetona e em uma segunda etapa, suspensões à base de acetilacetona, relacionando a qualidade do filme obtido à suspensão utilizada.

- Verificar a influência dos parâmetros de processo, tempo de deposição e diferença de potencial na qualidade dos filmes obtidos.

- Realizar a irradiação com o laser pulsado Nd:YAG dos filmes cerâmicos obtidos com a finalidade de promover sua sinterização.

- Caracterização microestrutural dos filmes irradiados para verificar se houve de fato a sinterização. 


\section{REVISÃO BIBLIOGRÁFICA}

\subsection{Titânio}

\subsubsection{Propriedades e aplicações}

O titânio, representado pelo símbolo $\mathrm{Ti}$ na tabela periódica de elementos químicos, tem número atômico 22 e massa atômica 47,90 u. É um metal de transição que foi descoberto em 1791, pelo químico e mineralogista britânico William Gregor [2].

As propriedades que mais se destacam no titânio e suas ligas são sua resistência à corrosão e resistência mecânica, que o faz metal de grande destaque no setor aeroespacial, químico e engenharia médica. É um metal que também chama atenção por sua baixa densidade $\left(4,51 \mathrm{~g} \cdot \mathrm{cm}^{-3}, \mathrm{Ti}\right.$ puro) quando comparado a alguns metais como ferro, níquel e cobre como mostrado na Figura 3-1 [3].

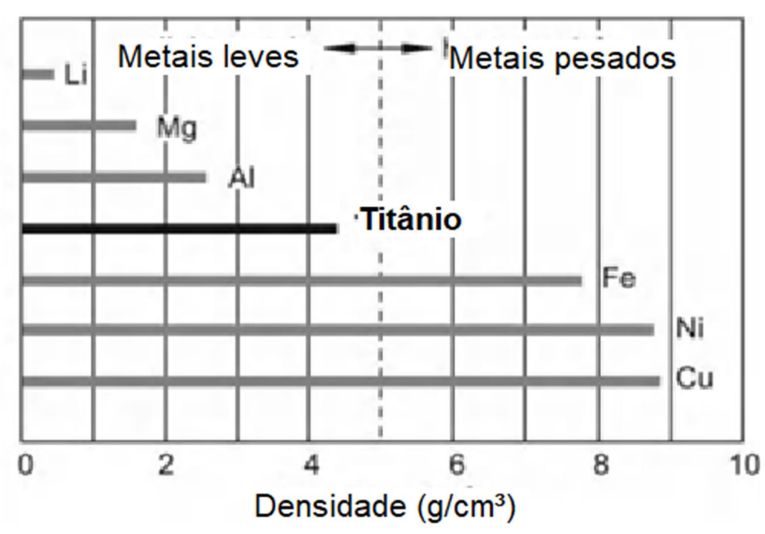

Figura 3-1 - Densidade de alguns metais comparada a do titânio [3].

O titânio é um elemento que sofre transformação alotrópica de acordo com a temperatura e pressão. A temperatura ambiente ele assume a forma hexagonal compacta (fase $\alpha$ ) e quando aquecido acima de $883^{\circ} \mathrm{C}$ assume a estrutura cúbica de corpo centrado (fase $\beta$ ), como mostrado na Figura 3-2 [4]. 


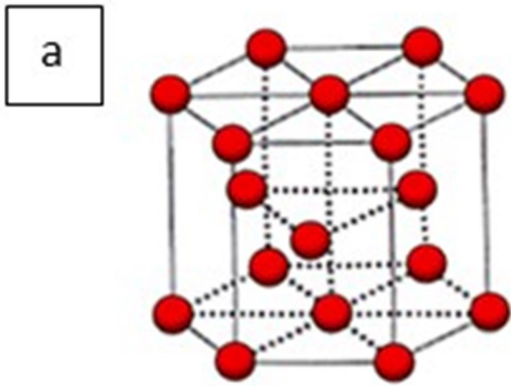

Titânio a

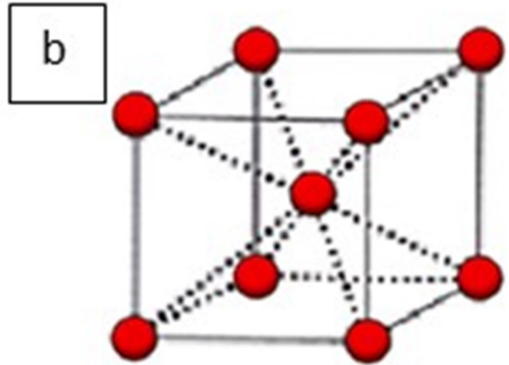

Titânio $\beta$

Figura 3-2 - Representação esquemática das formas alotrópicas assumidas pelo titânio. (a) estrutura hexagonal compacta - Fase $\alpha$. (b) estrutura cúbica de corpo centrado - Fase $\beta$ [4].

O titânio pode ser utilizado na forma pura ou em forma de ligas, sendo que estas foram desenvolvidas principalmente para atender o setor aeroespacial por volta de 1940 pelos Estados Unidos.

De maneira geral, o titânio puro, ou titânio comercialmente puro (Ti-Cp) é utilizado em aplicações biomédicas, principalmente na área de implantologia. Suas propriedades mecânicas como resistência à fadiga e ao desgaste, módulo de elasticidade e propriedades como biocompatibilidade, resistência à corrosão e baixa densidade, tornam o titânio metal adequado a ser utilizado como biomaterial, na fabricação de parafusos de fixação ortopédica e também pinos de implantes dentários [5]. O titânio puro pode ser classificado em graus de 1 a 4 de acordo com a ASTM F67, levando e consideração os elementos contaminantes e suas quantidades, como apresentado na Tabela 3-1 [3, 6, 7]. 
Tabela 3-1 - Contaminantes e seus limites máximos para a classificação do Ti puro de acordo com a ASTM F67.

Composição \% massa

\begin{tabular}{ccccc}
\hline Elemento & Grau 1 & Grau 2 & Grau 3 & Grau 4 \\
$\mathrm{N}$ & 0,03 & 0,03 & 0,05 & 0,05 \\
$\mathrm{C}$ & 0,08 & 0,08 & 0,08 & 0,08 \\
$\mathrm{H}$ & 0,015 & 0,015 & 0,015 & 0,015 \\
$\mathrm{Fe}$ & 0,20 & 0,30 & 0,30 & 0,50 \\
$\mathrm{O}$ & 0,16 & 0,25 & 0,35 & 0,40 \\
$\mathrm{Ti}$ & Balanceamento & Balanceamento & Balanceamento & Balanceamento \\
\hline
\end{tabular}

Fonte - ASTM, 2013

As ligas de titânio são utilizadas principalmente no setor aeroespacial, pois apresenta uma boa relação peso/resistência, alta resistência à corrosão e maior estabilidade a altas temperaturas se comparadas às superligas a base de níquel e aços de alta resistência. Em um avião de grande porte, por exemplo, cerca de $7 \%$ de sua parte estrutural é composta de ligas de titânio, ao passo que mais de um terço dos componentes do motor são de titânio puro. Atualmente, as ligas também são usadas em tubos hidráulicos de aeronaves mais modernas, promovendo uma diminuição de até $40 \%$ do peso se comparado ao uso de tubos de aço. A liga Ti3Al2.5V é mais utilizada para esta aplicação, pois é bastante deformável, além de apresentar resistência suficiente [3].

Embora o setor aeroespacial represente aproximadamente $50 \%$ do consumo mundial de titânio, podendo chegar até a $70 \%$ nos Estados Unidos, seu consumo na indústria química, energética, na tecnologia de transportes, bem como arquitetura, esportes e laser, vem crescendo a cada.

Apesar de ser bastante reativo, o titânio apresenta boa resistência a corrosão devido a sua grande afinidade com o oxigênio, formado uma camada apassivadora de $\mathrm{TiO}_{2}$ na superfície, tornando-o bastante estável à temperatura ambiente, motivo pelo qual vem ganhando cada vez mais destaque no setor químico, de processo e geração de energia. Atualmente é usado em meios bastante agressivos contendo ácido acético, nítrico e brometo úmido, além de acetona. Apresenta boa estabilidade também em ácidos cítrico, tartárico, 
esteático, podendo ser utilizado também com misturas de ácidos orgânicos e inorgânicos. Resiste a ambientes com até pH 12 e $75^{\circ} \mathrm{C}$ [3]

No setor de geração de energia, um dos principais problemas relacionados à inatividade das usinas atrela-se às falhas provocadas nos componentes das turbinas a vapor. Geralmente, estas falhas ocorrem em turbinas a vapor de baixa pressão, principalmente na zona de transição de vaporumidade, sendo o estresse operacional, o uso de materiais de baixa resistência à corrosão, e ambientes hostis os principais motivos dessas ocorrências. Por isso, em 1980 os Estados Unidos deram início os testes de uso de titânio (Liga Ti6Al4V) em turbinas de vapor o que mostrou bastante eficiência para tal aplicação, uma vez que apresentou uma redução de peso de $60 \%$ se comparado às lâminas de aço, e maior resistência à corrosão a cloretos e ácidos oxigenados $[3,8]$.

\subsubsection{Por que recobrir o titânio?}

Embora o titânio e suas ligas apresentem boas propriedades mecânicas e excelente resistência à corrosão, para algumas aplicações torna-se desejável o recobrimento do titânio com um material cerâmico.

No caso da utilização do titânio em turbinas de vapor há um grande interesse em melhorar ainda mais a resistência à corrosão em altas temperaturas, melhorando a resistência do material e consequentemente aumentando sua vida útil. Para que as ligas de titânio possam ser utilizadas em altas temperaturas é necessário que a entrada de oxigênio no material seja reduzida ou até mesmo evitada. Tendo em vista que a oxidação resulta da perda de material ocasionada pelo crescimento da camada de óxido e endurecimento da liga pela dissolução de oxigênio, os revestimentos cerâmicos servem de barreiras à ação do oxigênio na liga $[9,10]$. Geralmente, utiliza-se a aspersão térmica como técnica de recobrimento para a obtenção da camada de zircônia. Uma das desvantagens em usar essa técnica de deposição é a formação de recobrimentos com inúmeros defeitos, tais como inclusões e poros causados pelo resfriamento rápido do material espalhado pelo substrato. Há também o surgimento de microtrincas, principalmente em recobrimentos cerâmicos muito frágeis [11, 12]. 
Algumas limitações ao uso do titânio como biomaterial são as reações alérgicas causadas pela concentração de íons metálicos no tecido periimplantado. Quando utilizado em odontologia, a cor acinzentada do titânio compromete o resultado estético das reabilitações orais de duas maneiras: quando o paciente tem o biótipo gengival fino, deixando escurecida a região da gengiva onde foi implantado o material, ou quando o paciente tem retração de gengiva, deixando o implante à mostra [13]. Trabalhos recentes mostram que o recobrimento do implante com hidroxiapatita utilizando a técnica de aspersão térmica mostraramse eficientes quanto à biocompatibilidade para regeneração óssea [14], porém, testes realizados com ovelhas mostraram que o recobrimento com hidroxiapatita não foi eficiente para evitar a liberação de íons de titânio no organismo. Uma vez que a hidroxiapatita é absorvida, o metal continua em contato com o osso após a reabsorção. Foram feitos testes em duas ovelhas por períodos de 4, 8 e 12 meses. Ambas receberam implantes de titânio recobertos com hidroxiapatita e implantes sem recobrimento. Tanto para a ovelha um, quanto para a ovelha dois, 12 meses após a implantação, foram observados íons metálicos nos tecidos perimplantados, fígado, nódulos linfáticos e tecido conjuntivo [15]. Sendo assim, um aprimoramento à aplicação biomédica do titânio seria o recobrimento com uma cerâmica biocompatível que não seja absorvida pelo organismo.

Assim, para essas necessidades de recobrimento do titânio, tanto na forma de liga ou titânio puro, a zircônia tem grande potencial para ser utilizado, tanto como barreira térmica, quanto como material biocompatível.

\subsection{Zircônia}

A descoberta do elemento zircônio iniciou-se em 1789 quando químico alemão Martin Heinrich Klaproth, que conseguiu isolar o dióxido de zircônio a partir de um minério proveniente de Ceilão, a zirconita $\left(\mathrm{ZrSiO}_{4}\right)$. Porém o metal só foi de fato isolado em 1824 foi isolado por Berzelius. Devido à sua similaridade química com o Háfnio, em minérios, o zircônio ocorre geralmente associado a esse elemento em uma proporção de $0,5 \%$ - 2\% de háfnio [16, 17$]$.

Entre as principais formas em que é encontrado o zircônio, uma de grande importância é o dióxido de zircônio $\left(\mathrm{ZrO}_{2}\right)$, ou zircônia. Devido às suas propriedades físicas e química, tais como alta dureza, resistência ao desgaste, 
inércia química, condutividade iônica, baixa condutividade térmica e alta temperatura de fusão, esta cerâmica desperta grande interesse como material de engenharia, uma vez que pode ser utilizada na fabricação de molde de fundição, refratários, células a combustível de alta temperatura, abrasivos na indústria cerâmica convencional, e também como biomaterial [18, 19].

A zircônia pura não apresenta propriedades mecânicas satisfatórias, uma vez que quando está em sua fase estável a temperatura ambiente (fase monoclínica) e é submetida a ciclos térmicos, ocorre o polimorfismo (que é a transformação de fase decorrente da mudança de temperatura ou pressão) que afeta suas propriedades mecânicas. Dessa maneira, para inibir as transformações de fase adicionam-se óxidos estabilizantes como óxido de magnésio, óxido de cálcio e dióxido de cério e óxido de ítrio, garantindo melhores propriedades mecânicas à cerâmica $[20,21]$.

\subsubsection{Transformação de fase}

A zircônia é uma cerâmica polimórfica e pode apresentar-se em três estruturas cristalinas, dependendo da temperatura e da pressão. São as fases, monoclínica $(M)$, tetragonal $(T)$ e cúbica $(C)$ apresentadas esquematicamente na Figura 3-3 [22]. Na temperatura ambiente, a zircônia assume a fase monoclínica, sendo estável até $1170^{\circ} \mathrm{C}$. Acima desta temperatura assume a estrutura tetragonal, transformando-se em cúbica acima de $2370^{\circ} \mathrm{C}$ [23]. Esta transformação é martensítica e não ocorre o processo de difusão.
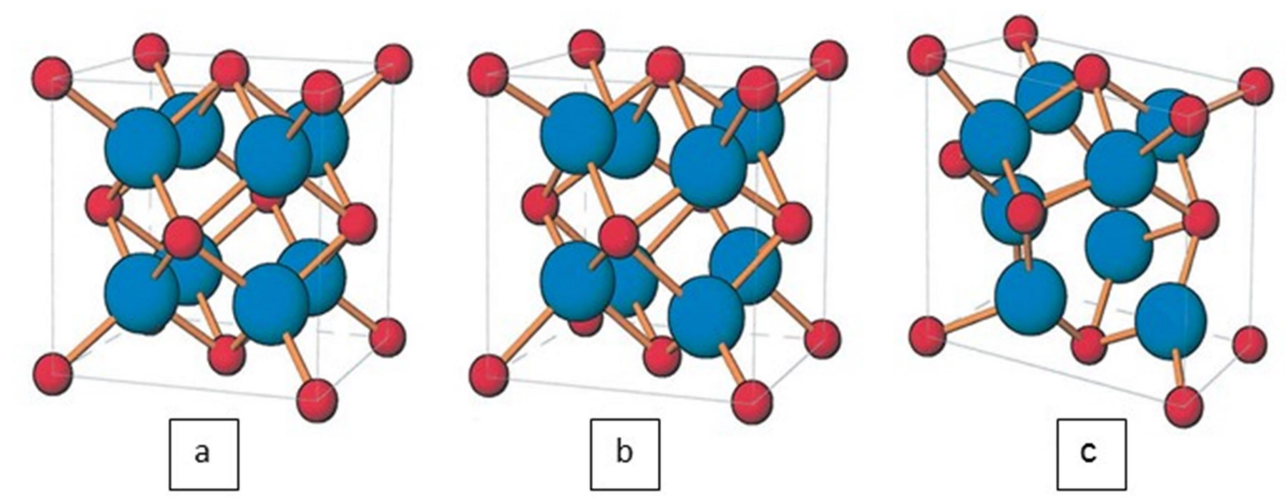

Figura 3-3 - Representação esquemática das três estruturas cristalinas assumidas pela zircônia (a) Cúbica; (b) Tetragonal; (c) Monoclínica [22]. 
No resfriamento, quando há transformação da fase tetragonal para monoclínica (transformação T-M), há expansão volumétrica que varia de $3 \%$ a $4 \%$ gerando tensão e provocando o surgimento de trincas após a sinterização (temperatura de sinterização entre $1500^{\circ} \mathrm{C}$ e $1700^{\circ} \mathrm{C}$ ), impossibilitando o uso da zircônia pura.

\subsubsection{Zircônia estabilizada}

Adicionando-se íons como cálcio $\left(\mathrm{Ca}^{2+}\right)$, cério $\left(\mathrm{Ce}^{4+}\right)$, ítrio $\left(\mathrm{Y}^{3+}\right)$, magnésio $\left(\mathrm{Mg}^{2+}\right)$ na forma de dopantes é possível estabilizar os grãos de zircônia na forma metaestável das fases tetragonal e cúbica à temperatura ambiente, evitando assim as transformações espontâneas que provocam a expansão volumétrica [23].

A zircônia totalmente estabilizada na fase cúbica (CSZ - Cubic Stabilized Zirconia) é obtida por meio da adição de quantidades de óxidos como $16 \%$ mol de $\mathrm{MgO}$, $8 \%$ mol de $\mathrm{Y}_{2} \mathrm{O}_{3}$ e $16 \%$ mol de $\mathrm{CaO}$, que são capazes de estabilizar totalmente fase cúbica na temperatura ambiente. O resfriamento rápido proporciona a conservação da fase cúbica, já que a transformação cúbica em tetragonal (C-T) ocorre por difusão [24].

A zircônia tetragonal policristalina (TZP - Tetragonal Zirconia Polycrystals), é caracterizada pela presença de até $98 \%$ da fase tetragonal metaestável à temperatura ambiente. É obtida por meio da adição, geralmente de $\mathrm{Y}_{2} \mathrm{O}_{3}$ em quantidade que variam de $2 \%$ mol-3\%mol. Esta cerâmica possui alta resistência a flexão de 900 a $1200 \mathrm{Mpa}$, boa resistência a fratura com K $\mathrm{K}_{\mathrm{IC}}$ de 7 a 10 MP.m ${ }^{1 / 2}$ e módulo de Young de $210 \mathrm{GPa}$, o que a permite ser usada em situações que alta solicitação mecânica, e condições em que há desgaste, como em componentes estruturais de equipamentos $[25,26]$. Um excelente método para a obtenção desse tipo de cerâmica é a coprecipitação de óxidos em meio amoniacal, sendo possível alcançar até $96 \%$ em peso de fase tetragonal e $4 \%$ em peso de fase monoclínica com grãos de aproximadamente 0,3 $\mu \mathrm{m}$ [20].

O mecanismo de tenacificação denominado "Tenacificação por transformação induzida por tensão", que foi observado por Garvie et al [27]. Observou-se que finos precipitados da fase tetragonal dispersos em matriz cúbica eram capazes de transformarem-se em monoclínicos quando um estado de 
tensão era aplicado no material, como por exemplo, uma trinca era iniciada. Como na transformação T-M há uma expansão volumétrica que varia de $3 \%$ a $4 \%$, o campo de tensão criado tende a barrar 0 aumento da trinca. $O$ mesmo comportamento de tenacificação é observado para a zircônia tetragonal policristalina, visto que sua fase tetragonal é metaestável. Na Figura 3-4 [21] está representado esquematicamente o mecanismo de tenacificação por transformação induzida por tensão.

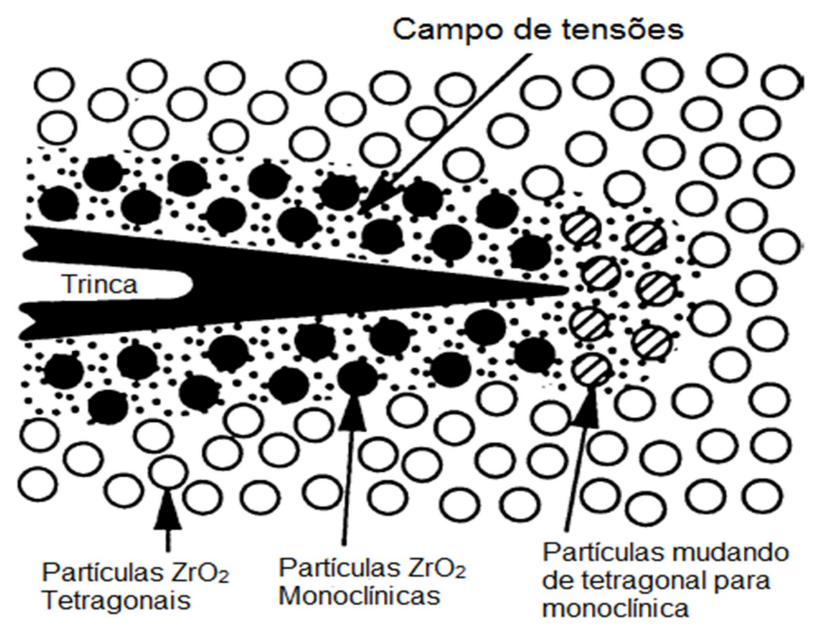

Figura 3-4 - Representação esquemática do processo de tenacificação da 3YTZP quando submetida a um estado de tensão [21].

\subsection{Deposição eletroforética}

A deposição eletroforética (EPD - Electrophoretic Deposition) é um processo coloidal para a produção de filmes de uma gama de materiais.

O processo da EPD consiste em duas etapas. Na primeira etapa, chamada de eletroforese, há a movimentação de partículas carregadas em uma suspensão quando aplicado um campo elétrico de corrente contínua entre dois eletrodos que estão imersos nessa suspensão, sendo que a movimentação das partículas se dá em direção ao eletrodo de carga oposta à da partícula. $\mathrm{Na}$ segunda etapa, a deposição, as partículas se depositam no eletrodo e se coagulam de forma densa, formando o filme. Na Figura 3-5 está representado esquematicamente o processo de deposição eletroforética evidenciando que as partículas negativamente carregadas se movimentam e se depositam no eletrodo de carga positiva $[28,29]$. 


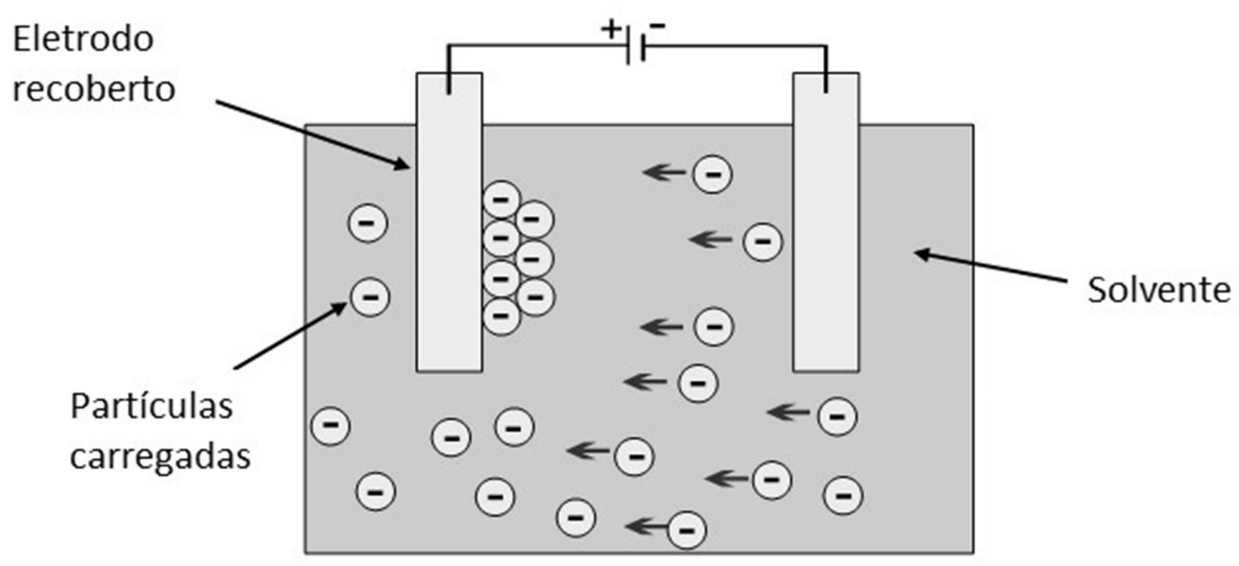

Figura 3-5 - Representação esquemática do processo de deposição eletroforética, em que as partículas carregadas negativamente movem-se e depositam-se no eletrodo de carga oposta.

Embora o conhecimento da técnica venha desde 1808, quando o cientista russo Ruess observou a movimentação de partículas de argila em água provocada pela indução de um campo elétrico, o uso prático da técnica ocorreu apenas em 1933, quando os Estados Unidos realizaram e patentearam a deposição de tória em um catodo de platina para a produção de um tubo emissor de elétrons. Os primeiros estudos mais aprofundados de EPD foram realizados por Hamaker [30, 56].

Há inúmeros relatos na literatura referentes à aplicação tecnológica da técnica de $\operatorname{EPD}[32,33,34,38,58]$. Sua utilização inclui recobrimento para eletrólito de célula a combustível, obtenção de recobrimento cerâmico em uma variedade de substratos para inúmeras aplicações, tais como melhorar a resistência a corrosão, aumentar a resistência ao desgaste, ou atém mesmo recobrimento bioativo para aplicações biomédicas, além de recobrimentos funcionais para aplicação eletrônica [31].

Besra et al [32] desenvolveu um método simples e bastante econômico para a preparação de um anodo para célula a combustível utilizando a deposição eletroforética. Seu método consistia na deposição de uma camada do NiO-YSZ sobre uma folha de carbono, o que serviria como anodo e sobre esta camada a deposição de YSZ para servir como eletrólito, seu experimento resultou em bons depósito com espessura de aproximadamente $10 \mu \mathrm{m}$. Basu [58] mostrou que é 
possível a obtenção de filmes eletrolíticos de zircônia com espessuras de 10-50 $\mu \mathrm{m}$ de espessura em tubos de $\mathrm{LaMnO}_{3}$, catodo poroso de célula a combustível. As propriedades destes filmes obtidos para célula a combustível, como densidade, espessura uniforme e integridade da interface são similares às dos filmes obtidos pelos métodos usuais que são deposição por vapor eletroquímico e por plasmaspray, porém o custo é menor.

Kawakami et al [33] produziram filmes finos de $\mathrm{TiO}_{2}$ em substratos de vidro de índio-estanho para aplicação em células solares. Foi possível a obtenção de um recobrimento com alta transparência óptica, característica fundamental para o $\mathrm{TiO}_{2}$ apresente alta performance na aplicação como catodo de célula solar.

Ananth et al [34] promoveram o recobrimento via deposição eletroforética da liga de Ti6Al4V com bicamada, sendo que a primeira era composta por zircônia de aproximadamente $5 \mu \mathrm{m}$ de espessura e a segunda de uma mistura de biovidro reforçado com zircônia de aproximadamente $15 \mu \mathrm{m}$ de espessura. E seus estudos comprovaram que o recobrimento torna o conjunto bioativo, melhorando também a resistência à corrosão.

A EPD apresenta uma série de vantagens quando comparada a outros processos de deposição. O equipamento empregado é de baixo custo, constituído basicamente por uma fonte de energia com voltagem variada e uma célula eletroquímica simples. O processo é rápido, com o tempo de duração de uma deposição variando de alguns segundos a minutos, pode ser usado para produção em larga escala e tem baixa restrição quanto ao formato dos substratos. A versatilidade do processo permite também a incorporação de aditivos na suspensão para melhorar a resistência mecânica do depósito, bem como para aumentar a força adesiva deste com o substrato.

\subsubsection{Fatores que influenciam na deposição eletroforética}

Para se avaliar a qualidade do filme depositado e a eficiência do depósito devem ser levados em consideração os parâmetros relacionados à suspensão e os parâmetros relacionados ao processo.

Quanto aos parâmetros relacionados à suspensão as principais variáveis são o tamanho de partículas, constante dielétrica do solvente utilizado, condutividade e viscosidade da suspensão. Estas variáveis afetam o potencial 
zeta, uma vez que este caracteriza o equilíbrio eletroquímico na interface partícula-líquido. Assim o potencial zeta tem um papel importante quando se fala em estabilidade e também quando se fala em mobilidade eletroforética, sendo esta a facilidade com que as partículas se movimentam em meio líquido [56].

Solventes como acetilacetona, acetona e etanol mostraram-se eficientes para o processo de EPD, pois são capazes de formar suspensões estáveis, com boa condutividade [35, 36].

Quanto aos parâmetros relacionados ao processo tem-se o tempo de deposição, diferença de potencial aplicada, concentração dos sólidos na suspensão [56]. Quanto à concentração de partículas de 3YTZP é usual concentrações de 10 a 30 g.L $\mathrm{L}^{-1}$ dependendo solvente, no caso do uso de acetilacetona, é comum suspensões com $20 \mathrm{~g} \cdot \mathrm{L}^{-1}$ e no caso de acetona pura ou mistura com etanol, é comum $10 \mathrm{~g} \cdot \mathrm{L}^{-1}$. Quanto ao tempo e diferença de potencial, há relatos de bons depósitos obtidos com diferença de potencial entre $20 \mathrm{~V}$ e $80 \mathrm{~V}$ e tempos de deposição variando de 20 segundos a 60 segundos [35, 36].

\subsubsection{Fatores relacionados à suspensão}

A deposição eletroforética é um processo coloidal que permite a obtenção de filmes por meio da aplicação de um campo elétrico de corrente contínua entre dois eletrodos, sendo assim, as propriedades das suspensões são de grande importância para que sejam obtidos bons filmes, livres de trincas e homogêneos.

Levando em consideração o tamanho de partícula, embora não exista uma regra para o tamanho ideal para a EPD, bons depósitos são reportados na literatura em sistemas com tamanho de partícula na faixa de 1-20 $\mu \mathrm{m}$. Porém, isso não quer dizer que a EPD não é possível para tamanhos de partícula fora dessa faixa, como por exemplo, o crescimento na obtenção de materiais nanoestruturados atualmente, torna a EPD uma técnica bastante atrativa para a deposição de filmes utilizando estes nanomateriais. Sato et al investigaram o efeito da redução do tamanho de partícula na formação de trincas em depósitos feitos por EPD de filmes de $\mathrm{YBa}_{2} \mathrm{Cu}_{3} \mathrm{O}_{7-\delta}$. Foi observado que a incidência de trincas foi menor para os depósitos realizados com as suspensões com menor 
tamanho de partícula $(0,06 \mu \mathrm{m})$ do que para os realizados com suspensões com maior tamanho de partícula $(3 \mu \mathrm{m})[32,55]$.

Powers [57] em sua investigação sobre a influência da constante dielétrica e condutividade dos líquidos usados como solventes em suspensões de beta alumina observou que a condutividade elétrica aumenta com o aumento da constante dielétrica do liquido. Em seu experimento observou que se a constante dielétrica do líquido é muito baixa há falhas na deposição causadas pela dificuldade de dissociação do pó, ao passo que se a constante dielétrica é muito alta, a alta concentração iônica reduz a mobilidade eletroforética. Sendo assim, a concentração iônica na suspensão deve permanecer baixa, condição que favorecida para líquidos com baixa constante dielétrica. Ferrari e Moreno [37] observaram também que se a condutividade da suspensão é muito baixa, a partícula carrega-se eletronicamente, e a estabilidade é perdida, foi observado um aumento da condutividade com o aumento da temperatura, assim como com a adição de agentes dispersantes (polieletrólitos).

O potencial zeta é o fator chave para o processo de deposição eletroforética. É um fator de extrema importância na determinação da estabilidade da suspensão, da direção e velocidade de deposição das partículas e fundamental para determinar a densidade a verde do depósito. De acordo com Besra [56] a estabilidade de um sistema depende da interação entre as partículas da suspensão que é afetada pela eletrostática e também pelas forças de Van der Waals. A formação ou não de aglomerados em um sistema coloidal depende da energia de interação resultante dessas forças. É necessária alta repulsão eletrostática devido à alta carga da partícula para que esses aglomerados sejam evitados na suspensão. À medida que as partículas depositam-se elas se aproximam aumentando a força de atração entre elas. Se a carga superficial das partículas for baixa, elas se coagulam mesmo a distâncias maiores, gerando filmes com baixa densidade [38]. A teoria mais aceita neste caso é que as partículas possuem uma dupla camada de cargas quando em suspensão, que é distorcida devido à ação do campo elétrico no processo de deposição, seguida do arranjo das partículas no eletrodo, como mostrado na Figura 3-6 [28]. 


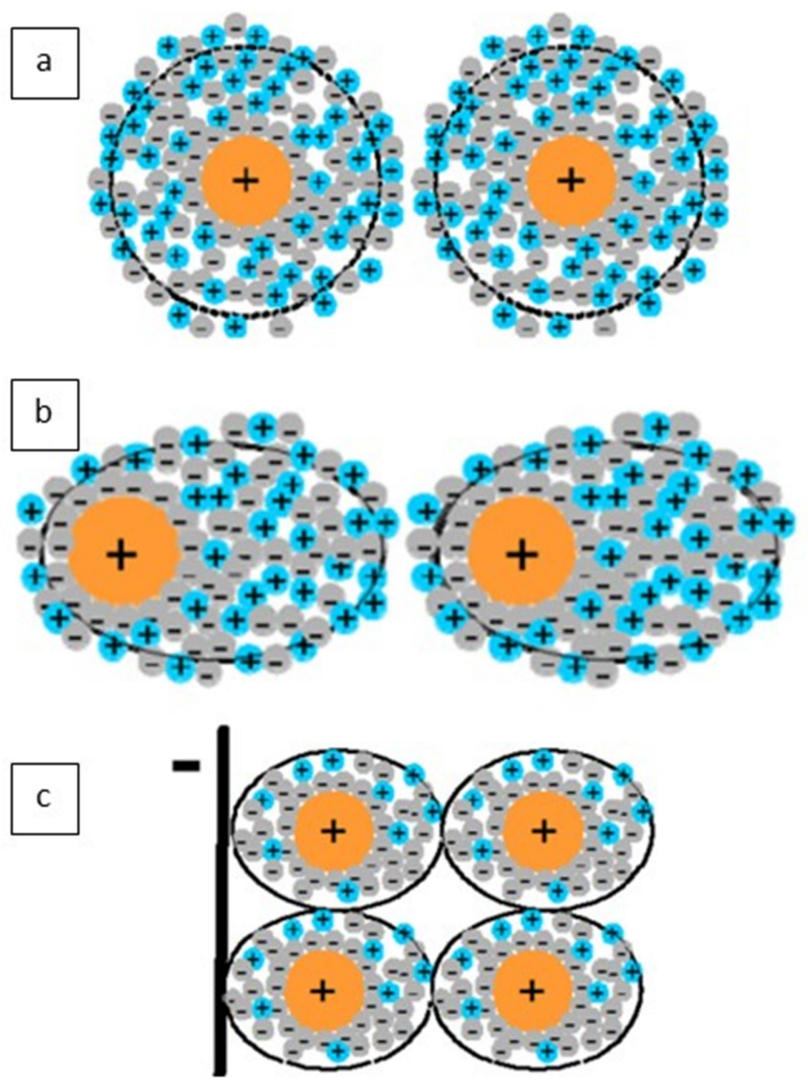

Figura 3-6 - (a) Representação esquemática da dispersão eletrostática das partículas em suspensão. (b) a distorção da dupla camada devido à ação do campo elétrico e (c) arranjo das partículas no eletrodo [28].

Besra define uma suspensão como estável quando esta não tem tendência em formar aglomerados e sedimentar-se. Suspensões estáveis tendem a proporcionar bons filmes com boa aderência ao substrato [56].

\subsubsection{Fatores relacionados ao processo}

Basu et al [58] observaram que o coeficiente de deposição diminui com o aumento do tempo de deposição, comportamento também observado por Wang et al quando realizaram a deposição de óxido de zinco em substrato de cobre [39]. Para Zhitomirsky e Gal-or [40] tal comportamento é esperado, pois, com o decorrer do tempo de deposição, mesmo quando a diferença de potencial é mantida constante, a camada cerâmica formada no eletrodo provoca a diminuição da influência do campo elétrico na deposição, porém, geralmente no início da 
deposição, é estabelecida uma relação linear entre a massa depositada e o tempo de deposição.

A diferença de potencial aplicado é um parâmetro relacionado ao processo que deve ser controlado para que depósitos de boa qualidade sejam obtidos. Geralmente, a quantidade de material depositado aumenta com o aumento da diferença de potencial aplicado, porém a qualidade do depósito pode ser afetada devido ao aumento da velocidade de deposição. Basu et al [58] observaram que em diferenças de potenciais menores (entre 25 - $100 \mathrm{~V}$ ) a deposição de hidroxiapatita em substratos da liga de Ti6Al4V é bem sucedida, proporcionando depósitos homogêneos, ao passo que para deposição realizada a maiores diferenças de potenciais (potenciais maiores que $100 \mathrm{~V}$ ) os filmes mostram-se menos homogêneos. A aplicação de uma elevada diferença de potencial pode provocar turbulências na suspensão e o filme pode ser afetado pelo meio, mesmo durante deposição. Além disso, as partículas podem movimentar-se tão rapidamente a ponto de não terem tempo suficiente para agregarem-se umas às outras, não formando então uma estrutura com empacotamento denso [56].

\subsection{Sinterização a Laser}

O conceito de sinterização a laser surgiu no fim dos anos de 1980 quando a prototipagem rápida começou a ser usada como técnica de manufatura passando a ser difundida no meio industrial para a produção de componentes 3D mais complexos. A técnica exige apenas uma única operação, diminuindo tempo de produção, além de poder ser utilizada para uma gama de materiais, como plásticos e metais.

A técnica da prototipagem rápida consiste em um feixe de laser de alta energia que varre uma camada de material particulado promovendo a sinterização, ou a união entre as partículas. As camadas são sucessivamente depositadas e sinterizadas até a formação de um formato 3D complexo [41]. 


\subsubsection{Sinterização a laser de filmes cerâmicos}

Há poucos relatos na literatura sobre a sinterização a laser de filmes cerâmicos, principalmente utilizando o laser pulsado de Nd:YAG.

Wang et al realizaram a deposição eletroforética de um compósito cerâmico zircônia/alumina em substratos de Fecralloy (Fe72.8/Cr22/Al5/Y0.1/Zr0.1) e promoveram um processamento usando o laser de diodo de alta potência. Antes de ser submetido ao processamento com laser, o conjunto metal/cerâmica foi tratado termicamente a $1225^{\circ} \mathrm{C}$ por 2 horas. Os filmes a verde possuía espessura de 200 um e após sinterizados, aproximadamente 120 $\mu \mathrm{m}$. Depois de submetido ao processamento a laser notou-se um aumento da densificação do filme cerâmico além de melhora de suas propriedades mecânicas [42].

\subsubsection{Mecanismos de ligação na sinterização a laser}

$\mathrm{Na}$ sinterização a laser podem ocorrer três mecanismos de ligação entre as partículas para que ocorra a densificação do material. São eles sinterização no estado sólido, indução química e sinterização em fase líquida. [44, 45, 43]

A sinterização no estado sólido é um processo térmico que ocorre entre $T_{f}$ 12 até a $T_{f}$ em que $T_{f}$ é a temperatura de fusão do material. De acordo com Van der Schueren [45], neste processo acontecem muitos fenômenos físicos e químicos, porém o mais importante é a difusão que permite a formação do pescoço entre as partículas adjacentes como mostrado na Figura 3-7. A força motriz para que haja a sinterização é a diminuição da energia livre quando as partículas crescem juntas. O gradiente de concentração de lacunas entre o pescoço formado (alta concentração de lacunas) e as partículas com regiões planas (baixa concentração de lacunas) provoca um fluxo de átomos para o pescoço, aumentando assim seu tamanho. Para a sinterização no estado sólido a temperatura deve ser alta o bastante para fornecer energia para as vacâncias migrarem para o contorno de grão, porém o processo deve ser relativamente lento para favorecer a taxa de difusão dos átomos de modo também a obter-se uma taxa de varredura do laser aceitável [44, 45]. 


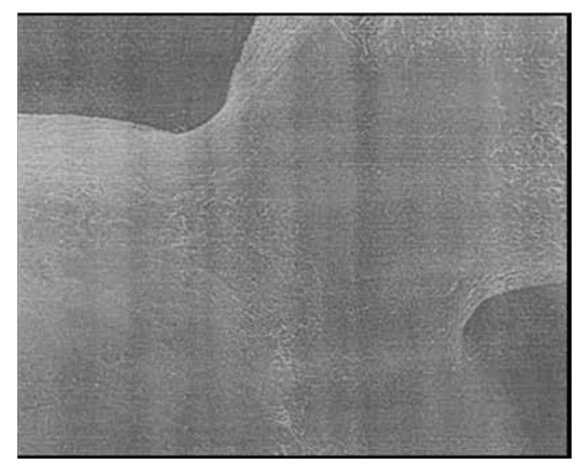

Figura 3-7 - Formação do pescoço entre duas partículas de aço obtido com laser $\mathrm{Nd}: Y A G$ [45].

No mecanismo de ligação por indução química de acordo com o estudo feito por Klocke e Wirtz na produção de cerâmicas de SiC, quando o material foi submetido a altíssimas temperaturas houve a desintegração do $\mathrm{SiC}$ em $\mathrm{Si}$ e C. O Si livre em contato com o oxigênio formou $\mathrm{SiO}_{2}$, que agiu como um ligante entre as partículas de $\mathrm{SiC}$. Como não havia ligantes misturados ao $\mathrm{SiC}$ inicial e o tempo de interação com laser foi curto não permitindo o processo de difusão para ocorrer sinterização em estado sólido o mecanismo mais aceitável para este tipo de fenômeno é o quimicamente induzido [43].

$\mathrm{Na}$ sinterização em fase líquida, ou fusão parcial pode acontecer em duas situações: quando se tem um material ligante e materiais estruturais, ou quando não há um material ligante ou estrutural. No caso da sinterização em fase líquida na presença de um material ligante e um estrutural, geralmente o ligante dá origem a fase líquida que tem ponto de fusão mais baixo. Por forças capilares - líquido se espalha pelas partículas preenchendo os poros e formando a estrutura densa na solidificação, como apresentado na Figura 3-8. [44, 46]. 


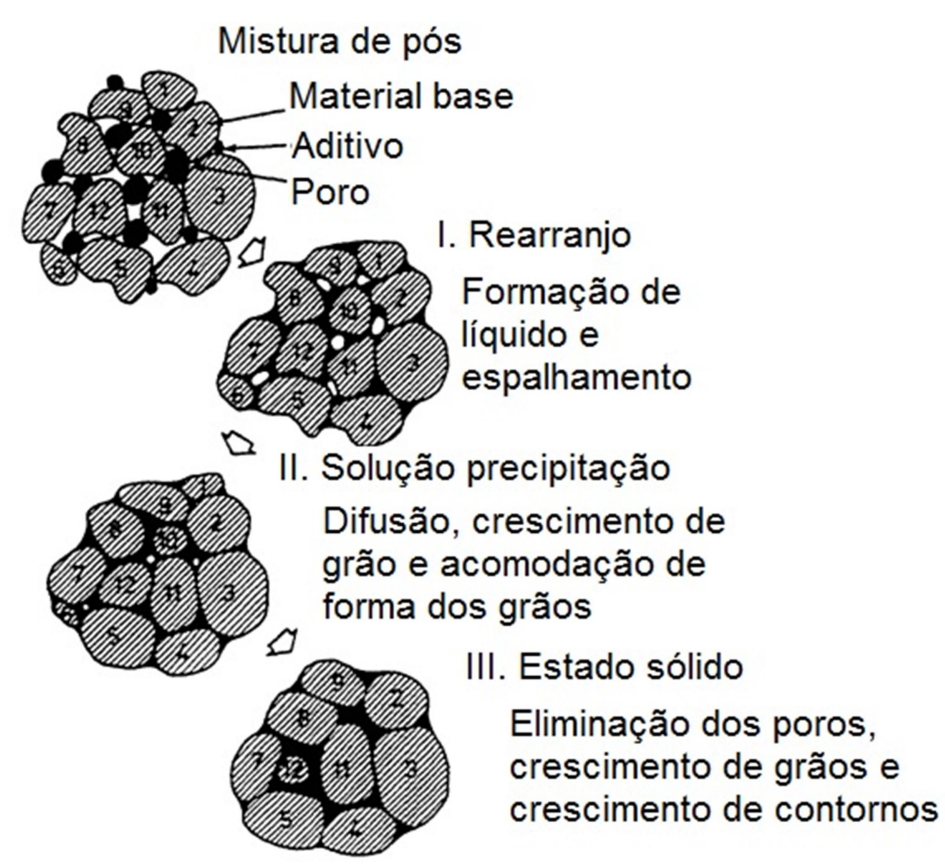

Figura 3-8 - Representação esquemática das etapas da sinterização em fase líquida de uma mistura de pós [46].

$\mathrm{Na}$ sinterização em fase líquida quando há a presença de uma única fase, o mecanismo mais aceito é a fusão parcial proposto por Karapatis. Segundo ele, quando a energia térmica fornecida não é suficiente para fundir toda a partícula, apenas a região do contorno de grão é fundida, permanecendo o núcleo o grão sólido. Sendo assim, o material fundido do contorno de grão serve como um aglutinante, unindo os núcleos não fundidos [47].

\subsubsection{Laser Nd:YAG}

O termo YAG geralmente é usado para lasers no estado sólido constituídos de neodímio dopado com YAG (Nd:YAG, mais precisamente $\left.\mathrm{Nd}^{3+}: Y A G\right)$. YAG é um acrônimo de granada de alumínio e ítrio $\left(\mathrm{Y}_{3} \mathrm{Al}_{5} \mathrm{O}_{12}\right)$ um cristal sintético, que se tornou popular como cristal de laser na década de 1960, sendo que comprimento de onda de emissão do laser Nd:YAG mais comum é $1064 \mathrm{~nm}$.

Quanto às suas vantagens de utilização, é um laser que apresenta baixo consumo de energia e sua eficiência é bem maior, se comparado, por exemplo, ao laser de rubi. 
No setor militar, por exemplo, é usado como direcionador de objetos para ataque, e também para determinar a distância de um objeto de ataque. $\mathrm{Na}$ medicina é usado para corrigir a opacificação capsular posterior (condição clínica de opacificação da região posterior do saco capsular onde foi implantada a lente durante a cirurgia ao cristalino, que ocorre geralmente depois da cirurgia de catarata), usado também para a remoção de tumores de pele. Na manufatura são usados na gravação de plásticos e metais, além de soldagem e corte de aço [48, 49].

\subsubsection{Feixe gaussiano}

Diz-se que um feixe de luz é gaussiano quando o perfil do campo elétrico que é perpendicular ao eixo do feixe pode ser descrito por uma função gaussiana. Em óptica, mais particularmente na física dos lasers, os feixes de laser ocorrem na forma de feixes gaussianos, e foram nomeados depois do matemático e físico Johann Carl Friedrich Gauss.

Na Figura 3-9 tem-se a representação esquemática de um feixe de laser que obedece a essa função gaussiana. Em que tem-se $Z_{R} 0$ comprimento de Rayleigh e $\theta_{0}$ o espalhamento angular o eixo da distância focal (Eixo Z) e o raio do feixe quando este está no foco $\left(\mathrm{W}_{0}\right)$, assumindo situação de maior intensidade [50] . 


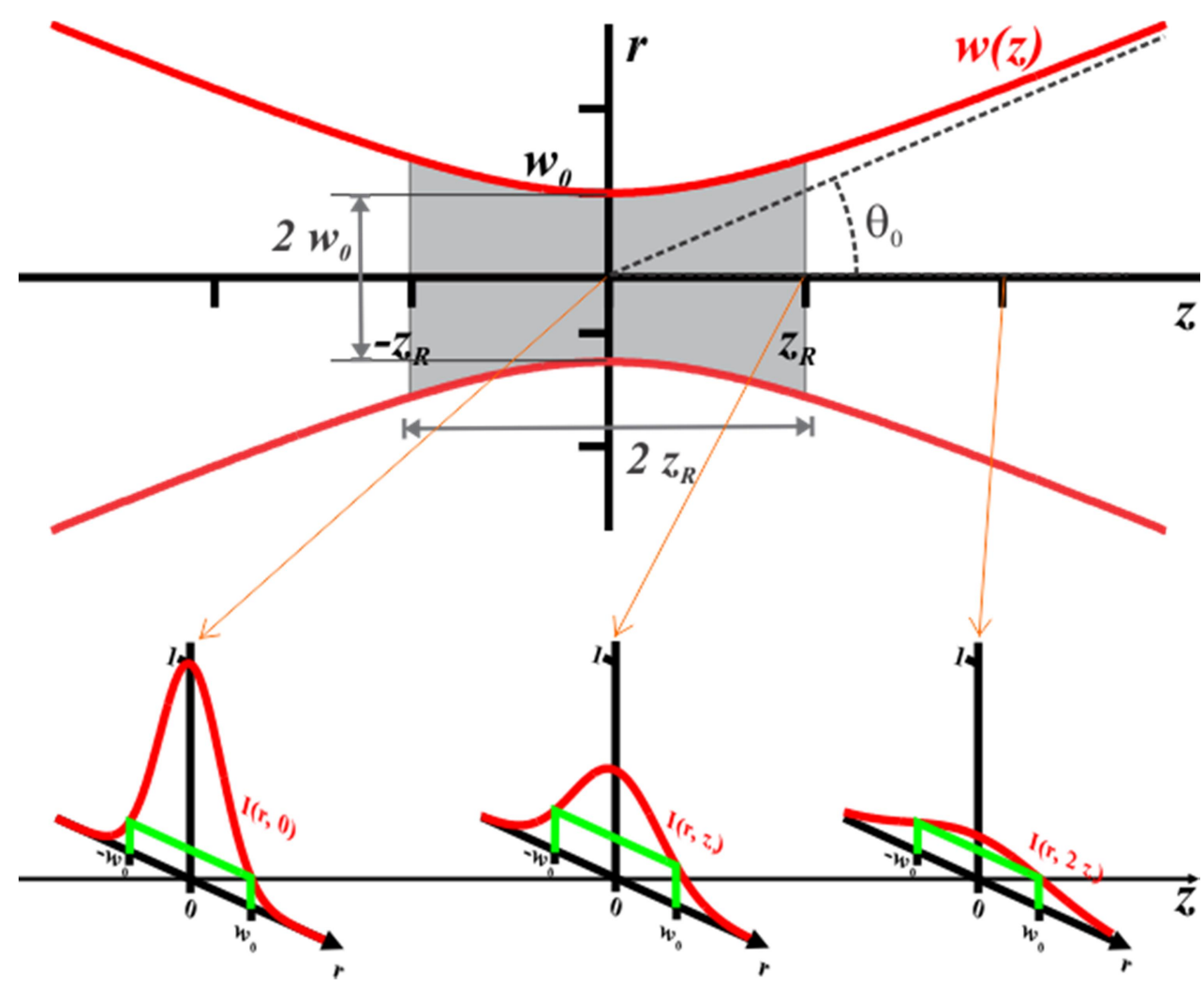

Figura 3-9 - Raio do feixe gaussiano W (Z) em função da distância $Z$ do feixe de laser relacionando-se a intensidade. (OpenSPIM - Theorical basics. Acessado em 22 de agosto de 2017) [50].

O raio do feixe de laser varia ao longo da direção de propagação obedecendo a Equação 3-1:

$$
W(Z)=W_{0} \sqrt{1+\left(\frac{Z}{Z_{R}}\right)^{2}}
$$

Sendo que o comprimento de Rayleigh $\left(Z_{R}\right)$ é dado pela Equação 3-2:

$$
Z_{R}=\frac{\pi W_{0}^{2}}{\lambda}
$$


Neste caso, o perfil transversal da intensidade óptica do feixe com potência $\mathrm{P}$ pode ser descrito pela função gaussiana da Equação 3-3:

$$
I(r, Z)=\frac{P}{\pi W(Z)^{2} / 2} \exp \left(-2 \frac{r^{2}}{W(Z)^{2}}\right)
$$

Em que $P$ é a potência aplicada, $Z$ é a distância focal, ou seja, a distância entre o foco e a amostra, $W(z)$ o raio do feixe relacionado a distancia $z$ e r o raio inicial do feixe de laser.

Os feixes gaussianos geralmente são usados em situações em que a divergência do feixe é relativamente pequena de modo que a chamada aproximação paraxial pode ser aplicada. Esta aproximação permite a omissão do termo da derivada de segunda ordem na equação de propagação (derivada das equações de Maxwell), resultando em uma equação diferencial de primeira ordem. Dentro dessa aproximação, a propagação do feixe gaussiano no espaço livre permanece gaussiana, exceto que é claro que seus parâmetros evoluem. Para um feixe monocromático, propagando em uma direção $Z$ com comprimento de onda $\lambda$, a complexa amplitude do campo elétrico é dada pela Equação 3-4:

$$
E(r, Z)=E_{0} \frac{W_{0}}{W_{Z}} \exp \left(-\frac{r^{2}}{W(Z)^{2}}\right) \exp \left(-i\left[k Z-\arctan \frac{Z}{Z_{R}}+\frac{k r^{2}}{2 R(Z)}\right]\right)
$$

Com pico de amplitude $\left|E_{0}\right|$, raio $w_{0}$ na cintura do feixe, número de onda $k=2 \pi / \lambda, Z_{R}$ o comprimento de Rayleigh e $\mathrm{R}(Z)$ o raio de curvatura das frentes de onda. Na Figura 3-10 apresenta-se um exemplo da distribuição do campo elétrico em torno do foco de um feixe gaussiano, em que o raio do feixe é apenas um pouco maior do que o comprimento de onda e a divergência do feixe é forte [51]. 
Figura 3-10 - Distribuição do campo elétrico em torno do foco de um feixe gaussiano. (RP Photonics Encyclopedia. Gaussian Beams. Acessado em 22 de agosto de 2017) [51].

Na Figura 3-11 é apresentado esquematicamente um arranjo de laser, em que o feixe de laser é focalizado por uma lente de comprimento focal $f$.

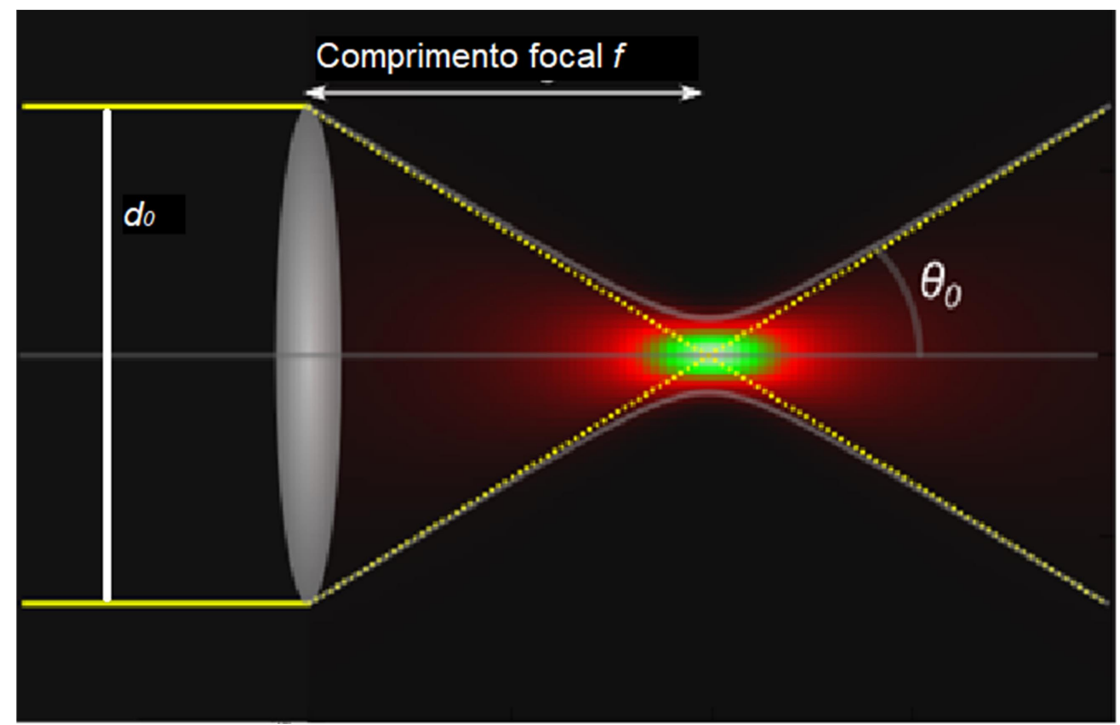

Figura 3-11 - Feixe de laser focalizado. (OpenSPIM - Theorical basics. Acessado em 22 de agosto de 2017) [50].

A Equação 3-1 e Equação 3-2 são válidas para um sistema de laser perfeito, caso contrário devem-se utilizar fatores de correção, como o $M^{2}$, chamado fator de qualidade do feixe, que é usado para quantificar a qualidade do feixe de laser, sendo que o menor valor admitido para esse fator é 1 . Como o feixe de laser é focalizado por uma lente com comprimento focal $f$, como mostrado na Figura 3-11, este parâmetro deve ser introduzido na Equação 3-1. 
Assim o diâmetro mínimo do feixe de laser focalizado é definido pela Equação 3-5:

$$
d_{\min }=\frac{4 M^{2} \lambda f}{\pi d_{0}}
$$

E o raio do feixe em função da distância focal $Z$ definido pela Equação 3-6:

$$
W(Z)=W_{0} \sqrt{1+\left(\frac{M^{2} \lambda Z}{\pi\left(W_{0}\right)^{2}}\right)^{2}}
$$

Assim, a distância $Z$ relaciona-se também à fluência do laser, dada pela Equação 3-7, definindo-se fluência como a energia total fornecida dividida pela área abrangida (dada em $\mathrm{J} / \mathrm{cm}^{2}$ ). À medida que se distancia do foco do laser há um aumento da área iluminada pelo feixe, e visto que a energia fornecida é constante, há uma diminuição da fluência.

$$
F=\frac{E}{A}
$$

Em que $E$ é a energia fornecida e $A$ área do feixe.

Desta maneira, em um experimento de irradiação com laser, a fluência utilizada pode ser controlada pelo posicionamento da amostra com relação ao faixe de laser, de modo que se aumenta ou diminui-se a fluência dependendo do posicionamento no eixo. 


\section{MATERIAIS E MÉTODOS}

O procedimento experimental foi dividido em quatro etapas: a síntese do pó de 3YTZP, preparo do substrato para a deposição eletroforética, deposição eletroforética e irradiação com laser a fim de estudar a sinterização do material depositado.

\subsection{Síntese dos pós de 3YTZP}

Para a síntese do pó de 3YTZP foram utilizados os seguintes materiais precursores:

- Solução de oxicloreto de Zircônio (pureza de 99,5\% de Zr + Hf e $0,1 \%$ de $\mathrm{SiO}_{2}$, em massa), obtida pelas condições de processo adotada pela Usina Piloto de Zircônia do Ipen, a partir do minério zirconita.

- Cloreto de Ítrio, preparado pela dissolução de óxido de ítrio (99,9\% de pureza em massa, Aldrich)

- Hidróxido de amônio (Synth)

- Etanol e $n$-Butanol (Alphatec, PA)

A rota de coprecipitação de hidróxidos em meio amoniacal foi o método utilizado para a síntese do pó cerâmico de 3YTZP.

Inicialmente, partiu-se de uma solução contendo $35 \mathrm{~g} \cdot \mathrm{L}^{-1}$ dos óxidos correspondentes. A coprecipitação dos óxidos mistos, partiu da adição da mistura dos cloretos (Zircônio e ítrio), nas proporções desejadas, à solução de hidróxido de amônio com concentração de 7 molar, com injeção de ar comprimido e sob rigorosa agitação, afim de promover condição adequada de supersaturação e precipitação rápida. Após a adição total dos cloretos, para garantir a homogeneização, a solução foi mantida sob agitação por mais 15 minutos.

Do processo descrito acima, foi obtido um precipitado branco gelatinoso, que foi separado da solução por filtração, lavagem e repolpamento com água repetidas vezes, até não haver mais a detecção dos íons cloreto, feita pela reação de uma amostra do sobrenadante com $\mathrm{AgNO}_{3}$. A presença de cloretos no precipitado pode prejudicar a densificação da cerâmica na etapa de sinterização, ao passo que a presença de água, na etapa de secagem, favorece a formação de aglomerados fortes e pós pouco reativos, o que pode ser evitado tratando o precipitado com solventes orgânicos. Dessa maneira, o precipitado foi 
lavado com etanol, a fim de remover o excesso de água, e em seguida lavado e repolpado com $n$-butanol, ficando em repouso neste solvente por 24 horas. Após esse período de repouso, foi submetido à destilação azeotrópica para a eliminação da água remanescente. O n-butanol forma um azeotrópo com a água a $92,5^{\circ} \mathrm{C}$, o que possibilita a evaporação de toda a água antes que seja eliminado o $n$-butanol remanescente, $118^{\circ} \mathrm{C}$. Por fim o precipitado foi seco em estufa a $70^{\circ} \mathrm{C}$ por 72 horas e desagregado em almofariz de ágata.

O pó amorfo de 3 YTZP obtido foi calcinado a $800^{\circ} \mathrm{C}$ por 1 hora em forno mufla. Após calcinação, foi submetido à moagem em meio etanóico em moinho de alta energia por 4 horas, utilizando-se meios de moagem de zircônia, seguida por secagem a $70^{\circ} \mathrm{C}$ por 72 horas. $\mathrm{O}$ pó foi desaglomerado em almofariz de ágata e passado pelas peneiras de 32 mesh e 60 mesh.

\subsubsection{Caracterização do pó de 3YTZP}

O pó de zircônia tetragonal policristalina estabilizado com $3 \mathrm{~mol} \%$ de ítria (3YTZP) foi caracterizado empregando-se as seguintes técnicas descritas abaixo:

- Difração de raios X (Rigaku, Multiflex), para a identificação das fases cristalinas. As análises foram realizadas utilizando a radiação $\mathrm{Cu}-\mathrm{Ka}$, com faixa angular de $10^{\circ}$ a $90^{\circ}$, passo de $0,02^{\circ}$ e tempo de contagem de 6 segundos por passo, equipamento operando a $40 \mathrm{kV}$ e $20 \mathrm{~mA}$. A identificação das fases foi feita utilizando o software Crystalographica Search-Match ${ }^{\circledR}$, onde os dados obtidos foram comparados às fichas do banco de dados ICSD (Inorganic Crystal Struture Database).

- Microscopia Eletrônica de Varredura por Emissão de Campo (MEV-FEG, JSM 6701S, Jeol, EUA), permitiu a observação da morfologia das partículas e aglomerados de 3YTZP.

$\mathrm{Na}$ Figura 4-1 é apresentado um esquema do processo de coprecipitação e caracterização do pó cerâmico obtido. 


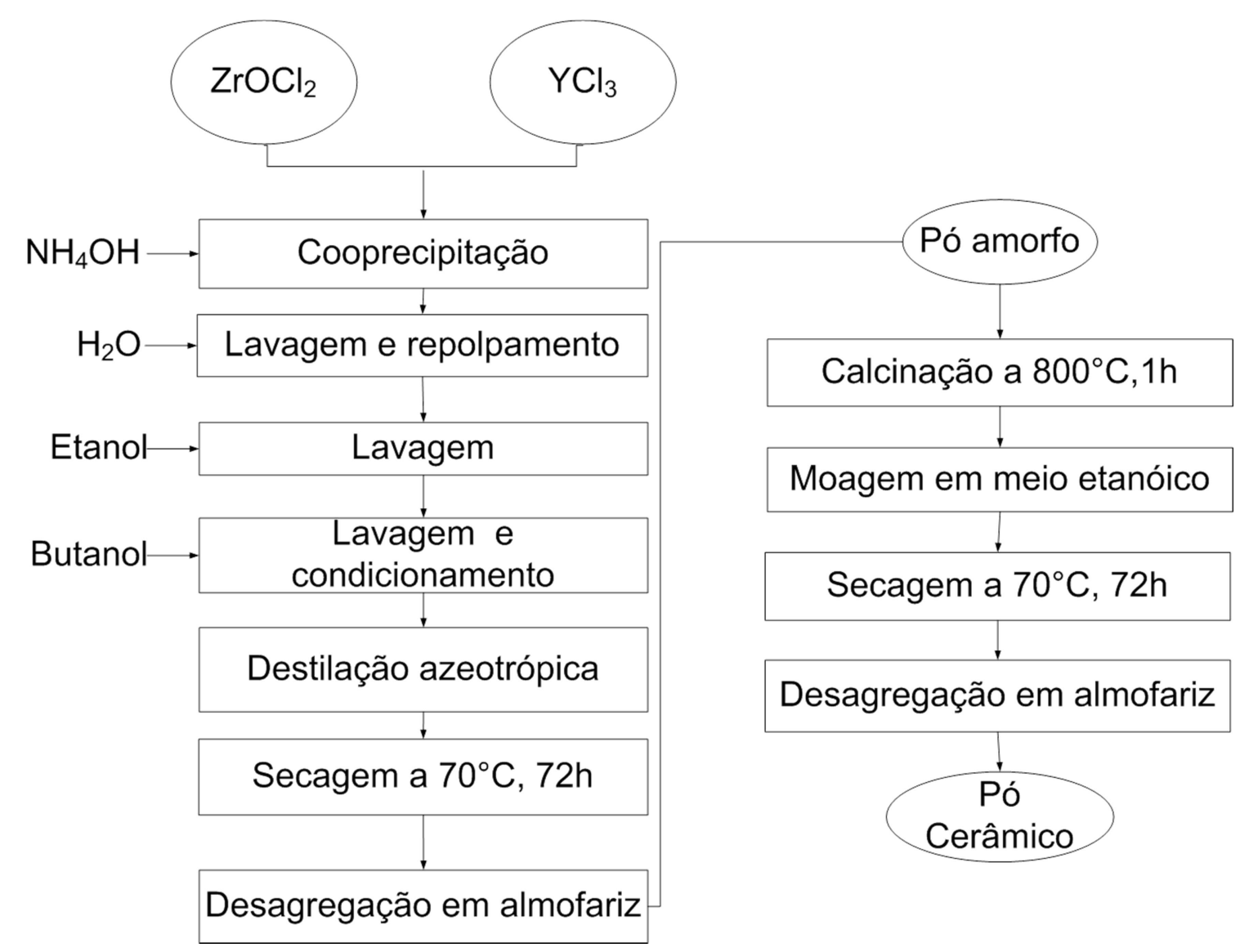

Figura 4-1 - Representação esquemática da síntese dos pós de 3YTZP pela rota de coprecipitação hidróxidos em meio amoniacal.

\subsection{Processamento Cerâmico}

Foi feito o processamento cerâmico do pó de 3YTZP produzido pela rota de coprecipitação de óxidos em meio amoniacal a fim de verificar-se a sinterabilidade do pó produzido.

Para isso, o pó foi compactado usando prensa uniaxial, pressão de 90 $\mathrm{MPa}$ e matriz cilíndrica de diâmetro interno de $10 \mathrm{~mm}$. Depois de prensado, o corpo cerâmico foi sinterizado. Adotou-se como condição de sinterização $1500^{\circ} \mathrm{C}$ por um período de 1 hora, sendo utilizado um forno elétrico tipo caixa (Lindberg, Blue $\mathrm{M}$ ), taxa de aquecimento de $10^{\circ} \mathrm{C} \cdot \mathrm{min}^{-1}$ até $1000^{\circ} \mathrm{C}, 5^{\circ} \mathrm{C} \cdot \mathrm{min}^{-1}$ até atingir $1500^{\circ} \mathrm{C}$. 


\subsubsection{Caracterização da cerâmica sinterizada}

A cerâmica de zircônia tetragonal policristalina estabilizada com 3mol\% de ítria (3YTZP) prensada uniaxialmente foi caracterizada empregando-se as técnicas:

- Difração de raios X (Rigaku, Multiflex), para identificação das fases cristalinas. Foram utilizadas as mesmas condições usadas para a análise do pó.

- Densidade aparente pelo método de imersão - Para a determinação da densidade aparente foi utilizado o método de imersão baseados no princípio de Archimedes de acordo de acordo com as normas da ASTM C20 [52] Equação 4-1.

$$
\rho_{\text {amostra }}=\frac{M_{s} x d_{\text {água }}}{M_{u}-M_{i}}
$$

Em que:

$\mathrm{d}=$ densidade $\left(\mathrm{g} \cdot \mathrm{cm}^{-3}\right)$

$M_{s}, M_{u}$ e $M_{i}$ são respectivamente, massa da amostra seca, úmida e imersa, em gramas $(\mathrm{g})$.

Os valores de densidade teórica foram extraídos das fichas do banco de dados ICSD (Inorganic Crystal Struture Database)

- Microscopia eletrônica de varredura (TableTop, HITACHI), utilizado para observação e análise microestrutural da superfície de fratura.

Na Figura 4-2 estão apresentados esquematicamente o processamento cerâmico e a caracterização da cerâmica de 3YTZP sinterizada. 


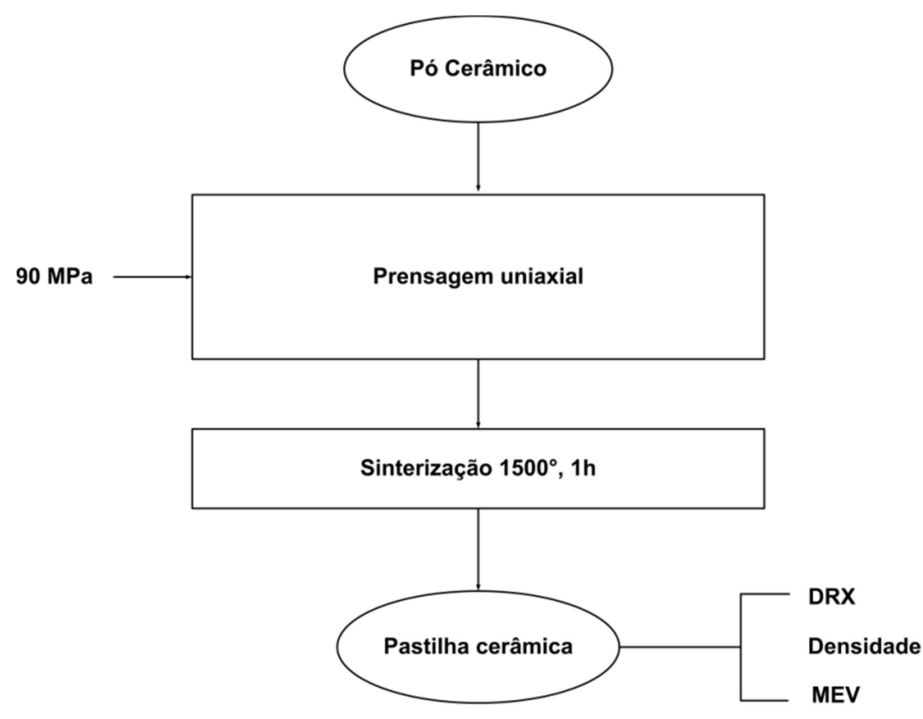

Figura 4-2 - Representação esquemática do processamento cerâmico e caracterização da cerâmica de 3YTZP sinterizada.

\subsection{Deposição eletroforética}

\subsubsection{Substrato}

Como substrato para a deposição eletroforética de 3YTZP foram utilizadas placas de titânio de pureza comercial com espessura aproximada de 0,5 $\mathrm{mm}$ e foram cortadas com dimensões de $15 \mathrm{~mm} \times 15 \mathrm{~mm}$. Como técnica de caracterização do substrato foi utilizada a difração de raios X (Rigaku, Multiflex) para a identificação das fases presentes nas placas, usando radiação $\mathrm{Cu}$-Ka, faixa angular de $20^{\circ}$ a $90^{\circ}$, passo de $0,06^{\circ}$, tempo de contagem de 6 segundos por passo e equipamento operando a $40 \mathrm{kV}$ e $20 \mathrm{~mA}$.

Para melhorar a ancoragem das partículas cerâmicas ao substrato foi feito o estudo de possíveis tratamentos de superfície para o titânio. Foram feitos dois tipos de ataques ácidos à temperatura ambiente, um realizado com solução de ácido sulfúrico $50 \%$ em volume $\left(\mathrm{H}_{2} \mathrm{SO}_{4}\right.$, Satelit, PA) e outro com solução de ácido nítrico $25 \%$ em volume $\left(\mathrm{HNO}_{3} 65 \%, \mathrm{PA}, \mathrm{CRQ}\right)$.

A finalidade destes tratamentos de superfície foi determinar para qual solução e qual tempo de ataque resultaria em melhor rugosidade para a superfície do substrato de titânio $[53,54]$.

As chapas de titânio foram mergulhadas nas soluções ácidas por 10 segundos e 30 segundos, posteriormente enxaguadas com água, após, lavadas 
em ultrassom com acetona por 10 minutos e secas ao ar. Os substratos atacados foram caracterizados pelo ensaio de rugosidade (Mitutoyo, SJ301). Na Figura 4-3 está apresentado esquematicamente o processo de preparação do substrato de titânio para EPD.

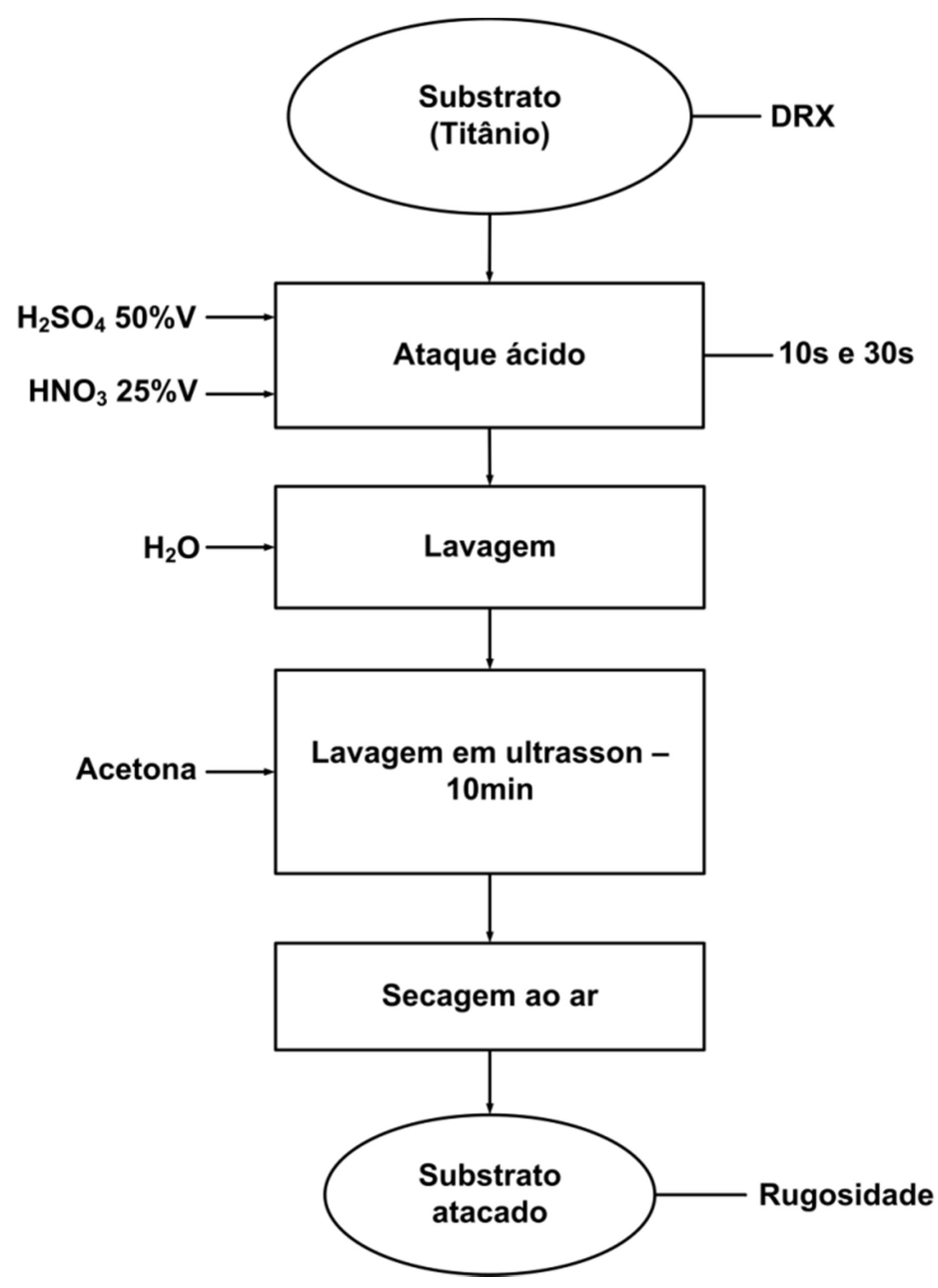

Figura 4-3 - Representação esquemática da preparação do substrato de titânio para EPD.

\subsubsection{Sistema para deposição eletroforética}

Inicialmente, para a deposição eletroforética foi utilizado um aparato produzido parte em PVC, parte em nylon, levando em conta que nos experimentos iniciais foram usados como solvente etanol e acetona. Quando se modificou o solvente, passando a se usar acetilacetona, este ocasionou a degradação do PVC, fazendo-se necessário o desenvolvimento de outro aparato. 
Testes foram feitos com alguns polímeros, e verificou-se que o Teflon não era degradado pela acetilacetona, sendo este usado para substituir o PVC.

Pequenas modificações foram feitas no sistema a fim de melhorar o processo. Os parafusos de fixação da peça onde se situa o eletrodo a ser recoberto que no sistema anterior eram paralelos à base do sistema, no novo sistema tomaram-se perpendiculares à base. Isso possibilitou maior precisão da distância entre os eletrodos, um dos parâmetros relacionados ao processo. $\mathrm{Na}$ Figura 4-4 é apresentado o croqui da peça desenvolvida para a deposição eletroforética e na Figura 4-5 é apresentado o sistema de EPD já produzido com os novos materiais e com as melhorias realizadas.
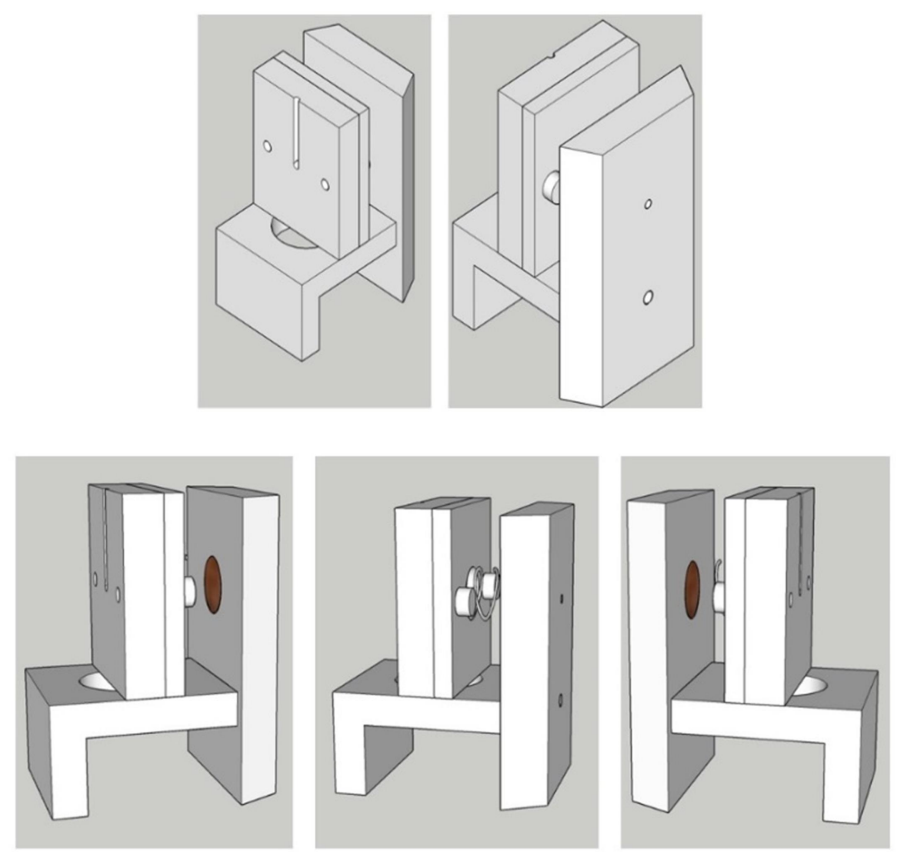

Figura 4-4- Croqui da peça utilizada no sistema de deposição eletroforética. 


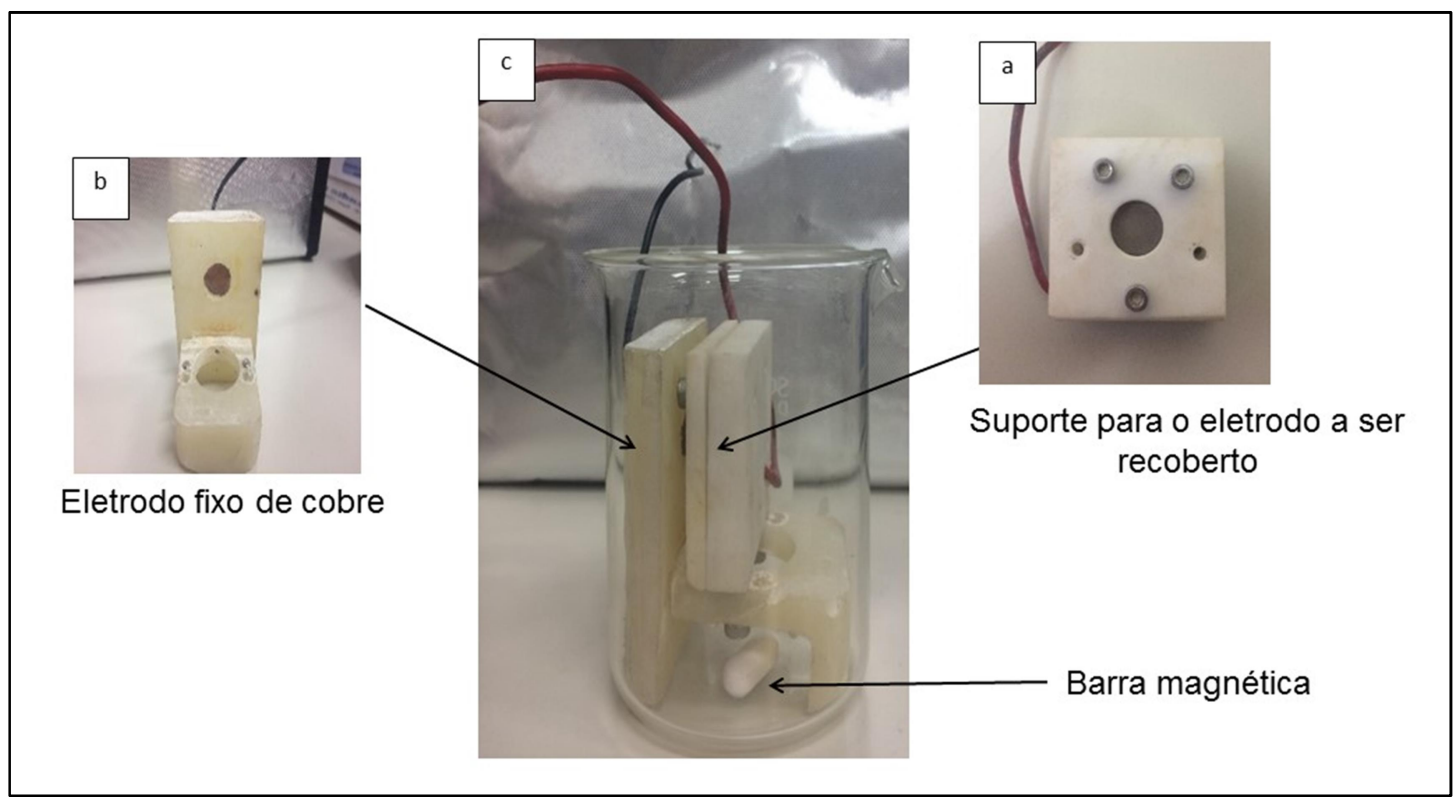

Figura 4-5 - Fotografia do aparato utilizado para o processo de deposição eletroforética. (a) suporte do eletrodo a ser recoberto. (b) suporte para o eletrodo fixo. (c) Sistema para EPD.

Para a deposição, as placas de titânio já atacadas quimicamente foram dispostas no suporte, de modo a estabelecer o contato desta com o fio de alimentação como mostrado na Figura 4-5 (a). Depois de inseridas as placas no suporte, este é disposto paralelamente ao eletrodo fixo (peça da Figura 4-5 (b)), obtendo-se o arranjo final, como mostrado na Figura 4-5 (c). Os eletrodos foram inseridos em um béquer de vidro, ficando imersos na suspensão e são alimentados por uma fonte de alta tensão (Stanford, PS310/1250 V - 25 W). O béquer é disposto sobre um agitador magnético como mostrado na Figura 4-6. 


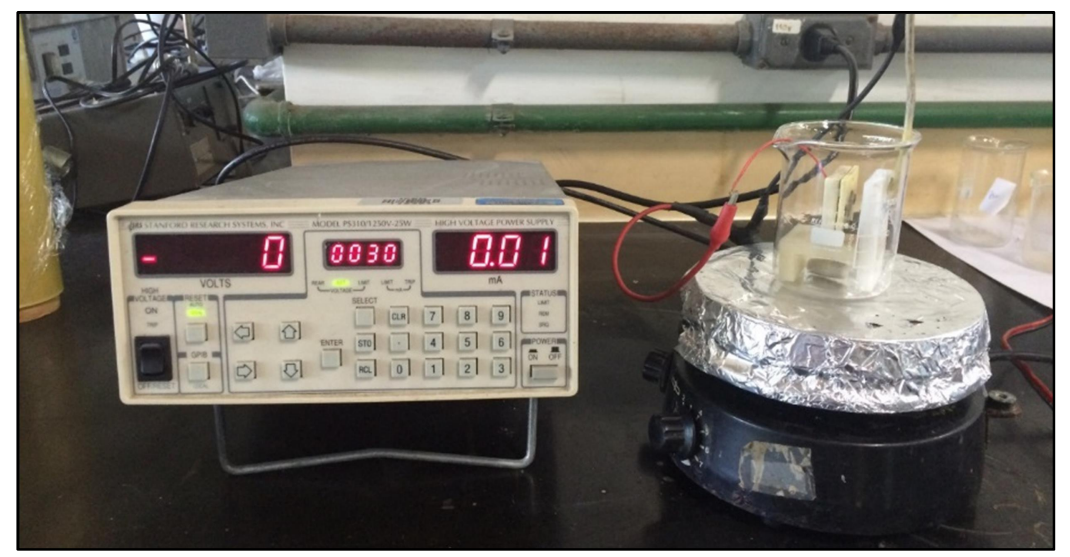

Figura 4-6 - Fotografia do aparato completo utilizado na EPD.

\subsubsection{Suspensões}

As suspensões para a deposição eletroforética foram preparadas utilizando três tipos de solvente, sendo a acetona (Merck, PA) e acetilacetona (CRQ, PA), os solventes principais, e o etanol (Moderna, 95\% PA) foi usado como solvente aditivo. Sendo assim, as suspensões foram classificadas em dois grupos, o das suspensões a base de acetona, e o grupo das suspensões a base de acetilacetona. Para as suspensões do grupo da acetona adicionou-se iodo como polieletrólito.

\subsubsection{Suspensões a base de Acetona}

Foram preparadas duas suspensões a base de acetona usando etanol como aditivo e concentração de $10 \mathrm{~g} \cdot \mathrm{L}^{-1}$ de 3 YTZP. Uma na proporção $75 \%$ acetona: $25 \%$ etanol em volume e outra na proporção $50 \%$ acetona: $50 \%$ etanol em volume, que foram codificadas de acordo com a Tabela 4-1.

Para ambas foram preparados $120 \mathrm{ml}$ de suspensão. Primeiramente foram misturados os dois solventes, e posteriormente o pó. A suspensão foi agitada em ultrassom por 40 minutos e, após isso, passou por um período de repouso por 2 horas, voltado a ser agitada novamente por 10 minutos. Após esse processo, adicionou-se iodo para servir como polieletrólito. 
Tabela 4-1 - Codificação das suspensões a base de acetona.

\begin{tabular}{cc}
\hline Suspensão (\%vol) & Codificação da suspensão \\
\hline $75 \%$ acetona:25\%etanol & $75 \mathrm{Ac}$ \\
$50 \%$ acetona:50\%etanol & $50 \mathrm{Ac}$ \\
\hline
\end{tabular}

$\mathrm{Na}$ Figura 4-7 está apresentado esquematicamente o preparo das suspensões a base de acetona.

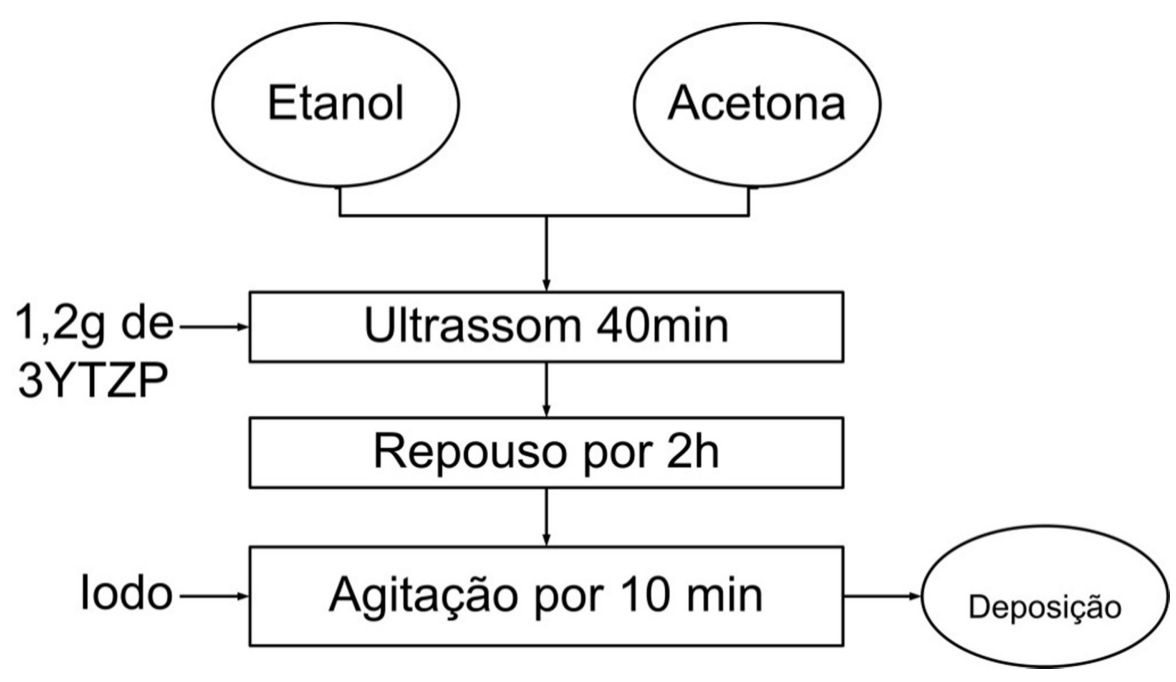

Figura 4-7 - Representação esquemática do preparo das suspensões a base de acetona usando etanol como solvente aditivo.

\subsubsection{Suspensões a base de Acetilacetona}

Foram preparadas duas suspensões a base de acetilacetona, uma com acetilacetona pura, e outra usando etanol como aditivo na proporção $25 \%$ acetilacetona: $75 \%$ etanol em volume, para ambas, a concentração de 3YTZP foi de 20 g. $\mathrm{L}^{-1}$, codificadas de acordo com a Tabela 4-2.

Foram preparados $100 \mathrm{ml}$ de suspensão. Primeiramente o pó de 3YTZP foi misturado à acetilacetona pura ou à mistura de solventes e agitado em ultrassom por 10 minutos. Assim que preparada a suspensão já se iniciou o processo de deposição, não deixando a suspensão passar por um período de repouso. 
Tabela 4-2 - Codificação das suspensões a base de acetilacetona.

\begin{tabular}{cc}
\hline Suspensão (\%vol) & Codificação da suspensão \\
\hline $25 \%$ acetilacetona:75\%etanol (\%vol) & $25 \mathrm{Aa}$ \\
Acetilacetona pura & $100 \mathrm{Aa}$ \\
\hline
\end{tabular}

Na Figura 4-8 está apresentado esquematicamente o preparo das suspensões a base de acetilacetona.

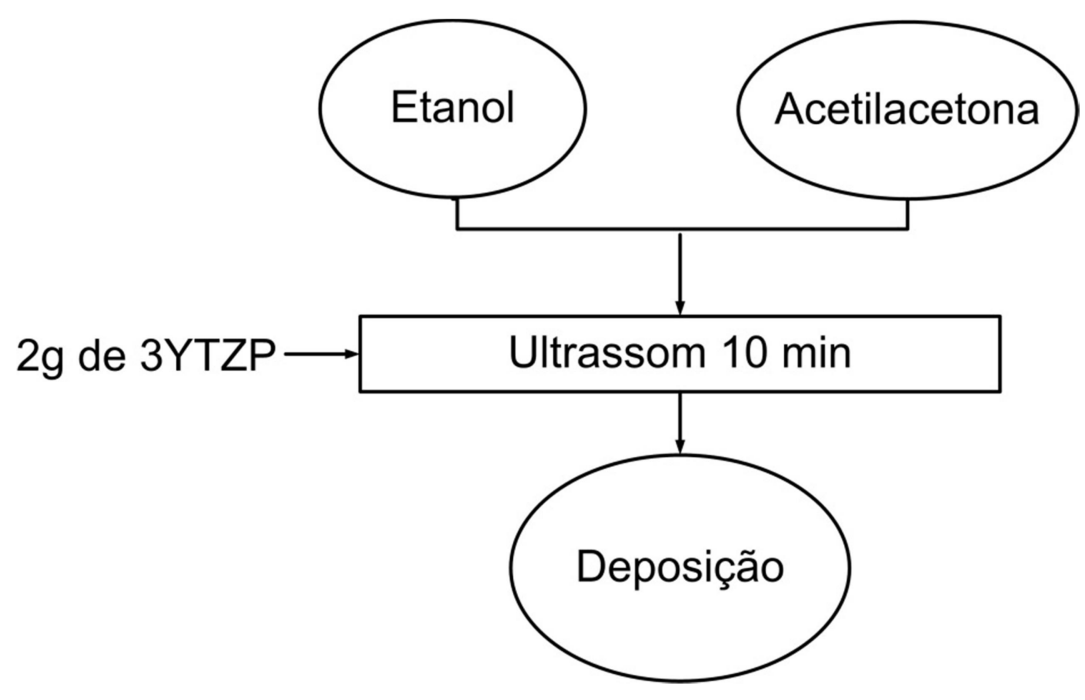

Figura 4-8 - Representação esquemática do preparo das suspensões a base de acetilacetona.

\subsubsection{Processo de deposição eletroforética}

Para obter-se a condição ideal para deposição eletroforética de 3YTZP em titânio foram feitas duas séries de deposição, denominadas de série 1 e série 2.

Para as séries de deposição manteve-se a distância de $10 \mathrm{~mm}$ entre os eletrodos, além de manter-se a suspensão sob agitação para pudesse ser evitada a decantação das partículas de 3YTZP. 
Tabela 4-3 - Suspensões e parâmetros da série 1 de deposição.

\begin{tabular}{|c|c|c|}
\hline & Série 1 & \\
\hline \multirow[t]{2}{*}{ Suspensão } & DDP (V) & Tempo (s) \\
\hline & & 30 \\
\hline \multirow[t]{3}{*}{ 75Ac } & 30 & 45 \\
\hline & & 60 \\
\hline & & 30 \\
\hline \multirow[t]{2}{*}{$50 \mathrm{Ac}$} & 20 & 45 \\
\hline & & 60 \\
\hline
\end{tabular}

Tabela 4-4 - Suspensões e parâmetros da série 2 de deposição.

\section{Série 2}

\begin{tabular}{lll}
\hline Suspensão & DDP (V) & Tempo (s) \\
\hline \multirow{2}{*}{ 25Aa } & 40 & 20 \\
\cline { 2 - 3 } & & 20 \\
& 60 & 40 \\
& & 60 \\
& 40 & 20 \\
& & 40 \\
100Aa & 60 & 20 \\
& & 40 \\
& & 60 \\
\hline
\end{tabular}


As duas primeiras séries foram feitas para que pudessem ser justados os parâmetros de EPD, assim como qual melhor solvente para a suspensão.

Com a finalidade de fazer uma relação entre a corrente inicial de deposição e a qualidade dos filmes obtidos obteve-se a corrente inicial de deposição (que era indicada no painel de controle da fonte) para cada suspensão utilizada.

Após determinas as melhores condições, foram produzidas amostras apenas nestas condições e estas foram caracterizadas por microscopia eletrônica de varredura (TableTop - HITACHI). As amostras produzidas foram a $2 \mathrm{~F}, 4 \mathrm{~F}, 5 \mathrm{~F}$, $6 \mathrm{G} 8 \mathrm{G}$ e $9 \mathrm{G}$.

Na Figura 4-9 está representado esquematicamente as séries 1 e 2 de deposição com as suspensões, as respectivas amostras geradas pelo processo de EPD e os parâmetros de processo para cada uma. 


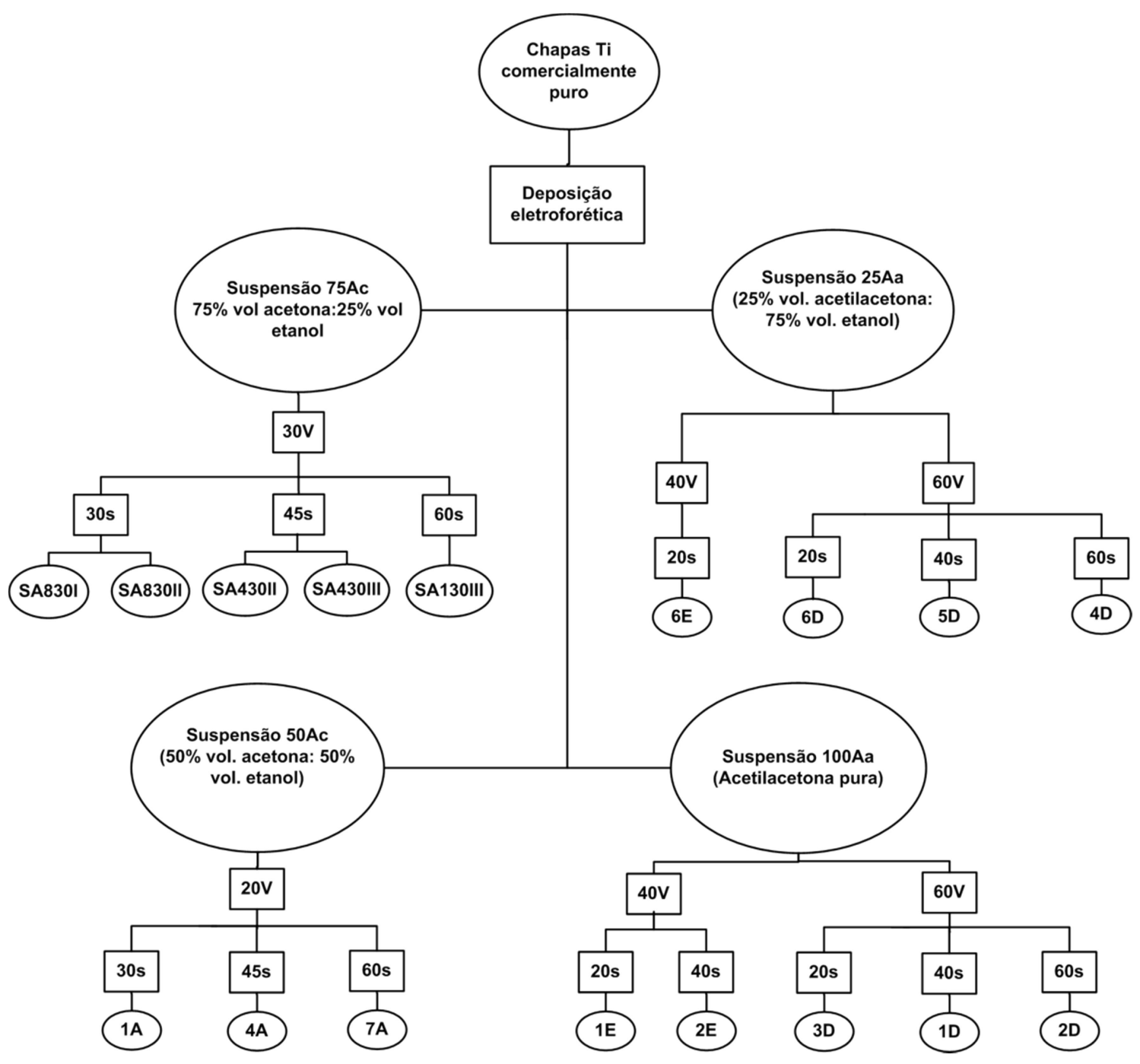

Figura 4-9 - Representação esquemática das amostras produzidas na série 1 e 2 de EPD.

\subsubsection{Caracterização do recobrimento a verde}

Os recobrimentos a verde foram caracterizados por microscopia óptica (Olympus, UC30) e microscopia eletrônica de varredura (TableTop - Hitachi), com a finalidade de observar-se a presença ou não de trincas no filme depositado.

Foi calculada também a diferença de massa, para ter-se uma estimativa da espessura do filme depositado com o auxílio da Equação 4-2 que foi obtida por meio da equação de densidade e área de deposição, considerando que para as para as amostras da série $S A, A$ e $D$ a área depositada foi de $1,56 \mathrm{~cm}^{2} \mathrm{e}$ para as amostras da série $E, F$ e $G$ a área depositada foi de $1,14 \mathrm{~cm}^{2}$, considerando também a densidade do recobrimento em torno de $40 \%$ da densidade teórica da cerâmica. 


$$
E=\frac{\Delta m}{A \cdot \rho}
$$

Equação 4-2

Em que $\Delta m$ é a diferença de massa, A é a área depositada e $\rho$ é a densidade considerada para o filme depositado.

\subsection{Irradiação com laser}

O processo de irradiação com laser foi feito no Centro de Laser e Aplicação do IPEN usando o laser pulsado de Nd:YAG

Foram realizados cinco testes de irradiação a fim de ajustar a melhor condição para que ocorra a sinterização.

\subsubsection{O laser Nd:YAG}

O laser de Nd:YAG funciona em modo pulsado, com comprimento de onda de 1,064 $\mu \mathrm{m}$, energia máxima de 6 Joules, taxa de repetição máxima de 500 $\mathrm{Hz}$ e largura temporal controlável de 0,2 a $10 \mathrm{~ms}$. Com este sistema também é possível o controle computadorizado (CNC) da varredura do feixe de laser a superfície da amostra. O laser foi focalizado sobre a amostra utilizando-se uma lente de comprimento focal de $100 \mathrm{~mm}$. Todos os experimentos foram feitos com energia de $0,5 \mathrm{~J}$, largura temporal de $10 \mathrm{~ms}$, e taxa de repetição de $10 \mathrm{~Hz}$.

\subsubsection{Parâmetros de Irradiação}

Foram realizados cinco testes de irradiação, os que chamamos de Teste 1, Teste 2, Teste 3, Teste 4 e Teste 5.

O Teste 1 foi realizado em duas amostras, a SA830II e SA830I. Foram feitas 8 linhas de irradiação, de modo que ao longo dessas linha em um $\Delta x$ de 8 $\mathrm{mm}$ variou-se a distância focal $Z$ como representado no gráfico da Figura 4-10. Assim, determinando a região de interesse na linha é possível obter-se o valor de $Z$ correspondente àquele ponto. Para cada linha foi atribuída uma velocidade de varredura e o número de incidência $\mathrm{NI}$, que foi o número de vezes que o laser incidiu na linha. 


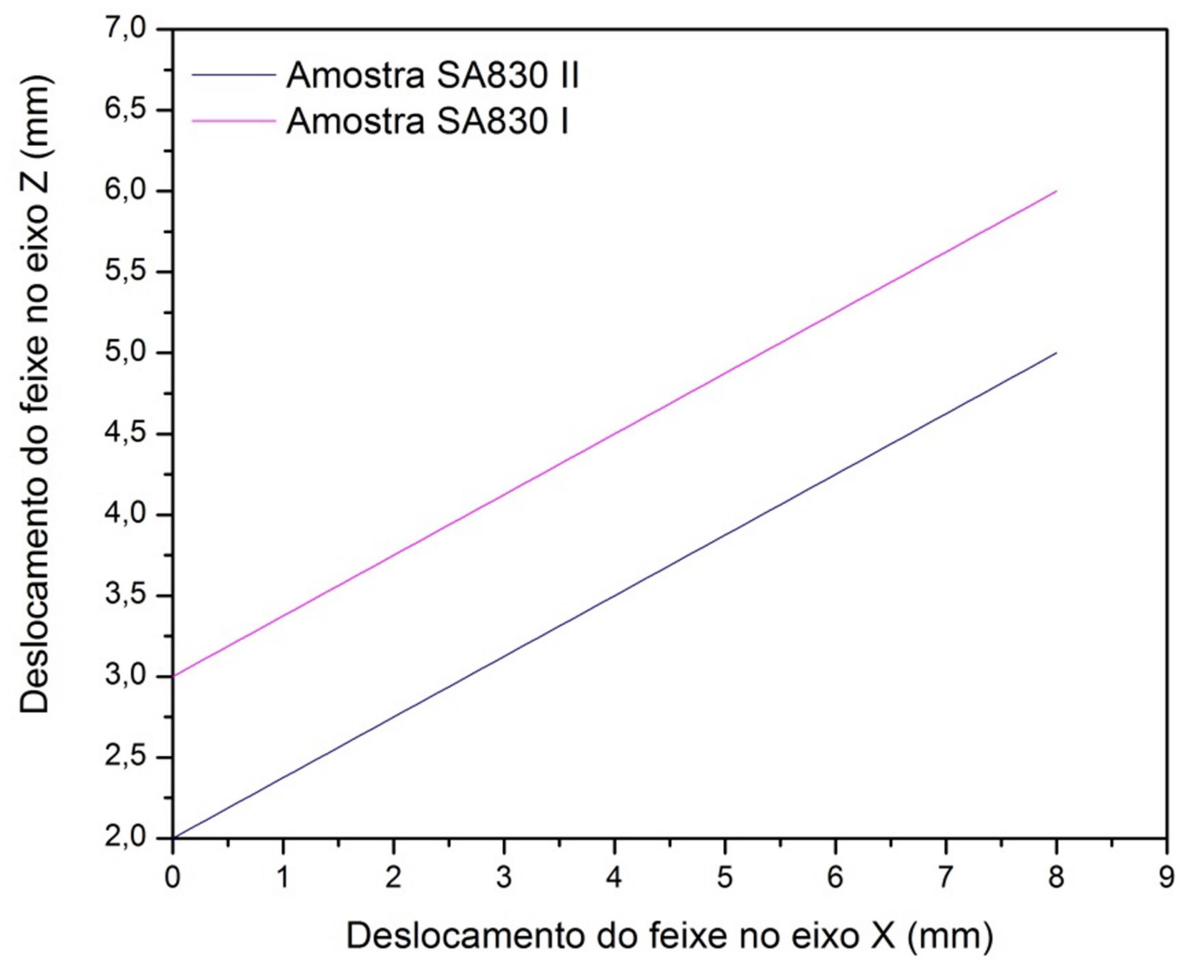

Figura 4-10 - Representação da variação da distância Z ao longo da linha irradiada para o teste 1 para as amostras SA830II e SA830I.

Para a amostra SA830II ao longo das linhas variou-se a distância Z de 2 a $5 \mathrm{~mm}$. Na Figura 4-11 apresentam-se as linhas de irradiação (de Y1 a Y8) e na Tabela 4-5 estão apresentados detalhadamente os parâmetros utilizados na irradiação desta amostra. 


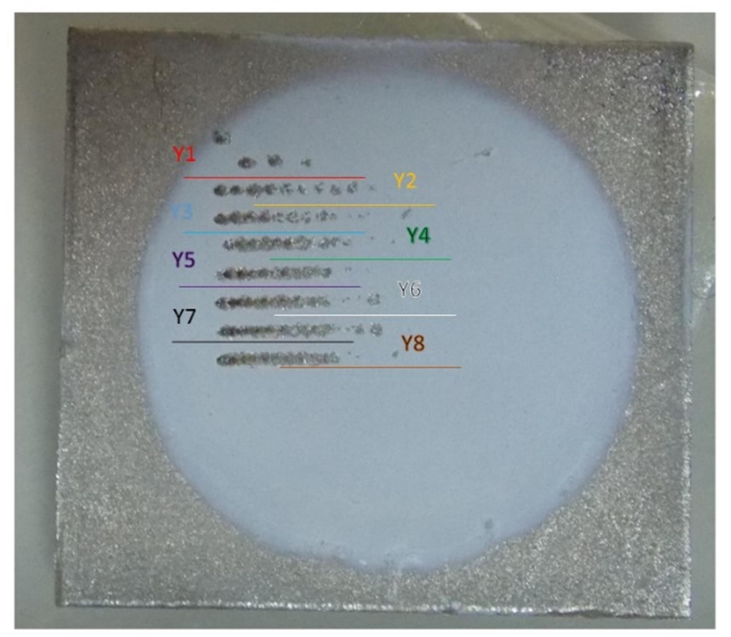

Figura 4-11 - Fotografia da amostra SA830II irradiada com laser de Nd:YAG com $Z$ variando de 2 a $5 \mathrm{~mm}$ longo de cada linha.

Tabela 4-5 - Parâmetros de Irradiação usando laser Nd:YAG da amostra AS830II.

\begin{tabular}{|c|c|c|}
\hline \multicolumn{3}{|c|}{$\Delta Z-$ de 2 a $5 \mathrm{~mm}$} \\
\hline \multicolumn{3}{|c|}{$\Delta \mathrm{X}-8 \mathrm{~mm}$ (da esquerda para a direita) } \\
\hline & $\Delta \mathrm{Y} \sim 0,8 \mathrm{~m}$ & \\
\hline Deslocamento em Y & $\mathrm{V} \mathrm{mm} / \mathrm{min}$ & $\begin{array}{c}\text { Número de incidência } \\
\text { (NI) }\end{array}$ \\
\hline 1 & 450 & \\
\hline 2 & 350 & \\
\hline 3 & 300 & 1 \\
\hline 4 & 250 & \\
\hline 5 & 450 & \\
\hline 6 & 350 & $?$ \\
\hline 7 & 300 & 3 \\
\hline 8 & 250 & \\
\hline
\end{tabular}

Para a amostra SA830I ao longo das linhas variou-se a distância $Z$ de 3 a $6 \mathrm{~mm}$. Na Figura 4-12 apresentam-se as linhas de irradiação (de Y1 a Y8) e na Tabela 4-6 estão apresentados detalhadamente os parâmetros utilizados na irradiação desta amostra. 


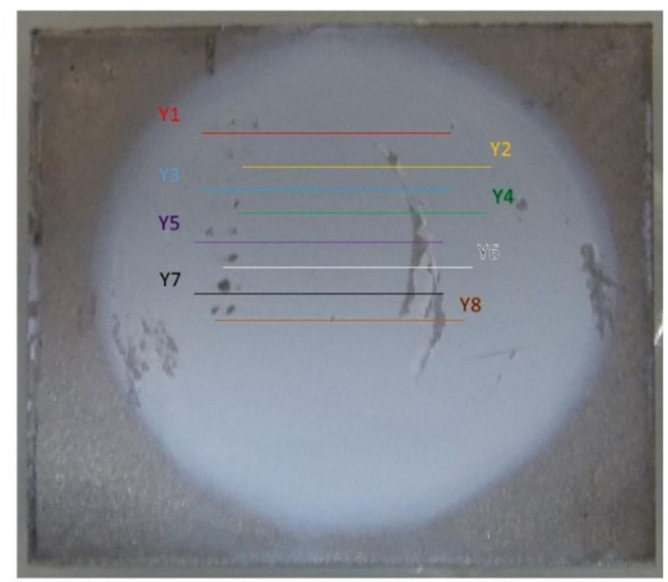

Figura 4-12 - Amostra SA830I irradiada com laser Nd:YAG com Z variando de 2 a $5 \mathrm{~mm}$ longo de cada linha.

Tabela 4-6 - Parâmetros de Irradiação usando laser Nd:YAG da amostra AS830I.

$$
\Delta Z-\text { de } 3 \text { a } 6 \mathrm{~mm}
$$

\section{$\Delta \mathrm{X}-8 \mathrm{~mm}$ (da esquerda para a direita)}

$$
\Delta \mathrm{Y} \sim 0,8 \mathrm{~mm}
$$

\begin{tabular}{ccc}
\hline & & \\
Deslocamento em $\mathbf{Y}$ & Númin & $\begin{array}{c}\text { (NI) incidência } \\
\text { (NI) }\end{array}$ \\
\hline 1 & 450 & \\
2 & 350 & 1 \\
3 & 300 & \\
4 & 250 & 3 \\
5 & 450 & \\
6 & 350 & \\
7 & 300 & \\
\hline
\end{tabular}

Com o auxílio da Equação 3-5 e Equação 3-6 é possível determinar o raio do feixe de laser em função da distância focal $Z$. Considerando o raio circular e usando a equação de área do círculo é possível determinar a área do feixe em função também da distância focal. 
Levando em consideração que a energia fornecida pelo feixe de laser é constante, foi possível determinar, com o auxílio da Equação 3-7, a fluência utilizada para os ensaios.

Depois de irradiadas com laser Nd:YAG, as amostras foram caracterizadas por microscopia óptica (Olympus, UC30) e microscopia eletrônica de varredura (TableTop - HITACHI) a fim de determinar as melhores condições para dar continuidade aos ensaios. Dessa maneira, determinou-se a linha, e qual a posição do ponto de interesse no eixo $X$ para que então pudesse ser determinada a distância focal $Z$, de modo que pudesse ser calculada a fluência no ponto, velocidade de varredura e também o número de incidência correspondente àquele ponto. Foi medido também o diâmetro do dano provocado na amostra irradiada. As duas amostras foram analisadas linha por linha, ao longo de toda a sua extensão. A finalidade dessas análises foi localizar uma região que fosse o limiar do dano, ou seja, região a partir da qual não havia mais a retirada do material depositado. Determinando-se a região de interesse, foi possível determinar os parâmetros usados naquele ponto para que então pudesse ser reproduzido em outra amostra.

O Teste 2 foi realizado utilizando-se as melhores condições estabelecidas pelo Teste 1. Foram irradiadas duas amostras: a SA430II em que foi utilizado $Z=5$, correspondendo à fluência de $120 \mathrm{~J} / \mathrm{cm}^{2}$; e a SA430III em que foi utilizado $Z=4$, correspondendo à fluência de $190 \mathrm{~J} / \mathrm{cm}^{2}$. Para ambas amostras o número de incidência foi 1 e a região de irradiação foi de $8 \mathrm{~mm} \times 8 \mathrm{~mm}$. $\mathrm{Na}$ Tabela 4-7 são apresentados os parâmetros e irradiação das amostras usadas no segundo teste.

Tabela 4-7 - Parâmetros para irradiação das amostras do segundo teste.

\begin{tabular}{ccc}
\hline & \multicolumn{2}{c}{ Número de incidência $=1$} \\
\hline Parâmetros & SA430II & SA430III \\
\hline Z (mm) & 4,00 & 5,00 \\
V (mm/min) & 375 & 250 \\
\hline
\end{tabular}

O Teste 3 foi realizado escolhendo-se a melhor condição determinada pelo Teste 2. Baseando-se nas microscopias eletrônicas de varredura, foi 
escolhida a condição que não provocou a retirada de material depositado. Esta condição foi reproduzida em uma amostra para o número de incidência do laser igual a 1 e 2, como mostrado no esquema da Figura 4-13. Foi escolhida como condição utilizada na irradiação da amostra SA430III $Z=5,00 \mathrm{~mm}$ (fluência de $\left.120 \mathrm{~J} / \mathrm{cm}^{2}\right)$ e $V=250 \mathrm{~mm} / \mathrm{min}$. Para a região 1 o número de incidência foi igual a 1 , e para a região 2 , o número de incidência foi igual a 2 .

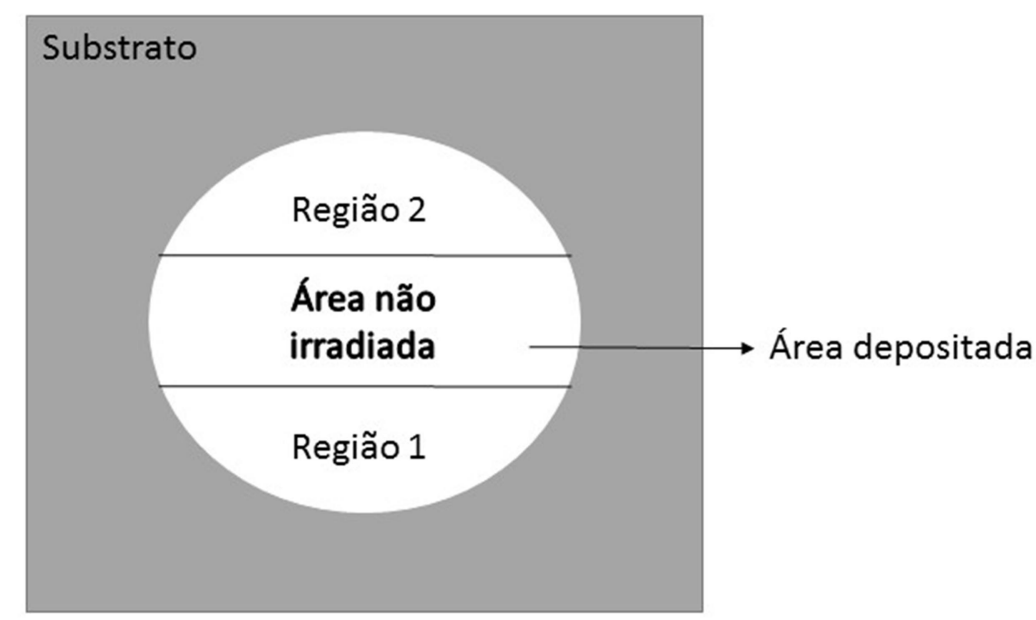

Figura 4-13 - Esquema do teste 3 de irradiação

No Teste 4 foi irradiada uma região de $6 \mathrm{~mm} \times 8 \mathrm{~mm}$ mantendo-se a fluência utilizada na irradiação das amostras do Teste $3\left(120 \mathrm{~J} / \mathrm{cm}^{2}\right)$, assim como a velocidade de $250 \mathrm{~mm} / \mathrm{min}$. Foi feita a variação do número de incidência do laser de 4, 6 e 8, para as amostras $2 \mathrm{~F}, 4 \mathrm{~F}$ e $5 \mathrm{~F}$ respectivamente. As amostras do foram avaliadas por microscopia eletrônica de varredura (TableTop - Hitachi) e difração de raios $x$ (MultiFlex, Higaku) na faixa angular de $20^{\circ}$ a $80^{\circ}$, com passo de 0,04 e tempo de contagem de 4 segundos por passo.

No teste 5 foram irradiadas 2 amostras, a $8 \mathrm{G}$ e a $9 \mathrm{G}$, com número de incidência do laser igual a 15 e 27, respectivamente. Foi irradiada uma área de 6 $\mathrm{mm} \times 8 \mathrm{~mm}$, com fluência de $120 \mathrm{~J} / \mathrm{cm}^{2}$ e velocidade de varredura de 250 $\mathrm{mm} / \mathrm{min}$. As amostras irradiadas também foram caracterizadas por microscopia eletrônica (TableTop, HITACHI), difração de raios x (MultiFlex, Higaku) na faixa angular de $20^{\circ}$ a $80^{\circ}$, com passo de 0,04, e Scratch (UMT-2,Tribometro CETR) em que foi utilizado para o risco um indentador do tipo Rockwell C (ponta cônica 
de diamante com $200 \mu \mathrm{m}$ de raio) com carga variável até $2 \mathrm{~N}, 3 \mathrm{~N}$ e $5 \mathrm{~N}$, e précarga de 0,5 $\mathrm{N}$ em uma distância de $2 \mathrm{~mm}$ com velocidade de 0,06 mm/min. 


\section{RESULTADOS E DISCUSSÃO}

\subsection{Caracterização dos pós de 3YTZP}

Na Figura 5-1 é apresentado o difratograma de raios $X$ do pó cerâmico de 3YTZP produzido via coprecipitação e calcinados a $800^{\circ} \mathrm{C}$ por 1 hora. Comparando com as fichas do ICSD (Inorganic Crystal Struture Database) de número 80-784 e 70-2491, observam-se picos referentes às fases tetragonal e monoclínica, respectivamente. Como característicos em difratogramas de pós, observam-se picos mais alargados, indicando menor tamanho de cristalito. Com o método da coprecipitação foi possível a produção do pó cerâmico maior quantidade de fase tetragonal com relação à monoclínica isso se deve ao fato de os grãos estarem livremente dispostos, o seja, não há uma força de compactação sendo exercida sobre eles.

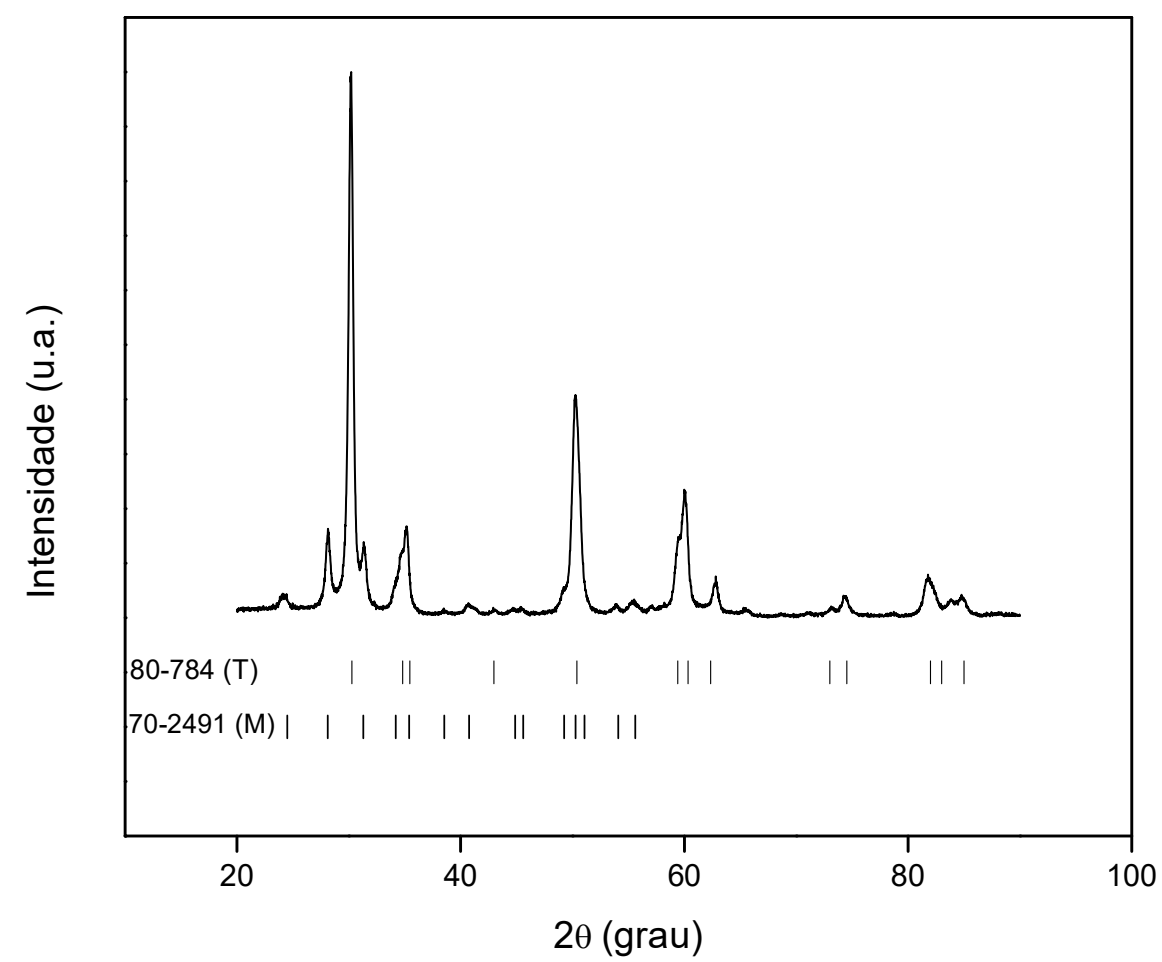

Figura 5-1 - Difratograma de raios $X$ do pó de 3YTZP obtido via coprecipitação química e calcinado a $800^{\circ} \mathrm{C}$ por 1 hora. Fase tetragonal (ficha $80-784$ ), fase monoclínica (ficha 70-2491). 
Na Figura 5-2 estão apresentadas as micrografias obtidas MEV-FEG do pó de 3YTZP calcinado a $800^{\circ} \mathrm{C}$ por 1 hora. Observam-se aglomerados de partículas, sendo que estas possuem estrutura mais alongada, na forma de bastões. Para ser usado como material particulado para deposição eletroforética é de extrema importância que se tenha um rigoroso controle do tamanho de partícula para que sejam obtidos bons depósitos, livres de trincas que podem surgir durante a secagem. Sato et al fizeram um estudo a fim de verificar o efeito do tamanho de partícula de $\mathrm{YBa}_{2} \mathrm{Cu}_{3} \mathrm{O}_{7}(\mathrm{YBCO})$ na formação de trincas durante a secagem de recobrimentos feitos por EPD. Verificou-se que a quantidade de trincas em recobrimentos feitos com suspensões de partículas relativamente menores (cerca de 0,06 $\mu \mathrm{m}$ ) foi bem menor do que em recobrimentos feitos com suspensões de partículas maiores (cerca de $3 \mu \mathrm{m}$ ) [55]. Dessa maneira torna-se necessário utilizar de um método de síntese que garanta tamanho de partícula pequeno, o que é possível pela rota de coprecipitação de hidróxidos em meio amoniacal.
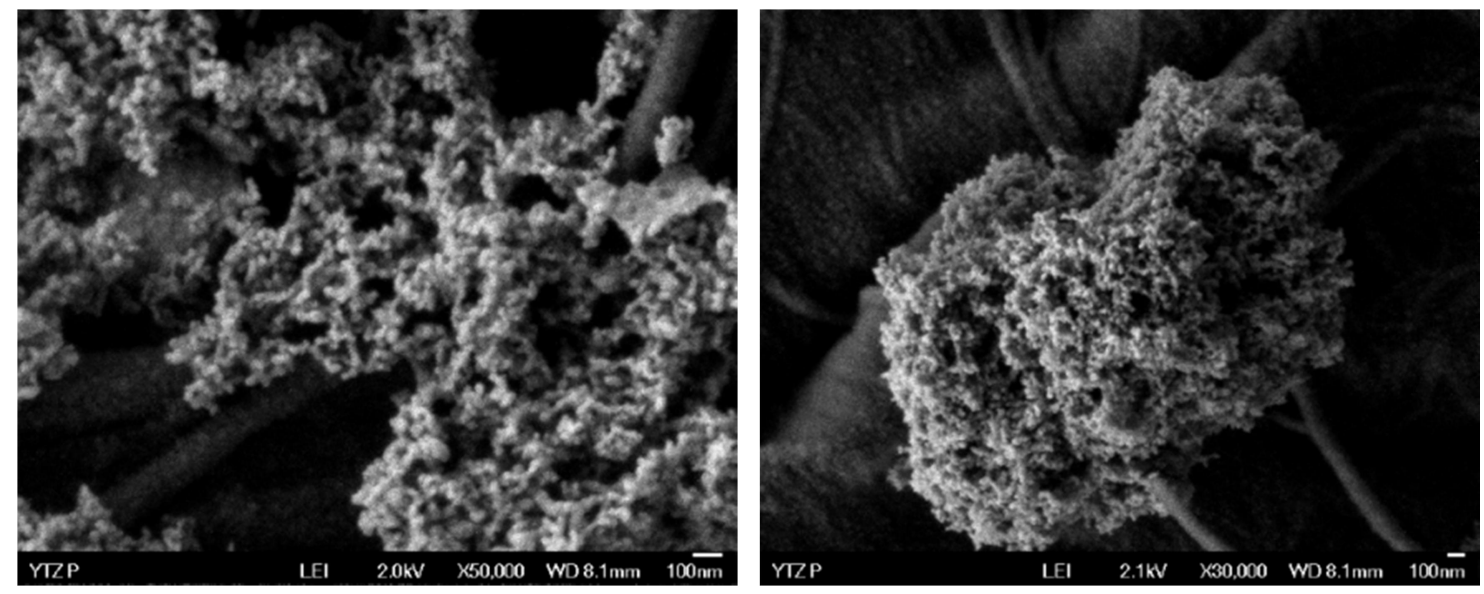

Figura 5-2 - MEV-FEG do pó de 3YTZP calcinado a $800^{\circ} \mathrm{C}$ por 1 hora.

\subsection{Caracterização da cerâmica sinterizada de 3YTZP}

Na Figura 5-3 é apresentado o difratograma de raios $X$ da cerâmica sinterizada a $1500^{\circ} \mathrm{C}$ por 1 hora. São observados picos referentes apenas à fase tetragonal de acordo com a ficha do ICSD 80-784. Observa-se um estreitamento dos picos com relação ao difratograma de raios $\mathrm{x}$ do pó apresentado na Figura $5-1$, indicando maior cristalinidade do material e aumento do tamanho de cristal 
em relação ao pó, além de o processo de sinterização garantir a fase tetragonal, o que confere maior resistência mecânica ao material [23].

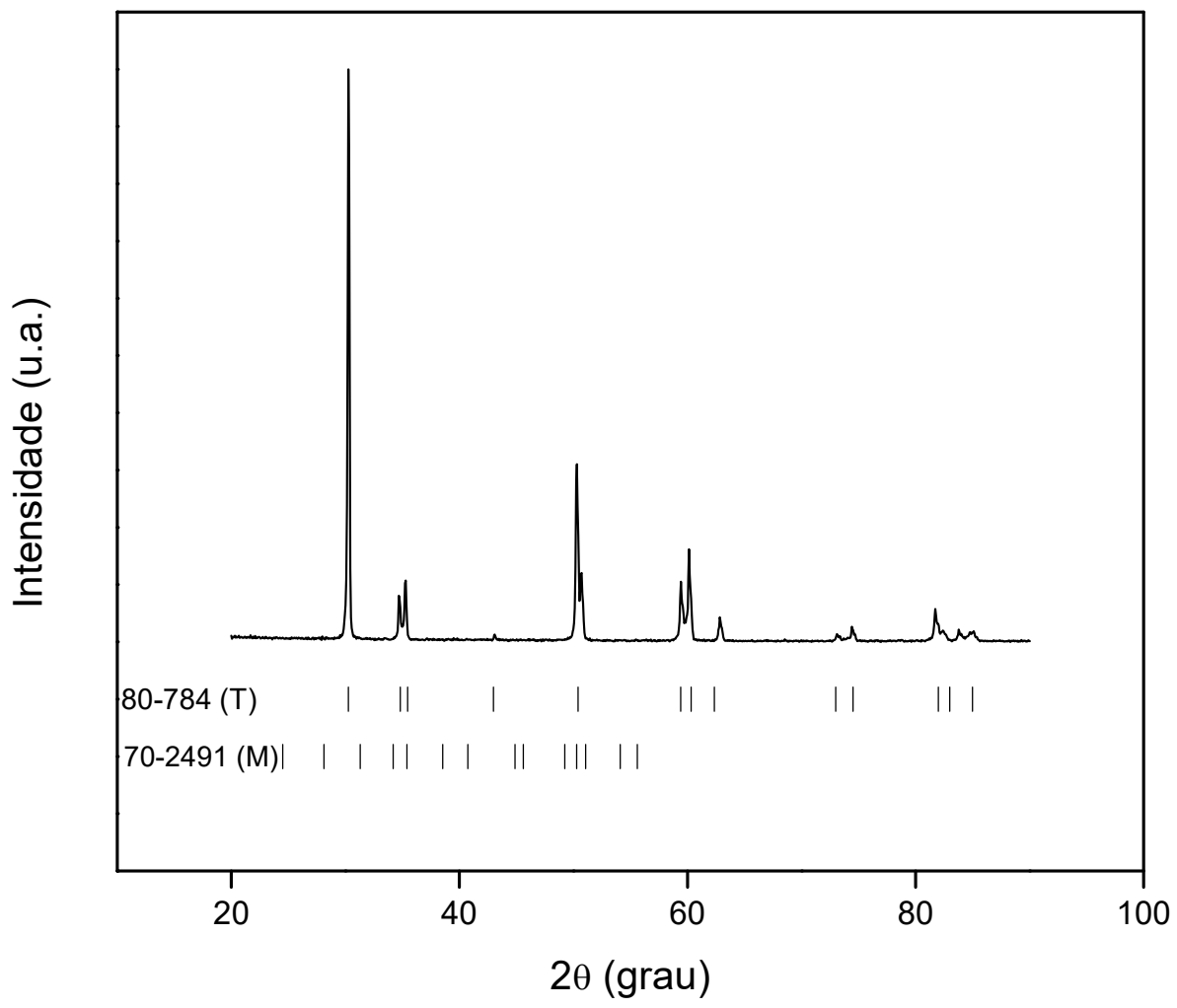

Figura 5-3 - Difratograma de raios X da cerâmica de 3YTZP sinterizada a $1500^{\circ} \mathrm{C}$ por 1 hora.

Pela densidade aparente obtida pelo método de imersão da cerâmica sinterizada verificou-se densificação de 94,4\% com relação à densidade teórica, sendo esta extraída do banco de dados do $\operatorname{ICSD}\left(6,12 \mathrm{~g} / \mathrm{cm}^{3}\right)$, determinando assim densidade de $5,78 \mathrm{~g} / \mathrm{cm}^{3}$ para a cerâmica produzida.

$\mathrm{Na}$ Figura 5-4 estão apresentadas as micrografias de fratura obtidas por MEV. Observam-se regiões com boa densificação, porém em algumas há a presença de poros (indicados na imagem pelas setas) o que confirma a diferença de entre densidade real e teórica verificada pelo método de imersão. 

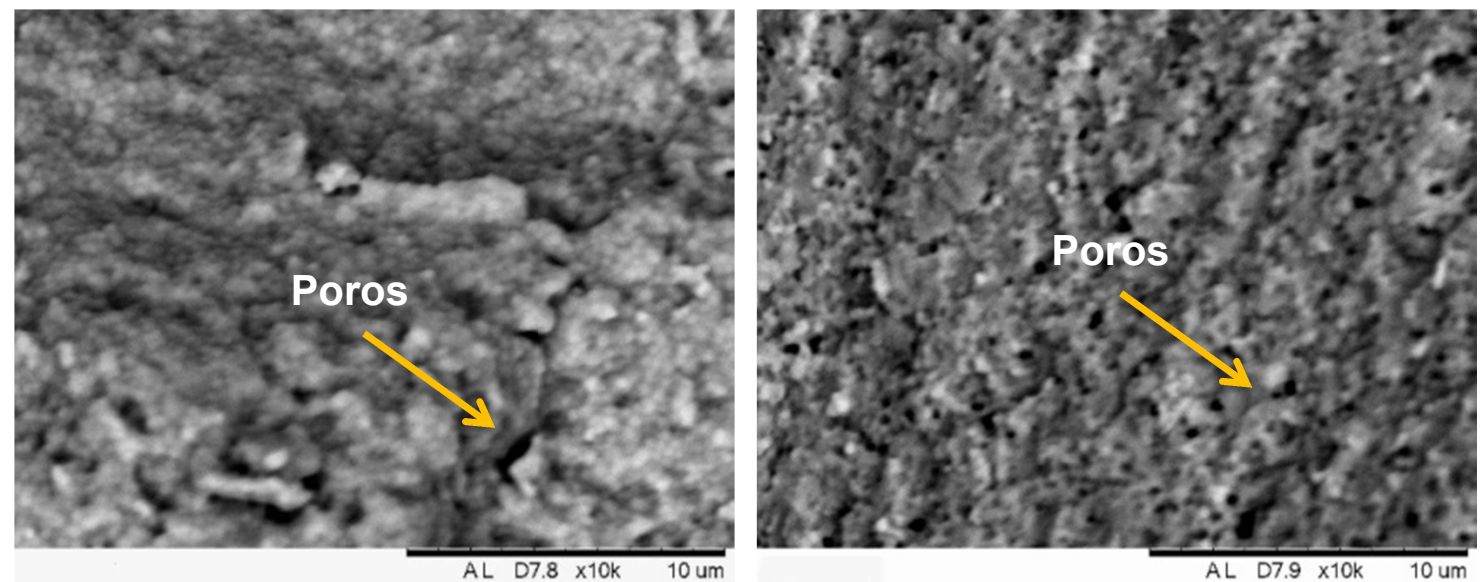

Figura 5-4 - Micrografias da superfície de fratura obtidas por MEV da cerâmica sinterizada a $1500^{\circ} \mathrm{C}$ por 1 hora.

\subsection{Caracterização do substrato para deposição eletroforética}

Na Figura 5-5 é apresentado o difratograma de raios $X$ das chapas de titânio utilizadas como substrato para deposição eletroforética. São observados picos referentes à fase alfa do titânio de acordo com a ficha do ICSD 89-2762. Concluindo-se então que o material utilizado é titânio comercialmente puro.

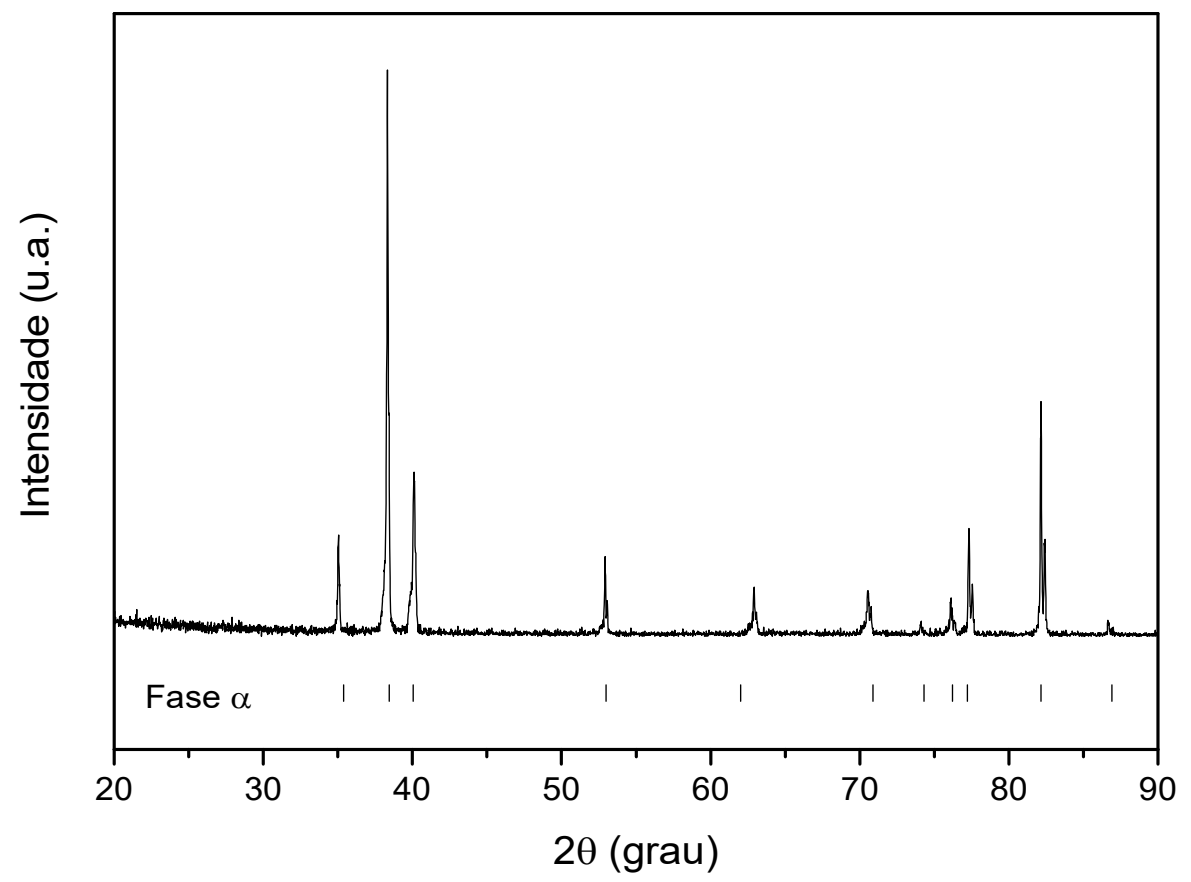

Figura 5-5 - Difratograma de raios X da chapa de titânio utilizada como substrato. 
$\mathrm{Na}$ Tabela 5-1 estão apresentados os valores médios de $R_{z}$, (rugosidade total), obtido pelo ensaio de rugosidade feitos nas amostras atacas com ácido sulfúrico $50 \%$ em volume e ácido nítrico $25 \%$ em volume para os definidos tempos com a finalidade de melhor adesão das partículas ao substrato. Determinou-se que o ataque químico mais adequado foi com o ácido sulfúrico e tempo de ataque de $10 \mathrm{~s}$, pois este já provocou rugosidade suficiente para que as partículas melhor se aderissem ao substrato o que pode garantir que em toda a extensão do filme depositado as partículas de pó (podem se acomodar nas irregularidades da superfície do metal), entrarão nas cavidades aumentando a área de contato e promovendo melhor aderência da camada depositada.

Tabela 5-1 - Valores de Rz e Ra para as amostras atacadas.

\begin{tabular}{ccccc}
\hline & $\mathbf{H}_{2} \mathbf{S O}_{4}(\mathbf{1 0 s})$ & $\mathbf{H}_{2} \mathbf{S O}_{4}(\mathbf{3 0 s})$ & $\mathbf{H N O}_{3}(\mathbf{1 0 s})$ & $\mathbf{H N O}_{3}(\mathbf{3 0 s})$ \\
\hline $\mathbf{R}_{\mathbf{z}}(\boldsymbol{\mu m})$ & 8,05 & 9,99 & 8,15 & 8,72 \\
$\mathbf{R}_{\mathbf{a}}(\boldsymbol{\mu m})$ & 1,53 & 1,81 & 1,43 & 1,55 \\
\hline
\end{tabular}

\subsection{Suspensões e condições para deposição eletroforética}

A melhor suspensão utilizada na deposição eletroforética assim como a melhor condição de tempo e diferença de potencial para o processo foi determinada principalmente com o auxílio da microscopia eletrônica de varredura e microscopia óptica do material depositado.

$\mathrm{Na}$ Tabela 5-2 estão apresentados os valores médios de corrente obtidos no processo de EPD para cada suspensão.

Tabela 5-2 - Valores médios de corrente inicial medidos na EPD para as suspensões utilizadas.

\begin{tabular}{ccccc}
\hline & $\begin{array}{c}\text { Suspensão } \\
\text { 75Ac }\end{array}$ & $\begin{array}{c}\text { Suspensão } \\
\text { 50Ac }\end{array}$ & $\begin{array}{c}\text { Suspensão } \\
\text { 25Aa }\end{array}$ & $\begin{array}{c}\text { Suspensão } \\
\text { 100Aa }\end{array}$ \\
\hline $\begin{array}{c}\text { Valores médios } \\
\text { de corrente } \\
\text { (mA) }\end{array}$ & 2,32 & 2,64 & $40 \mathrm{~V}-0,35$ & $40 \mathrm{~V}-0,062$ \\
& & $60 \mathrm{~V}-0,95$ & $60 \mathrm{~V}-0,31$ \\
\hline
\end{tabular}


Na Figura 5-6 (a), (b) e (c) estão apresentadas as micrografias obtidas por MEV das amostras SA830II ( $30 \mathrm{~s}, 30 \mathrm{~V}$ ), SA430II (45 s, $30 \mathrm{~V}$ ) e SA130l (60 s, $30 \mathrm{~V})$, respectivamente, produzidas na primeira série de deposição eletroforética com a suspensão $75 \mathrm{Ac}$ (75\%acetona:25\% etanol).

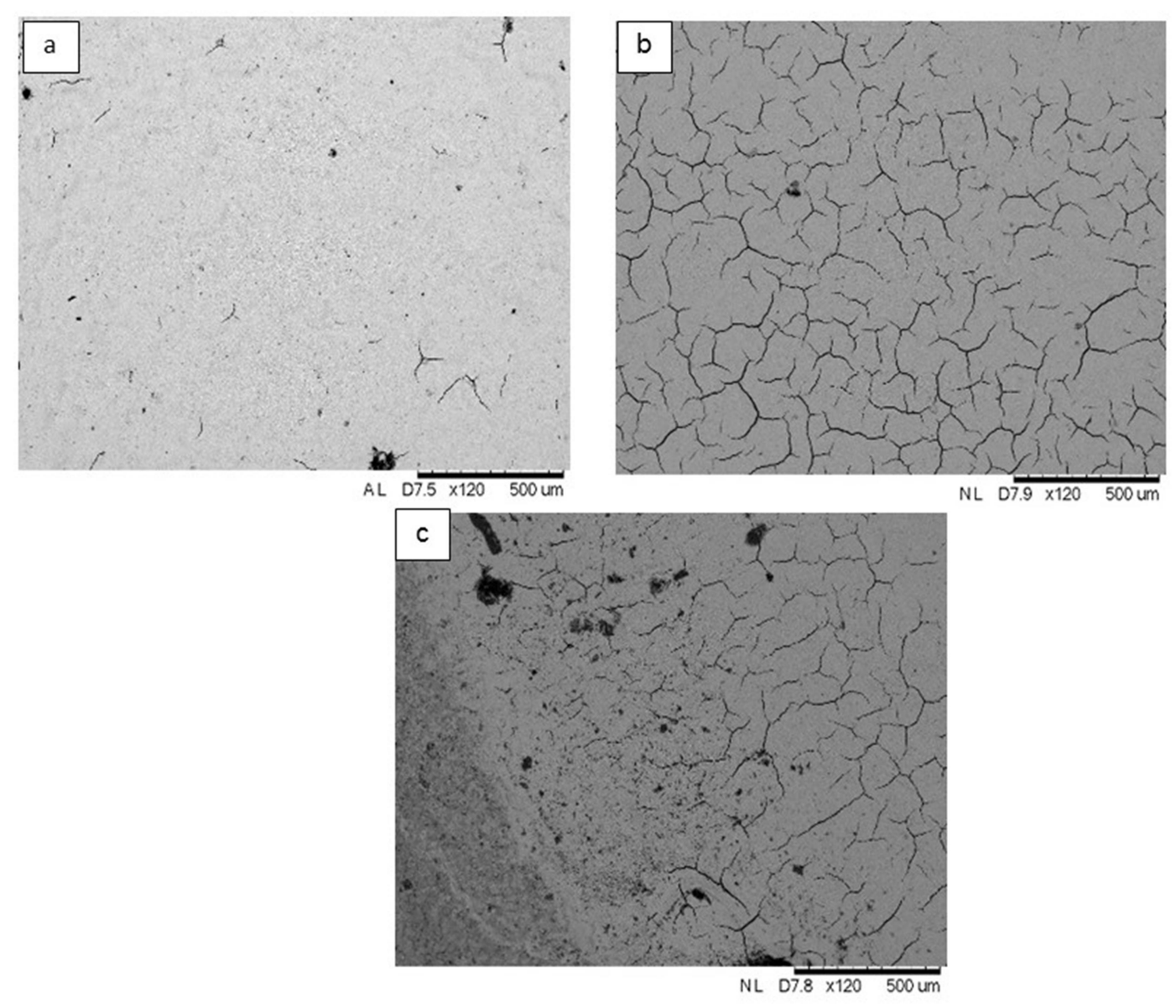

Figura 5-6 - Micrografias por MEV das amostras produzidas na primeira série de EDP utilizando a suspensão 75Ac. (a) SA830II (30 s, 30 V); (b) SA430II (45 s, 30 V) e (c) SA130l (60 s, $30 \mathrm{~V})$.

Na Figura 5-7 (a), (b) e (c) estão apresentadas as micrografias obtidas por MEV das amostras $1 \mathrm{~A}(30 \mathrm{~s}, 20 \mathrm{~V}), 4 \mathrm{~A}(45 \mathrm{~s}, 20 \mathrm{~V})$ e $7 \mathrm{~A}(60 \mathrm{~s}, 20 \mathrm{~V})$ respectivamente, produzidas na primeira série de deposição eletroforética com a suspensão $50 \mathrm{Ac}$ ( $50 \%$ acetona:50\%etanol).

Na Tabela 5-3 é apresentada a espessura aproximada do recobrimento obtidos com as suspensões 75Ac e 50Ac calculada com o auxílio da Equação 4-2 considerando que a densidade do recobrimento é aproximadamente $40 \%$ da densidade teórica da cerâmica. 

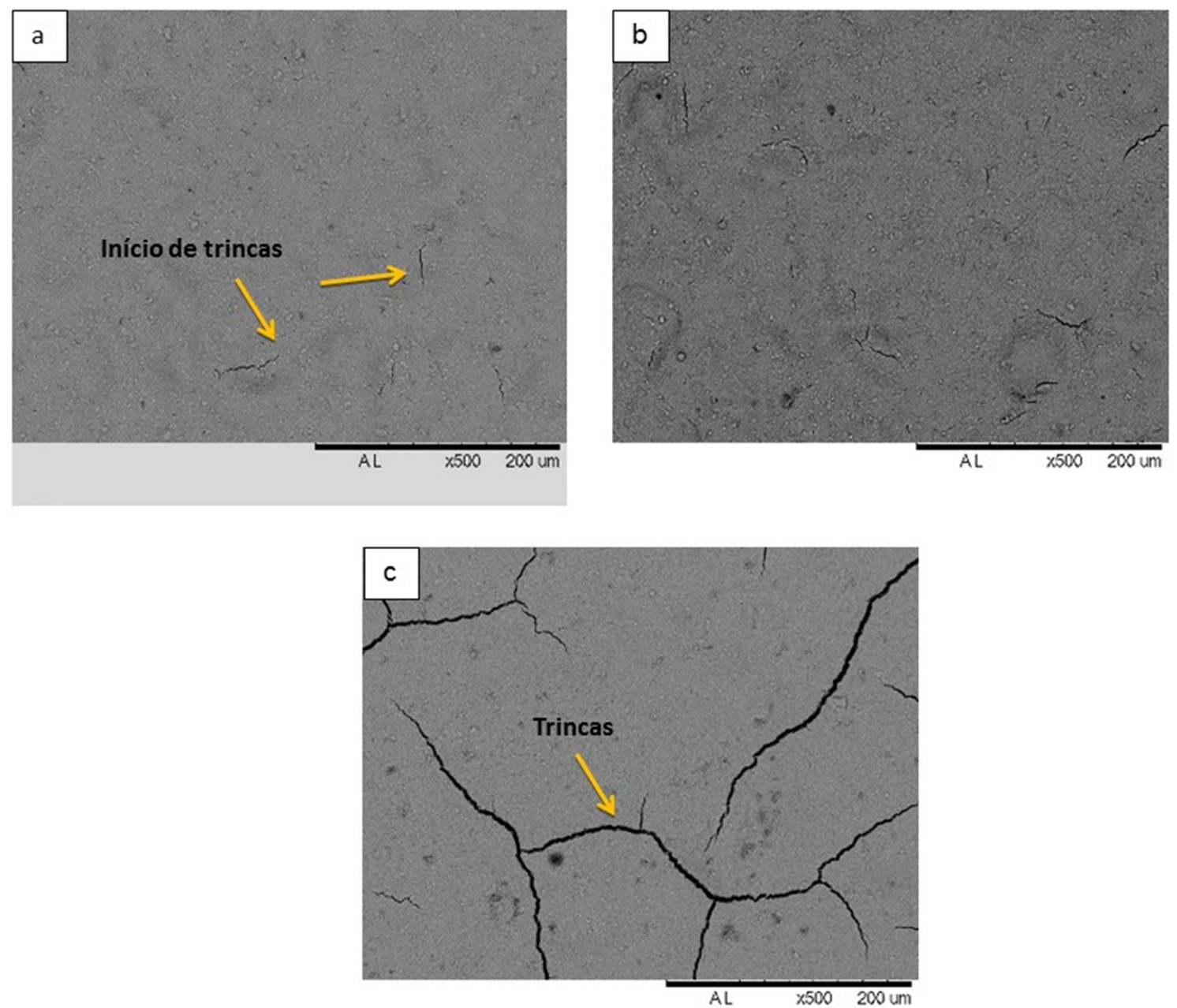

Figura 5-7 - Micrografias por MEV das amostras produzidas na primeira série de EPD utilizando a suspensão 50Ac. (a) $1 \mathrm{~A}$ (30 s, $20 \mathrm{~V}$ ); (b) 4A (45 s, $20 \mathrm{~V}$ ) (c) 7A (60 s, $20 \mathrm{~V})$.

Tabela 5-3 - Espessura aproximada dos filmes obtidos por EPD utilizando as suspensões 75Ac e 50Ac.

\begin{tabular}{cc|cc}
\hline \multicolumn{2}{c|}{ Suspensão 75Ac } & \multicolumn{2}{c}{ Suspensão 50Ac } \\
\hline Amostra & $\begin{array}{c}\text { Espessura } \\
(\mu \mathrm{m})\end{array}$ & Amostra & Espessura $(\boldsymbol{\mu m})$ \\
\hline SA830I $(30 \mathrm{~s}, 30 \mathrm{~V})$ & 12,29 & 1A $(30 \mathrm{~s}, 20 \mathrm{~V})$ & 10,98 \\
SA830II (30 s, 30 V) & 11,77 & 4A $(45 \mathrm{~s}, 20 \mathrm{~V})$ & 14,91 \\
SA430II $(45 \mathrm{~s}, 30 \mathrm{~V})$ & 14,65 & 7A $(60 \mathrm{~s}, 20 \mathrm{~V})$ & 17,79 \\
SA430III $(45 \mathrm{~s}, 30 \mathrm{~V})$ & 15,17 & & \\
SA130I $(60 \mathrm{~s}, 30 \mathrm{~V})$ & 17,53 & & \\
\hline
\end{tabular}


Analisando os recobrimentos obtidos a partir da suspensão 75Ac podese observar que são bastante heterogêneos, e que há formação de pequenas trincas para tempo menor de deposição sendo que estas trincas vão tornando-se cada vez mais acentuadas com o aumento do tempo de deposição.

O mesmo comportamento citado acima é observado para as amostras produzidas com a suspensão 50Ac.

Comparando os recobrimento feitos com as suspensão $75 \mathrm{Ac}$ e $50 \mathrm{Ac}$ a $30 \mathrm{~V}$ e $20 \mathrm{~V}$ por 30 segundos (Figura 5-6 (a) e Figura 5-7 (b) respectivamente) observa-se que ambos são heterogêneos, sendo esta é mais evidente para a amostra cujo recobrimento foi realizado a $30 \mathrm{~V}$. Observa-se também início de trincas para os recobrimentos obtidos em ambas condições.

Por meio da comparação feita entre o recobrimento realizado a $30 \mathrm{~V}$ e $20 \mathrm{~V}$ por 45 segundos (Figura 5-6 (b) e Figura 5-7 (c) respectivamente) observase também heterogeneidades em sua formação e presença de trincas mais acentuadas para $30 \mathrm{~V}$ e início de trincas para $20 \mathrm{~V}$.

A comparação feita entre os recobrimentos realizados a $30 \mathrm{~V}$ e $20 \mathrm{~V}$ por 60 segundos (Figura 5-6 (c) e Figura 5-7 (c) respectivamente) possibilita observar que ambos os recobrimentos são bastante heterogêneos, com rugosidades em sua formação, e trincas bastante acentuadas no recobrimento feito para as duas diferenças de potencial.

Assim uma comparação mais genérica feita entre os recobrimentos obtidos utilizando as suspensões 75Ac e 50Ac pode-se dizer que forma obtidos recobrimentos grosseiros e não homogêneos, além do início de trincas, para tempos menores de deposição, e uma grande tendência na formação de trincas mais acentuadas para os depósitos realizados em tempos maiores.

Na Figura 5-8 (a), (b), (c) e (d) estão apresentadas as micrografias obtidas pelo microscópio óptico das amostras $6 \mathrm{E}(20 \mathrm{~s}, 40 \mathrm{~V}), 6 \mathrm{D}(20 \mathrm{~s}, 60 \mathrm{~V}), 5 \mathrm{D}$ (40 s,60 V) e 4D (60 s,60 V) respectivamente, produzidas na segunda série de deposição eletroforética com a suspensão 25Aa (25\%acetilacetona: $75 \%$ etanol). 

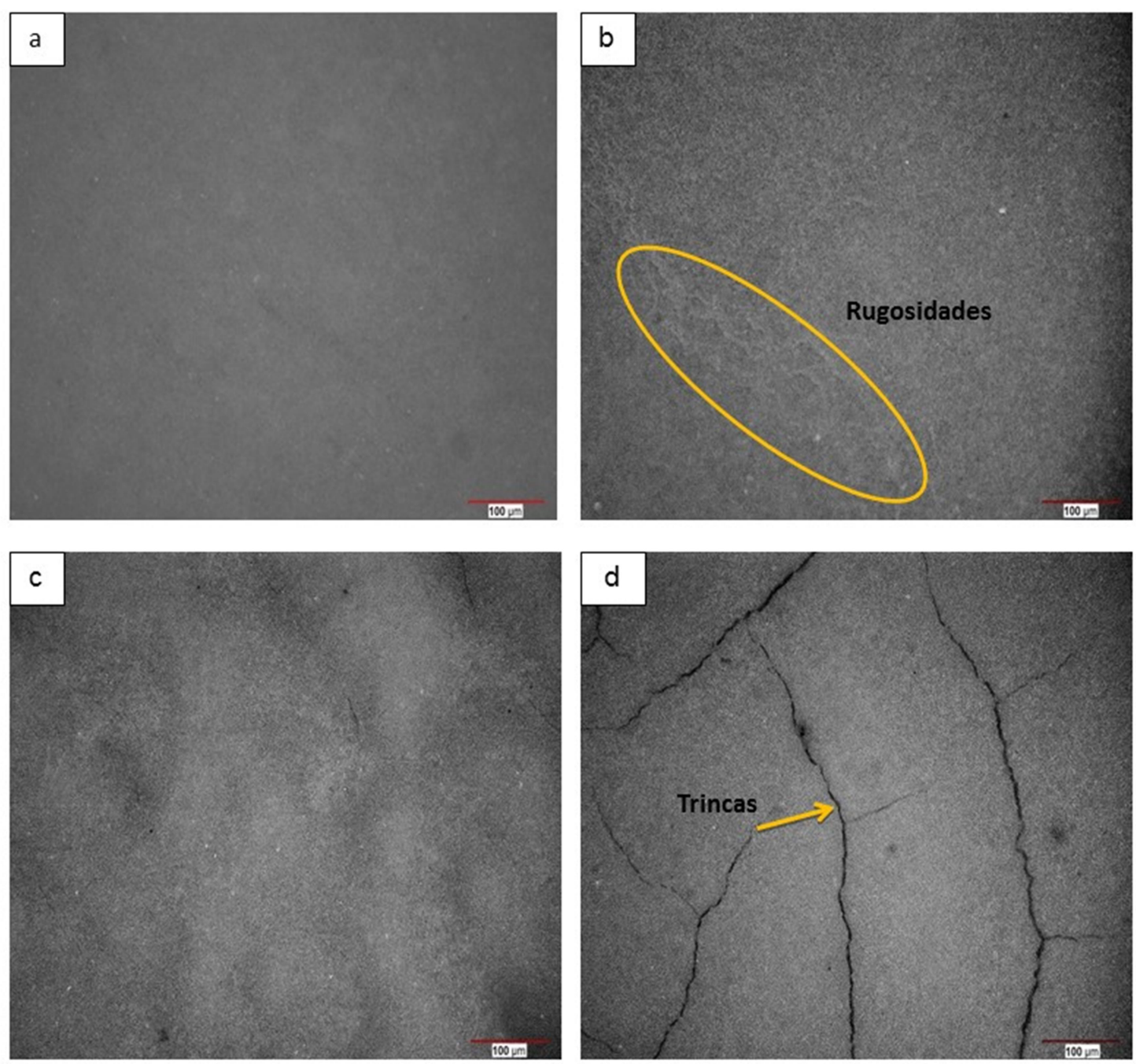

Figura 5-8 - Micrografias ópticas das amostras produzidas na segunda série de EPD utilizando a suspensão 25Aa. (a) $6 \mathrm{E}$ (20 s, $40 \mathrm{~V})$; (b) 6D (20 s, $60 \mathrm{~V})$; (c) 5D (40 s, $60 \mathrm{~V})$ e (d) 4D (60 s,60 V).

Na Figura 5-9 (a), (b), (c), (d) e (e) estão apresentadas as micrografias obtidas pelo microscópio óptico das amostras $1 \mathrm{E}(20 \mathrm{~s}, 40 \mathrm{~V}), 2 \mathrm{E}(40 \mathrm{~s}, 40 \mathrm{~V}), 3 \mathrm{D}$ $(20 \mathrm{~s}, 60 \mathrm{~V}), 1 \mathrm{D}(40 \mathrm{~s}, 60 \mathrm{~V}), 2 \mathrm{D}(60 \mathrm{~s}, 60 \mathrm{~V})$ respectivamente, produzidas na segunda série de deposição eletroforética coma suspensão 100Aa (acetilacetona pura). 

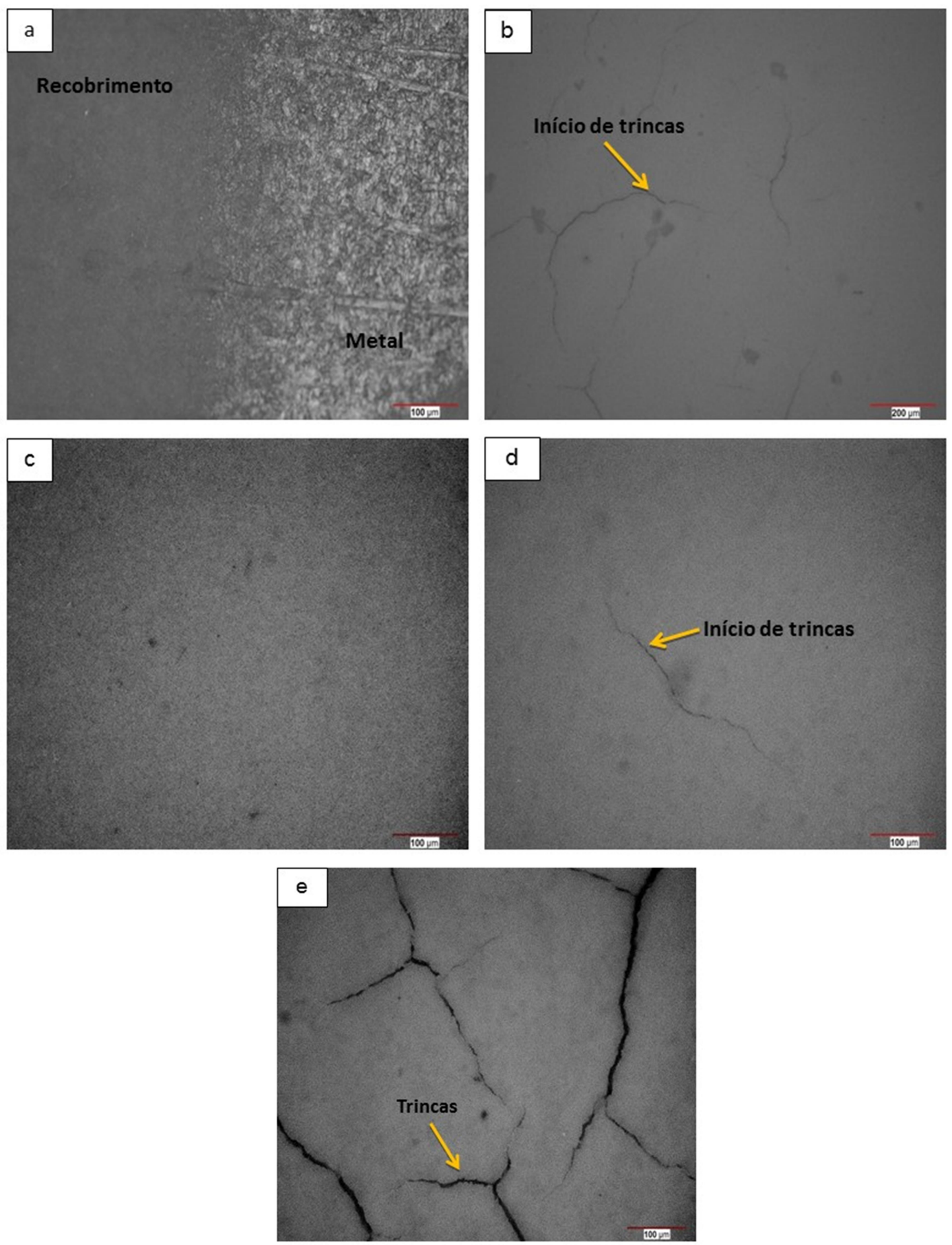

Figura 5-9 - Micrografias ópticas das amostras produzidas na segunda série de EPD com a suspensão 100Aa. (a) $1 \mathrm{E}(20 \mathrm{~s}, 40 \mathrm{~V})$; (b) $2 \mathrm{E}(40 \mathrm{~s}, 40 \mathrm{~V})$; (c) 3D (20 s, $60 \mathrm{~V}),(\mathrm{d}) 1 \mathrm{D}(40 \mathrm{~s}, 60 \mathrm{~V}) ;(\mathrm{e}) 2 \mathrm{D}(60 \mathrm{~s}, 60 \mathrm{~V})$

Na Tabela 5-4 é apresentada a espessura aproximada do recobrimento obtido com as suspensões 25Aa e 100Aa calculada com o auxílio da Equação 4-2 
considerando que a densidade do recobrimento a verde é de aproximadamente $40 \%$ da densidade teórica da cerâmica.

Tabela 5-4 - Espessura aproximada dos filmes obtidos por EPD utilizando as suspensões 25Aa e 100Aa.

\begin{tabular}{cc|cc}
\hline \multicolumn{2}{c|}{ Suspensão 25Aa } & \multicolumn{2}{c}{ Suspensão 100Aa } \\
\hline Amostra & $\begin{array}{c}\text { Espessura } \\
(\mu \mathrm{m})\end{array}$ & Amostra & Espessura $(\boldsymbol{\mu m})$ \\
\hline 6E $(20 \mathrm{~s}, 40 \mathrm{~V})$ & 7,16 & 1E $(20 \mathrm{~s}, 40 \mathrm{~V})$ & 12,88 \\
6D $(20 \mathrm{~s}, 60 \mathrm{~V})$ & 8,12 & 2E $(40 \mathrm{~s}, 40 \mathrm{v})$ & 33,65 \\
5D $(40 \mathrm{~s}, 60 \mathrm{~V})$ & 18,83 & 3D $(20 \mathrm{~s}, 60 \mathrm{~V})$ & 10,98 \\
4D $(60 \mathrm{~s}, 60 \mathrm{~V})$ & 38,72 & 1D $(40 \mathrm{~s}, 60 \mathrm{~V})$ & 25,64 \\
& & 2D $(60 \mathrm{~s}, 60 \mathrm{~V})$ & 43,43 \\
\hline
\end{tabular}

Comparando os recobrimentos realizados com a suspensão 25Aa por 20 segundos a $40 \mathrm{~V}$ e $60 \mathrm{~V}$ (Figura 5-8 a e b respectivamente) observa-se que ambos são livres de trincas, porém para $60 \mathrm{~V}$ notam-se rugosidades em sua formação, ao passo que para o recobrimento realizado a $20 \mathrm{~V}$ estas rugosidades não são perceptíveis. Comparando, os recobrimentos realizados a $60 \mathrm{~V}$ a 20, 40, e 60 segundos (Figura 5-8 b, c e d respectivamente), observa-se que são heterogêneos, e há formação de trincas bastante acentuadas para $60 \mathrm{~s}$ de deposição.

Analisando as micrografias dos recobrimentos feitos com a suspensão 100Aa, observa-se no geral são homogêneos, sem a presença de rugosidades. Comparando os recobrimentos realizados a $40 \mathrm{~V}$ com tempos de deposição de 20 e 40 segundos (Figura 5-9 a e b) observa-se que para $40 \mathrm{~s}$, maior tempo de deposição para $40 \mathrm{~V}$, há o início de trincas, ao passo que para $20 \mathrm{~s}$, que foi o menor tempo de deposição para $40 \mathrm{~V}$, o recobrimento mostrou-se livre de trincas. A comparação feita entre os recobrimentos realizados a $60 \mathrm{~V}$ com tempos de deposição de 20, 40 e 60 segundos (Figura 5-9 c, d e e, respectivamente) revela que a medida que se aumenta o tempo de deposição há uma maior tendência no aparecimento de trincas. 
Em uma avaliação mais genérica dos recobrimentos obtidos pode-se dizer que a suspensão 25Aa proporcionou recobrimentos livres de trincas para tempos menores, mas com aspecto menos homogêneo, com formações rugosas, ao passo que a suspensão 100Aa foi capaz de produzir recobrimentos mais homogêneos, sem a presença de formações rugosas e livres de trincas para tempos menores.

Para ser avaliada a qualidade de um recobrimento obtido por EPD, segundo Besra e Liu [56], devem ser levados em consideração os parâmetros relacionados à suspensão e os relacionados ao processo. Quanto aos parâmetros relacionados à suspensão tem-se, tamanho de partícula, constante dielétrica do líquido, condutividade da suspensão, viscosidade, potencial zeta, além da estabilidade da suspensão, e quanto aos parâmetros relacionados ao processo, tem-se tempo de deposição, diferença de potencial aplicada, concentração de partículas e condutividade do substrato.

Em primeiro momento analisando a qualidade do recobrimento relacionada à suspensão, segundo Power [57] quanto maior a constante dielétrica do solvente maior sua condutividade. Este comportamento dá-se, pois, as moléculas de líquidos com maior constante dielétrica polarizam-se mais facilmente, possibilitando maior solvatação das partículas carregadas quando misturadas ao solvente. Quando se tem condutividade muito alta, de acordo com Ferrari e Moreno [37], a mobilidade eletroforética tende a ser mais baixa, uma vez que os íons livres, sendo menores, tendem a se movimentar mais rapidamente que as partículas que foram solvatadas. Quando a condutividade é muito baixa a partícula se carrega eletronicamente e a estabilidade é perdida. Outro fator que deve ser levado em consideração é a viscosidade da suspensão Segundo Aruna [36], solventes com menor viscosidade tendem a ser mais promissores no processo de deposição.

Assim, levando em consideração os valores de corrente inicial obtidos para no processo de EPD, e relacionando-os ao comportamento exposto acima, é possível explicar porque a acetilacetona mostrou-se mais eficiente para a deposição de 3YTZP. Dentre os valores de corrente medidos os maiores foram para a suspensões 75Ac e 50Ac (etanol e acetona) os menores para as suspensões 25Aa e 100Aa (etanol e acetilacetona) (Tabela 5-2). Levando em consideração que constante dielétrica, condutividade e corrente são diretamente 
proporcionais, e tendo em vista que a constante dielétrica da acetilacetona é maior que a dos solventes acetona e etanol [56], esperava-se um comportamento contrário ao observado, isto é, que a corrente fosse maior para as suspensões contendo acetilacetona. Uma possível explicação para isso foi a adição de iodo (polieletrólito) nas suspensões 75Ac e 50Ac, que elevou a quantidade de íons livres, elevando a condutividade e, consequentemente, a corrente. Desta maneira, com corrente elevada e condutividade alta devido à adição de íons, a mobilidade eletroforética foi prejudicada, produzindo filmes não homogêneos. Com as suspensões de acetilacetona, a corrente foi mais baixa, não a ponto de provocar a perda de estabilidade da suspensão e, embora a viscosidade da acetilacetona seja maior que a dos demais solventes utilizados, foi possível observar alta estabilidade da suspensão, sem formações de aglomerados [56]. Outro fator, não pouco mencionado na literatura, que foi levado em consideração é a volatilidade do solvente. Constatou-se que solventes menos voláteis são consideravelmente mais favoráveis ao processo de secagem do material depositado, ao evitar a formação de trincas, devido à evaporação mais lenta. Logo, pode-se dizer que entre as suspensões utilizadas, as de acetilacetona (25Aa e 100Aa) mostraram-se mais eficientes no processo de EPD.

Fazendo-se a análise da qualidade do recobrimento quanto aos parâmetros relacionados ao processo, um comportamento unanime é observado nas micrografias da Figura 5-6, Figura 5-7, Figura 5-8 e Figura 5-9: para uma mesma diferença de potencial, com o aumento do tempo há uma maior tendência em gerar trincas, isso se dá pelo aumento da espessura do recobrimento. Para mesmo tempo, com o aumento da diferença de potencial nota-se perda da homogeneidade do recobrimento. De acordo com Basu et al [58] ao aplicar-se uma diferença de potencial elevada provoca-se uma certa turbulência na suspensão prejudicando a qualidade do filme depositado, pois as partículas podem se mover tão rapidamente a ponto de não conseguirem depositar-se em uma posição de maior empacotamento.

Analisando todo o conjunto de fatores relacionados à EPD, embora nos experimentos feitos com as suspensões 75Ac e 50Ac tenham sido utilizadas diferenças de potenciais menores, o uso de etanol e acetona não foi favorável ao processo, ao passo que para as suspensões 25Aa e 100Aa em que foram utilizadas diferenças de potenciais ligeiramente maiores, a acetilacetona mostrou- 
se favorável à deposição. Assim, considera-se neste trabalho que os melhores parâmetros para a EPD foi utilizando a suspensão 4, diferença de potencial de 40 V e tempo de deposição de $20 \mathrm{~s}$.

Na Figura 5-10 (a), (b) e c) e na Figura 5-11 (a), (b) e (c) estão apresentadas as micrografias obtidas por MEV das amostras da série $F(2 F, 4 F$ e $6 F$ ) e série $G(6 G, 8 G$ e $9 G$ ) respectivamente, produzidas com a suspensão 100Aa (acetilacetona pura) a 40V com tempo de deposição de 20 s, ou seja a melhor condição e suspensão que foi determinada dos testes de deposição feito e na Tabela 5-5 a espessura do recobrimento. Observa-se que os recobrimentos obtidos também foram livres de trincas e homogêneos, confirmando a reprodutibilidade da deposição eletroforética para esta condição.
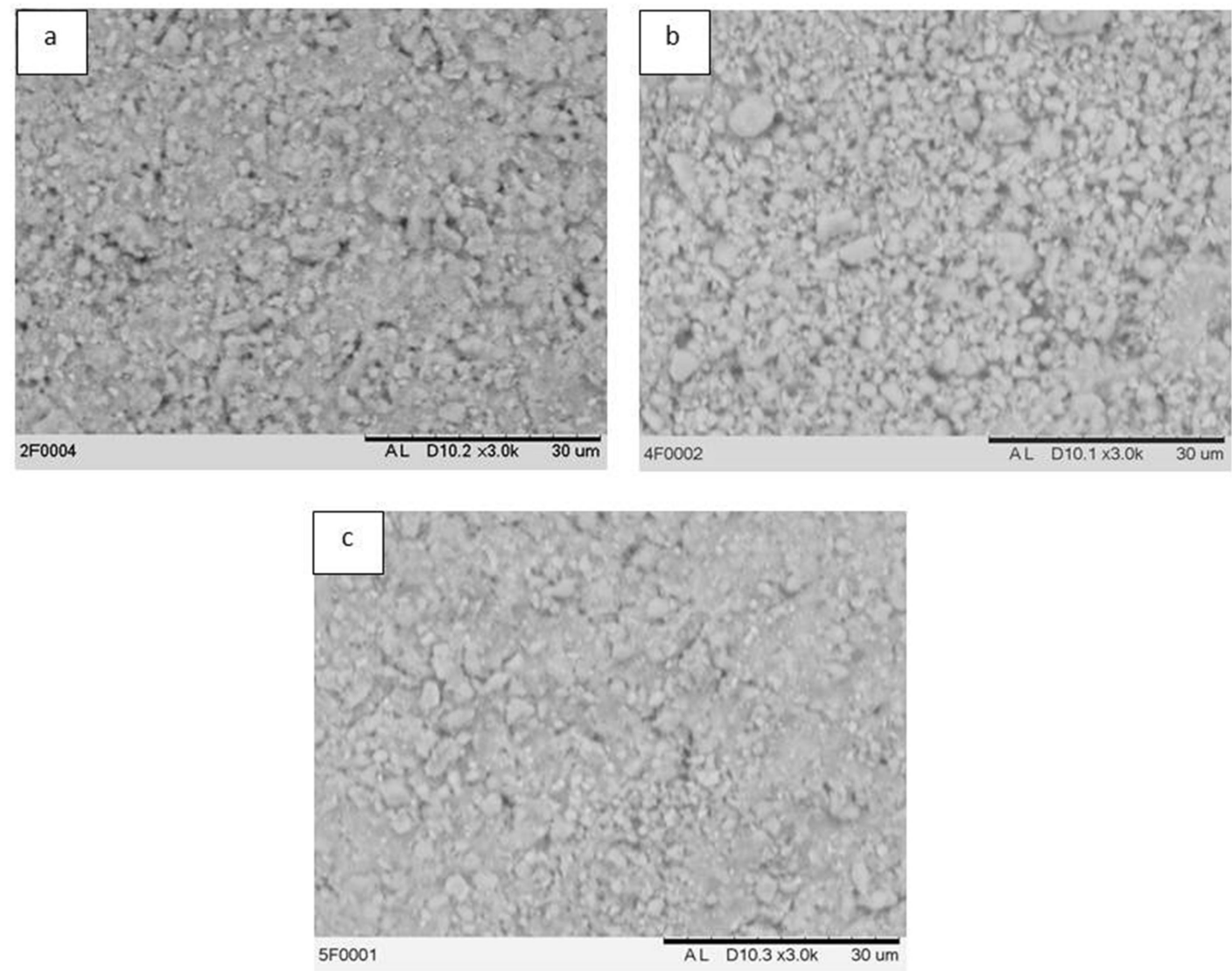

Figura 5-10 - Micrografias obtidas por MEV das amostras produzidas na série $\mathrm{F}$ de deposição usando a suspensão 100Aa (Acetilacetona pura) a $40 \mathrm{~V}$ por $20 \mathrm{~s}$ 

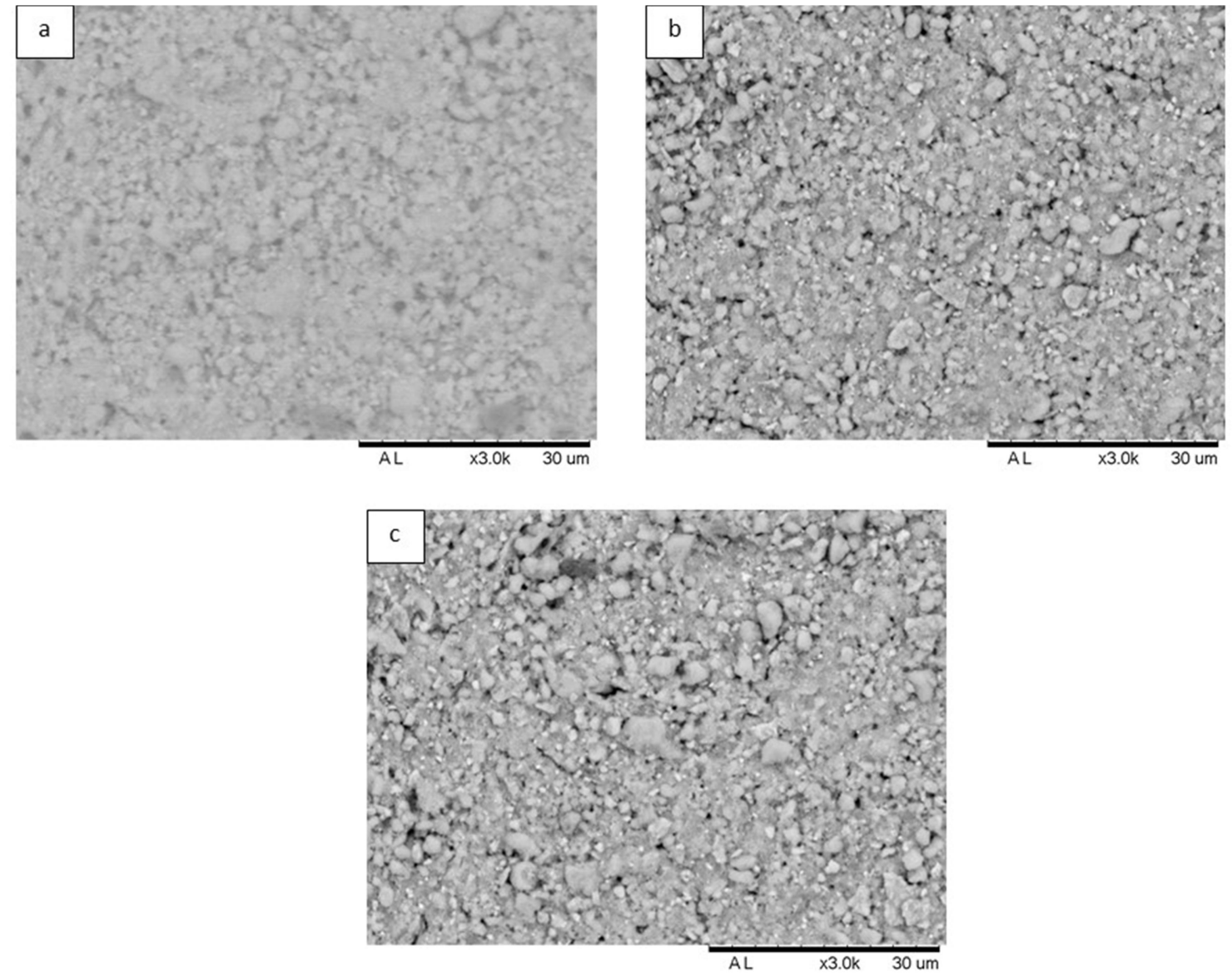

Figura 5-11 - Micrografias das amostras produzidas na série $G$ de deposição com a suspensão 100Aa (Acetilacetona pura) a $40 \mathrm{~V}$ por $20 \mathrm{~s}$.

Tabela 5-5 - Espessura calculada das amostras produzidas na série F e G de deposição.

\begin{tabular}{c|c|c|c|c|c|c}
\hline Amostras & $\mathbf{2 F}$ & $\mathbf{4 F}$ & $\mathbf{5 F}$ & $\mathbf{6 G}$ & $\mathbf{8 G}$ & $\mathbf{9 G}$ \\
\hline $\begin{array}{c}\text { Espessura } \\
(\boldsymbol{\mu m})\end{array}$ & 7,51 & 8,23 & 8,59 & 13,60 & 12,88 & 11,45 \\
\hline
\end{tabular}

\subsection{Irradiação com laser Nd:YAG}

Na Figura 5-12 está apresentada a relação entre a distância focal Z, a área do feixe de laser e a fluência calculados com o auxílio da Equação 3-6 e Equação 3-7 para o Teste 1 de irradiação. Observa-se que à medida que a 
distância focal aumenta há um aumento da área iluminada pelo feixe, provocando uma diminuição na fluência. Tal comportamento de diminuição da fluência é devido à energia constante fornecida ao feixe de laser ser distribuída em maior área.

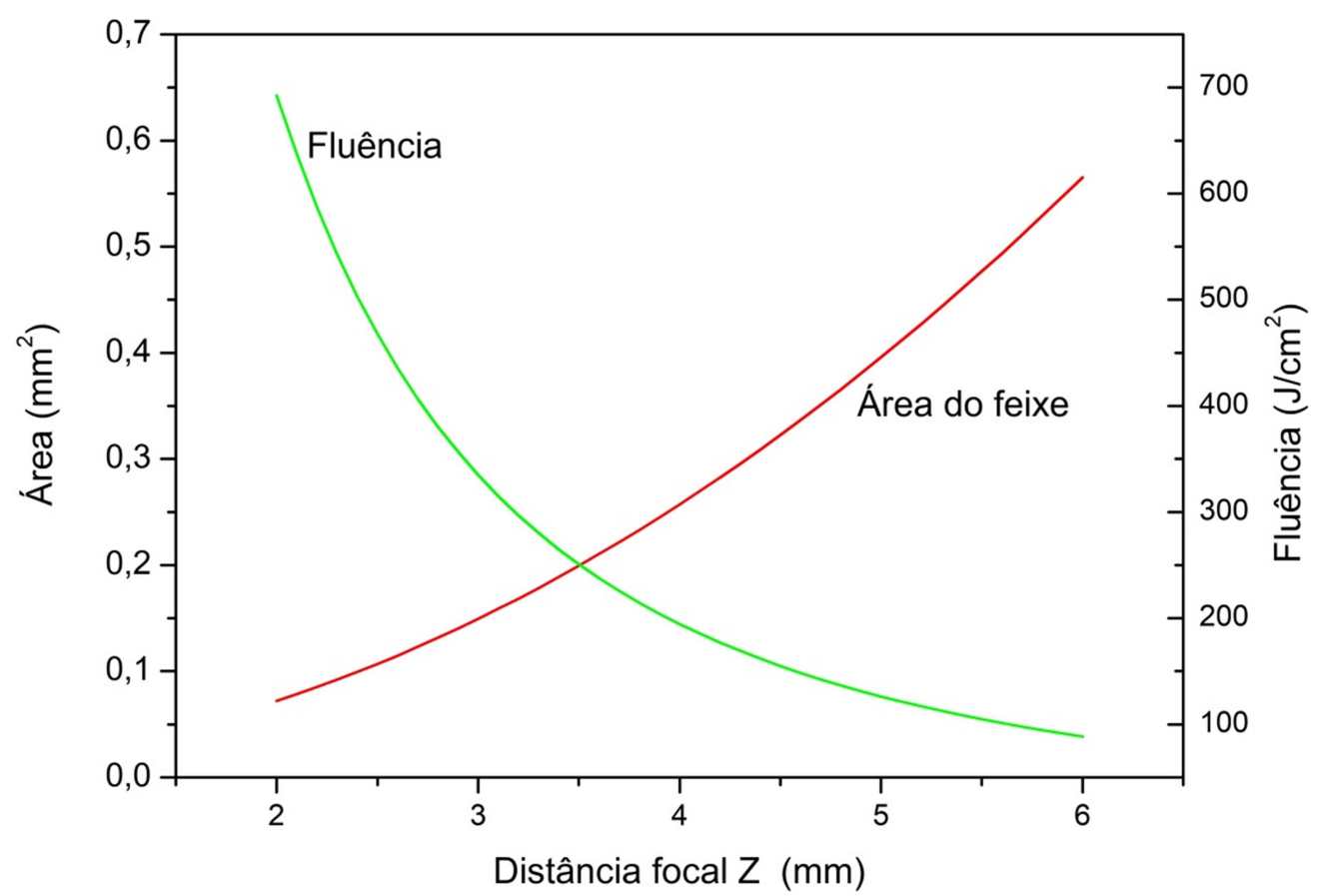

Figura 5-12 - Distância focal Z relacionada à área do feixe de laser e a fluência.

Na Figura 5-13 estão apresentadas as microscopias ópticas do Teste 1 de irradiação da amostras SA830II evidenciando as linhas de irradiação em que ao longo da linha a distância focal $Z$ varia de $2 \mathrm{~mm}$ a $5 \mathrm{~mm}$ o que corresponde à fluência variando $690 \mathrm{~J} / \mathrm{cm}^{2}$ a $120 \mathrm{~J} / \mathrm{cm}^{2}$ e na Figura 5-14 estão apresentadas as microscopias ópticas do Teste 1 de irradiação da amostra SA830I evidenciando as linhas de irradiação em que ao longo da linha a distância focal $Z$ varia de $3 \mathrm{~mm}$ a $6 \mathrm{~mm}$ o que corresponde à fluência variando de $330 \mathrm{~J} / \mathrm{cm}^{2}$ a $88 \mathrm{~J} / \mathrm{cm}^{2}$. 

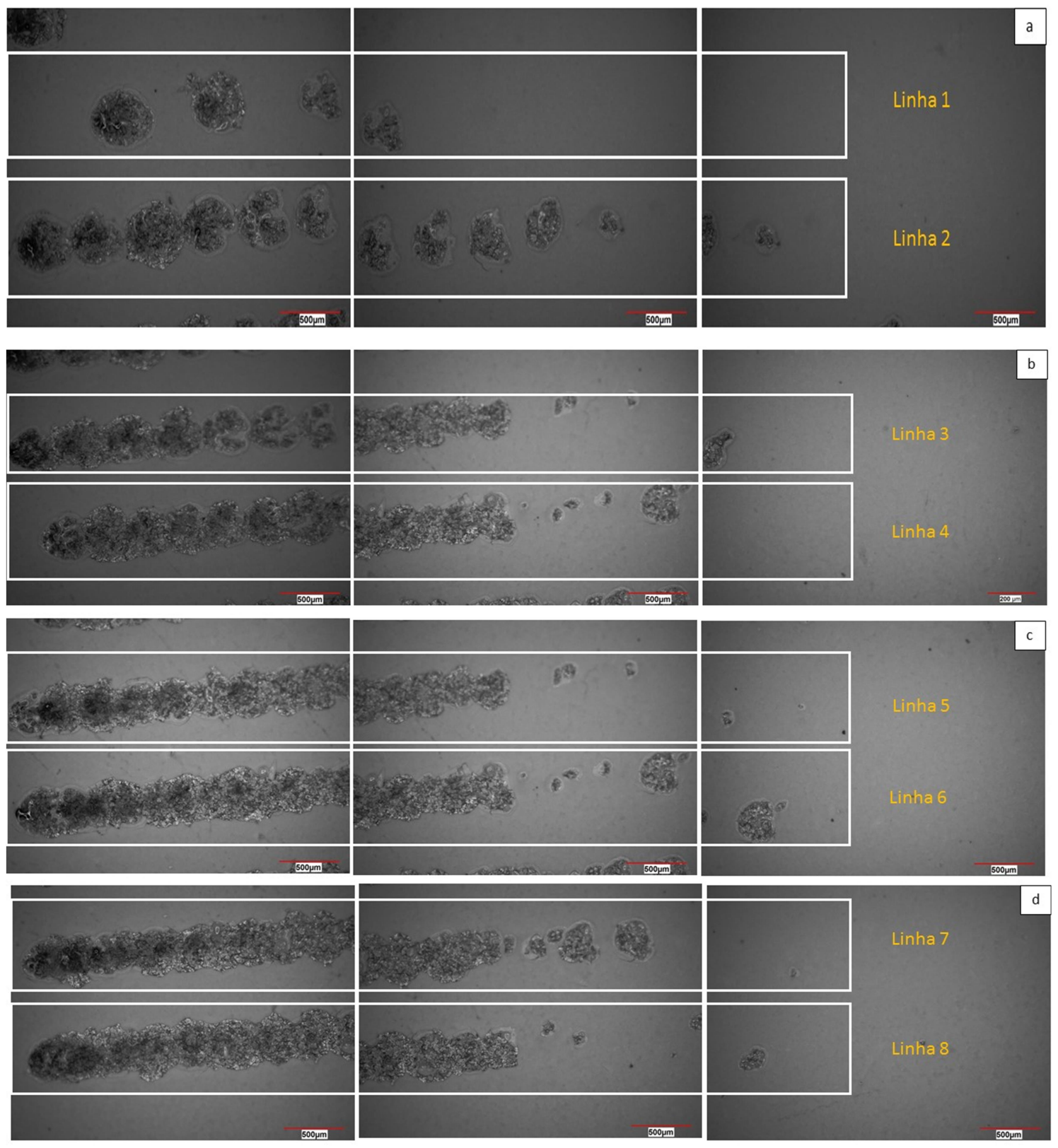

Figura 5-13 - Micrografias ópticas da amostra SA830ll irradiada com laser pulsado Nd:YAG a) primeira e segunda linha de irradiação com velocidade de $450 \mathrm{~mm} / \mathrm{min}$ e $350 \mathrm{~mm} / \mathrm{min}$ e Número de incidência $=1$; b) terceira e quarta linha de irradiação com velocidade de $300 \mathrm{~mm} / \mathrm{min}$ e $250 \mathrm{~mm} / \mathrm{min}$ e Número de incidência $=1$; c) quinta e sexta linha de irradiação com velocidade de 450 $\mathrm{mm} / \mathrm{min}$ e $350 \mathrm{~mm} / \mathrm{min}$ e Número de incidência = 3; d) sétima e oitava linhas de irradiação com velocidade de $300 \mathrm{~mm} / \mathrm{min}$ e $250 \mathrm{~mm} / \mathrm{min}$ e Número de incidência $=3$. 


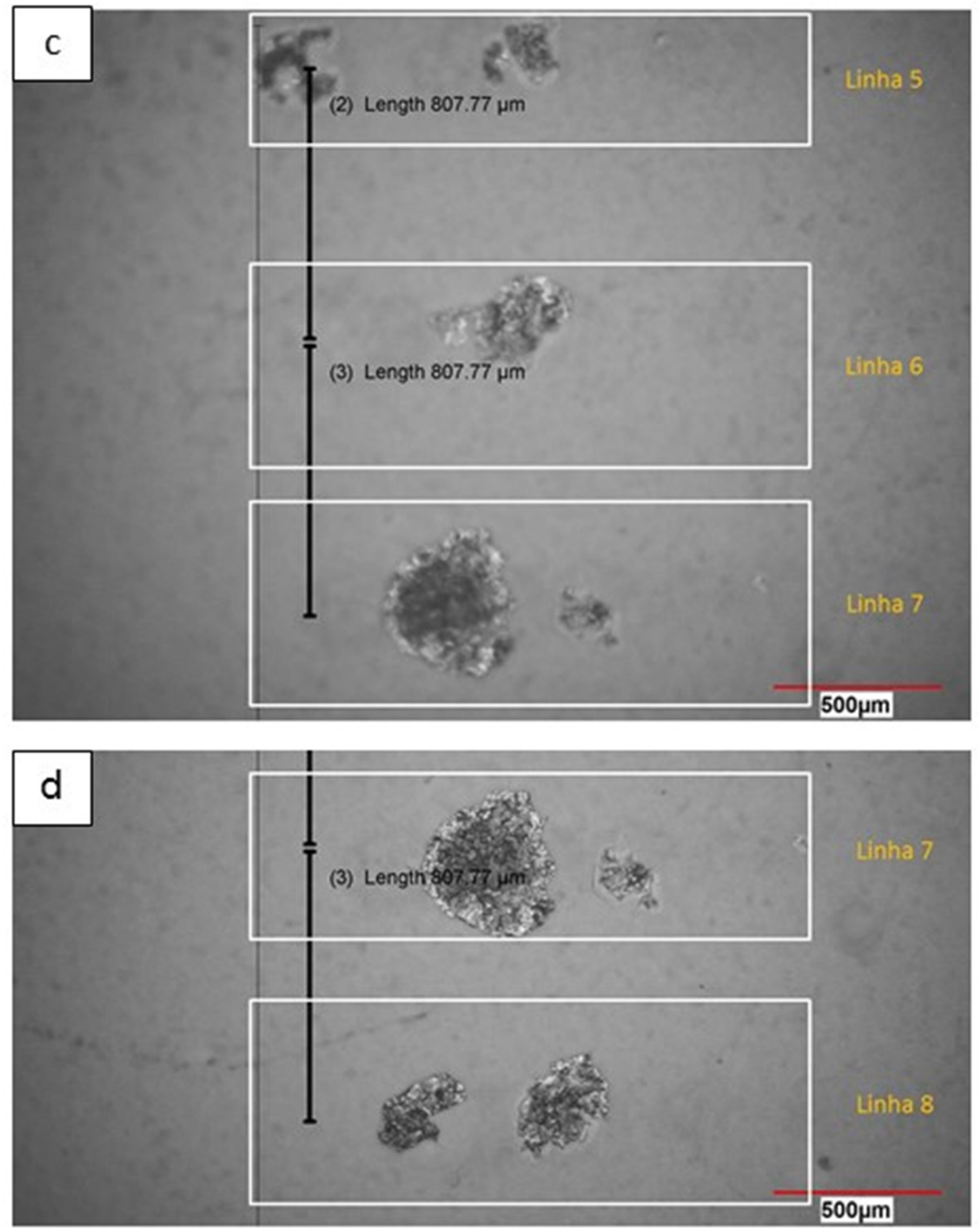

Figura 5-14 - Micrografia da amostra irradiada SA830I a) primeira e segunda linha de irradiação com velocidade de $450 \mathrm{~mm} / \mathrm{min}$ e $350 \mathrm{~mm} / \mathrm{min}$ e Número de incidência $=1$; b) terceira e quarta linha de irradiação com velocidade de 300 $\mathrm{mm} / \mathrm{min}$ e $250 \mathrm{~mm} / \mathrm{min}$ e Número de incidência = 1; c) quinta e sexta linha de irradiação com velocidade de $450 \mathrm{~mm} / \mathrm{min}$ e $350 \mathrm{~mm} / \mathrm{min}$ e Número de incidência = 3; d) sétima e oitava linhas de irradiação com velocidade de $300 \mathrm{~mm} / \mathrm{min}$ e 250 $\mathrm{mm} / \mathrm{min}$ e Número de incidência $=3$. 
Analisando as micrografias da amostra SA830ll (Figura 5-13), é possível observar que a variação da distância focal $Z$ ao longo da linha (2 a $5 \mathrm{~mm}$, que corresponde à fluência de $690 \mathrm{~J} / \mathrm{cm}^{2}$ a $120 \mathrm{~J} / \mathrm{cm}^{2}$ ) provoca danos bastante acentuados, resultado na remoção do material depositado em todas as linhas de irradiação, dano que se torna mais acentuado à medida que se diminui a velocidade de varredura do laser, visto que os pulsos tomam-se cada vez mais próximos assim como mostrado por Savalani et al [59]. Um fator que acentua ainda mais o dano provocando a remoção do material é o aumento do número de incidência do laser para 3.

Para a amostra SA830I (Figura 5-14) é possível observar, de modo geral, que o dano provocado pela variação da distância focal Z (3 a $6 \mathrm{~mm}$, que corresponde a fluência de $330 \mathrm{~J} / \mathrm{cm}^{2}$ a $88 \mathrm{~J} / \mathrm{cm}^{2}$ ) é mais tênue, porém é observado no início da linha de irradiação, onde a fluência é maior. Para as linhas de 1 a 4 (Figura 5-14 (a) e (b)) em que se aumentou a velocidade $\left(V_{1}>V_{2}>V_{3}>\right.$ $\mathrm{V}_{4}$ ) e número de incidência do laser foi igual a 1 observa-se que a diminuição da velocidade não provocou nenhuma mudança evidente na proximidade dos pulsos, e não houve a remoção de material, apenas algumas modificações que deixa evidente onde incidiu o pulso do laser, exceto para a linha 4 em um pequeno dano que pode ter sido provocado por uma imperfeição no filme depositado, pois pela lógica, como no ponto anterior não ocorreu dano, no seguinte não ocorreria, uma vez que a abertura do foco foi ampliada. Um fator que provocou uma modificação bastante evidente foi o aumento do número de incidência do laser para 3 (Figura 5-14 (c) e (d)) nas linhas de irradiação de 5 a 8, pois mesmo para menor fluência foi provocado dano, acarretando na retirada do material, o que não foi observado para número de incidência igual a 1.

Tendo então a necessidade de escolher uma região modificada, porém sem danos, para que pudesse reproduzir sua condição em outra amostra, escolheu-se a linha 4, com região de interesse situada a uma distância aproximada de $8 \mathrm{~mm}$ no eixo X com relação a origem. Esta posição corresponde à distância focal $Z$ de $5 \mathrm{~mm}$ (fluência de $120 \mathrm{~J} / \mathrm{cm}^{2}$ ), velocidade de $250 \mathrm{~mm} / \mathrm{min}$ e número de incidência igual a 1.

Na Figura 5-15 e Figura 5-16 estão apresentadas as micrografias das amostras SA430II e SA430III, respectivamente, do Teste 2 que foram irradiadas usando a condição pré-determinada do Teste 1. Como se estabeleceu que o valor 
de $Z$ naquele ponto foi de $5 \mathrm{~mm}$ (fluência de $120 \mathrm{~J} / \mathrm{cm}^{2}$ ), para este teste formam utilizadas duas condições de irradiação, em uma usou-se exatamente o valor de $Z$ determinado do teste 1 e a velocidade correspondente à linha escolhida, e em outra usou-se um valor de Z menor (4 mm, com fluência correspondente a 190 $\mathrm{J} / \mathrm{cm}^{2}$ ) e uma velocidade maior de $375 \mathrm{~mm} / \mathrm{min}$.
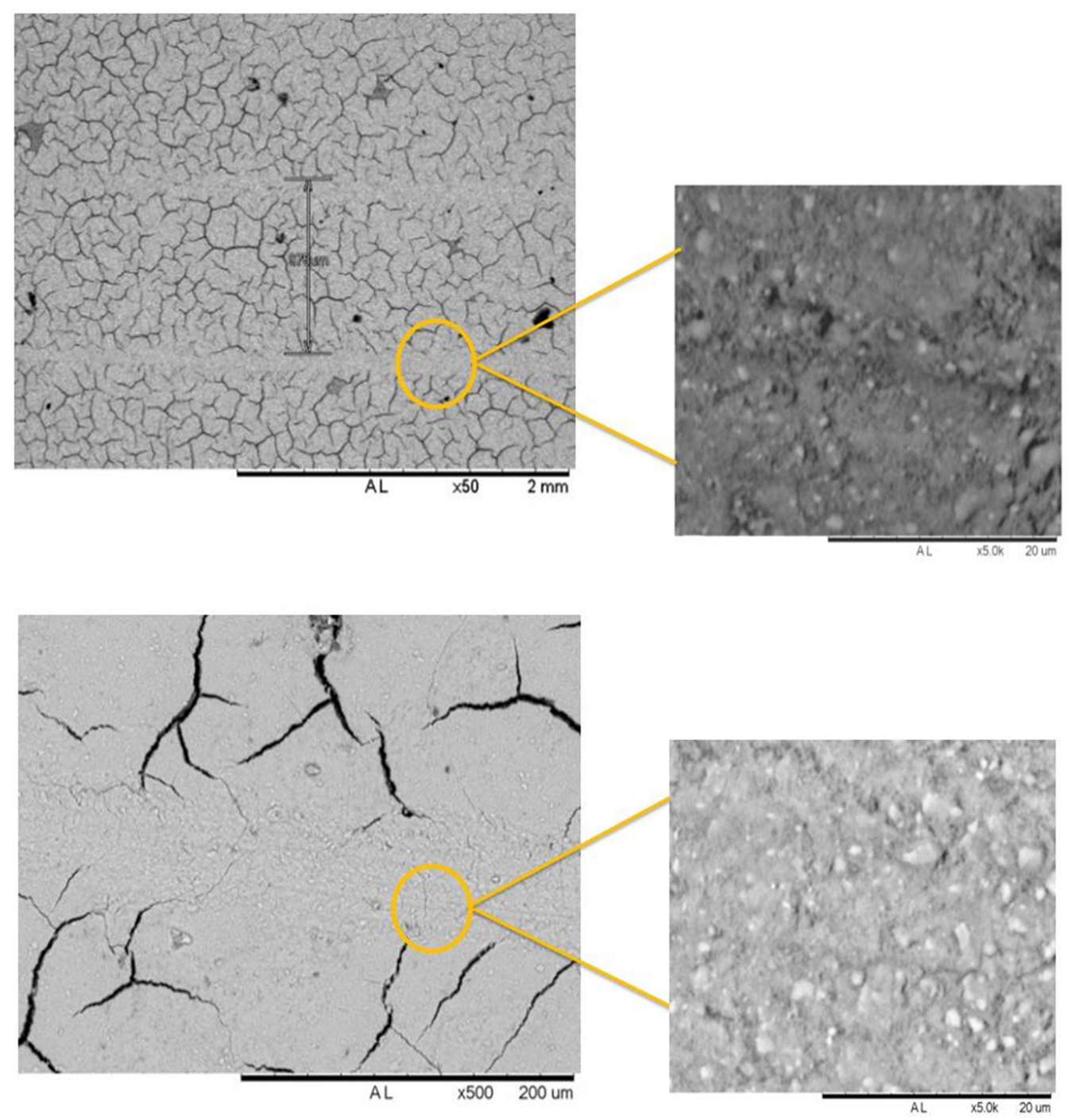

Figura 5-15 - Microscopia eletrônica de varredura da amostra SA430II Parâmetros de irradiação número de incidência $1, V=375 \mathrm{~mm} / \mathrm{min}$ e fluência de $190 \mathrm{~J} / \mathrm{cm}^{2}$. 

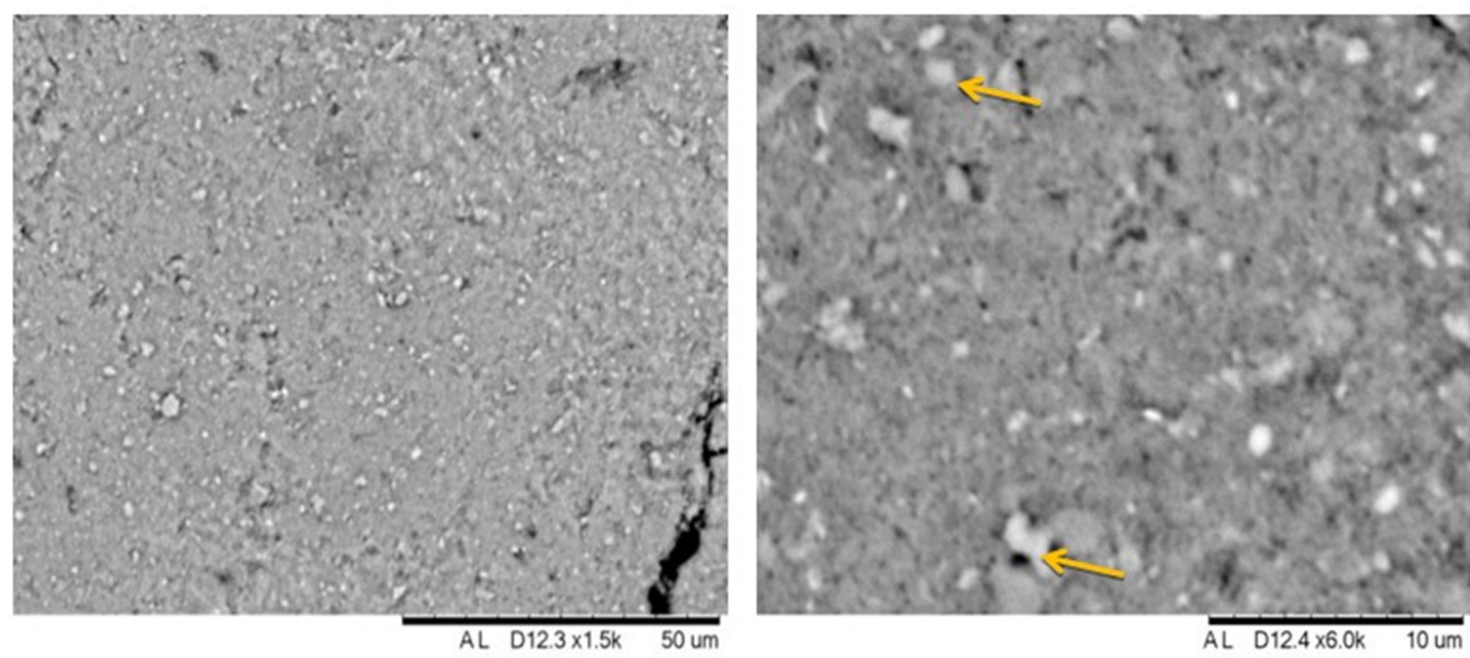

Figura 5-16 - Microscopia eletrônica de varredura da amostra SA430III Parâmetros de irradiação número de incidência $1, V=250 \mathrm{~mm} / \mathrm{min}$ e fluência de $120 \mathrm{~J} / \mathrm{cm}^{2}$.

Observa-se que para a amostra SA430II ( Figura 5-15) em que a fluência foi maior a modificação provocada na região é mais evidente, observa-se também que nas trilhas provocadas onde o feixe de laser foi incidido houve uma atenuação das trincas, podendo ser um indicio de que houve uma fusão, seguida de uma solidificação rápida, ou até mesmo uma expansão do material, causada pelo crescimento dos grãos com o aumento da temperatura na região. $\mathrm{Na}$ amostra SA430III não foram observadas estas trilhas, porém observou-se em algumas regiões uma possível formação do pescoço (indicado na Figura 5-16 com as setas em amarelo), podendo isso ser um indício de sinterização.

Tendo em vista os resultados obtidos do Teste 2 de irradiação, no Teste 3 foi reproduzida a condição de irradiação da amostra SA430III como o esquema da Figura 4-13. Na Figura 5-17 estão apresentadas as microscopias eletrônicas de varredura para amostra 3D para número de incidência igual a 1 e 2. 

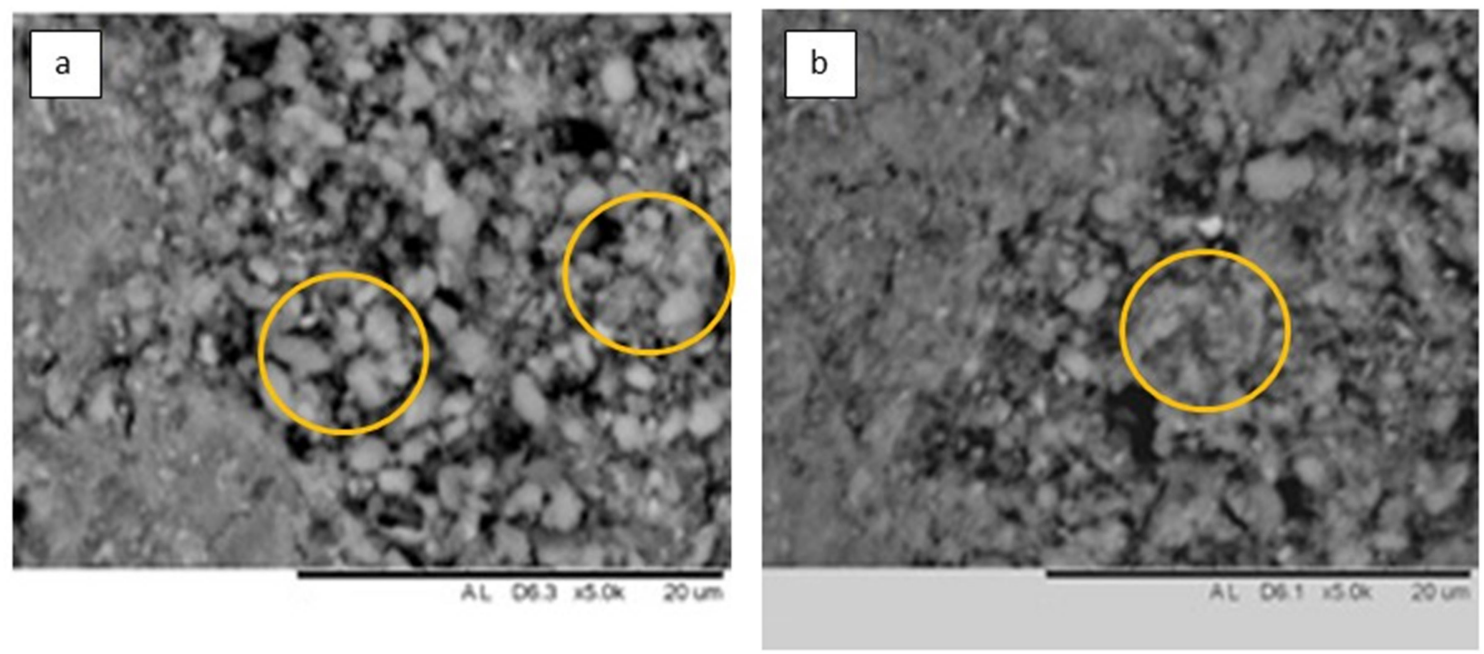

Figura 5-17 - Microscopia eletrônica de varredura da amostra 3D. Parâmetros de irradiação Fluência de $120 \mathrm{~J} / \mathrm{cm}^{2}, V=250 \mathrm{~mm} / \mathrm{min}$ a) Número de incidência 1 e b) número de incidência 2 .

Por meio das micrografias da Figura 5-17 (a) e (b) é possível observar que ambas as condições de irradiação foram capazes de promover a aglutinação das partículas, gerando regiões mais densas como indicado nas figuras pelos círculos amarelos, porém nota-se maior aglutinação para o número de incidência igual a 2.

Neste estágio determinou-se a fluência, e também a velocidade de varredura do laser e concluiu-se que o parâmetro que deveria ser ajustado nos futuros testes era o número de incidência do laser na amostra. Dessa menearia foi feito o Teste 4 de irradiação aumentando-se o número de incidência do laser. Na Figura 5-18, Figura 5-19 e Figura 5-20 estão apresentadas as micrografias das amostras $2 \mathrm{~F}, 4 \mathrm{~F}$ e $5 \mathrm{~F}$ em que se aumentou o número de incidência do laser para 4,6 e 8 respectivamente. 

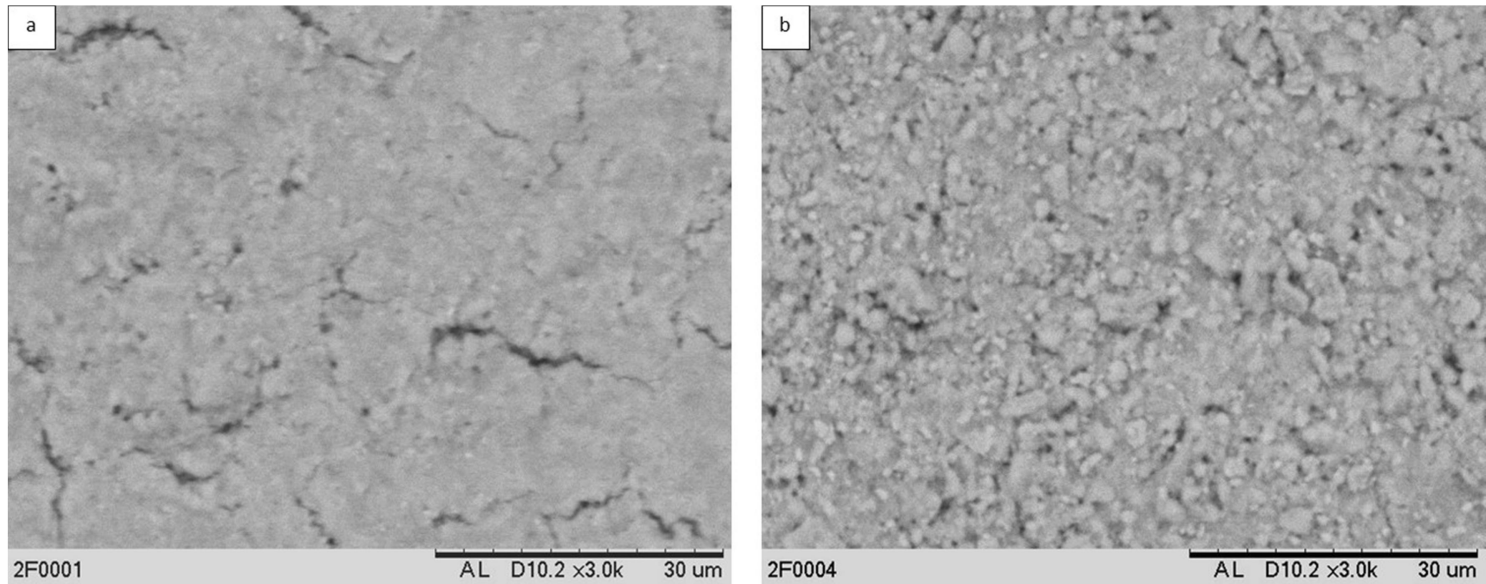

Figura 5-18 - Microscopia eletrônica de varreduras da amostra 2F. (a) Região irradiada; parâmetros de irradiação Fluência de $120 \mathrm{~J} / \mathrm{cm}^{2}, \mathrm{~V}=250 \mathrm{~mm} / \mathrm{min}$ e Número de incidência igual a 4. (b) Região não irradiada.
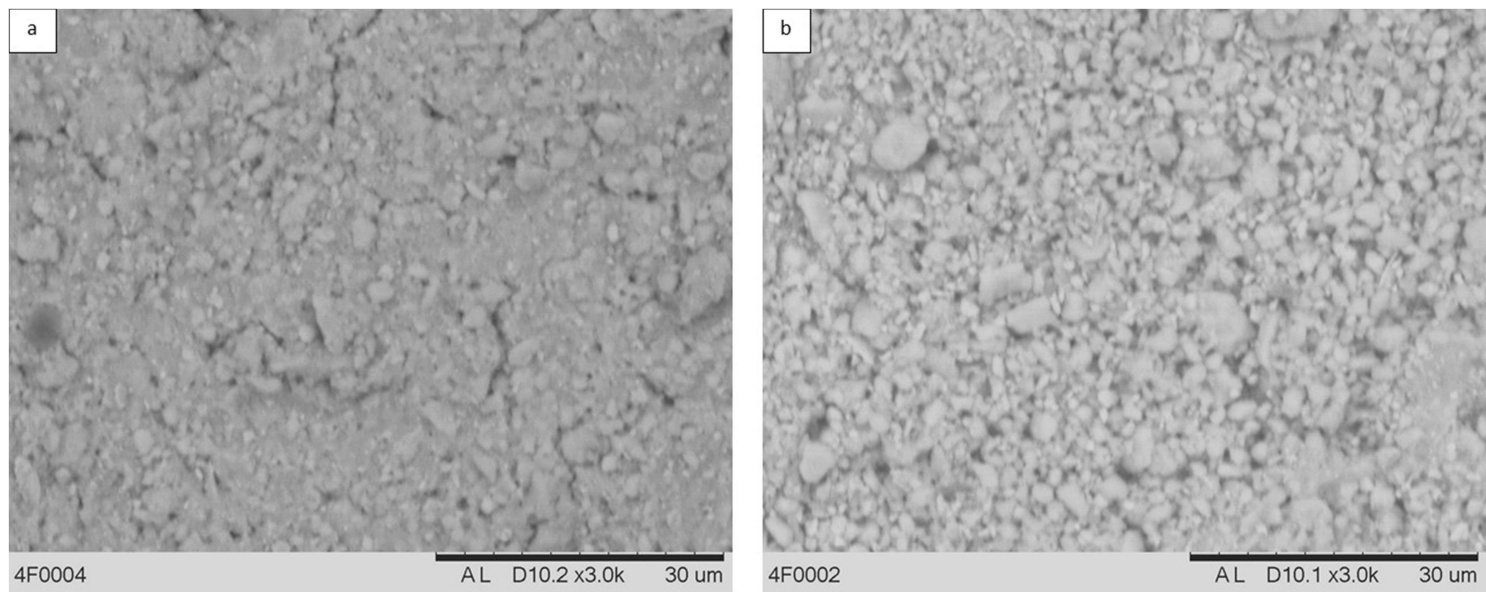

Figura 5-19 - Microscopia eletrônica de varreduras da amostra 4F. (a) Região irradiada; parâmetros de irradiação Fluência de $120 \mathrm{~J} / \mathrm{cm}^{2}, \mathrm{~V}=250 \mathrm{~mm} / \mathrm{min}$ e Número de incidência igual a 6. (b) Região não irradiada. 

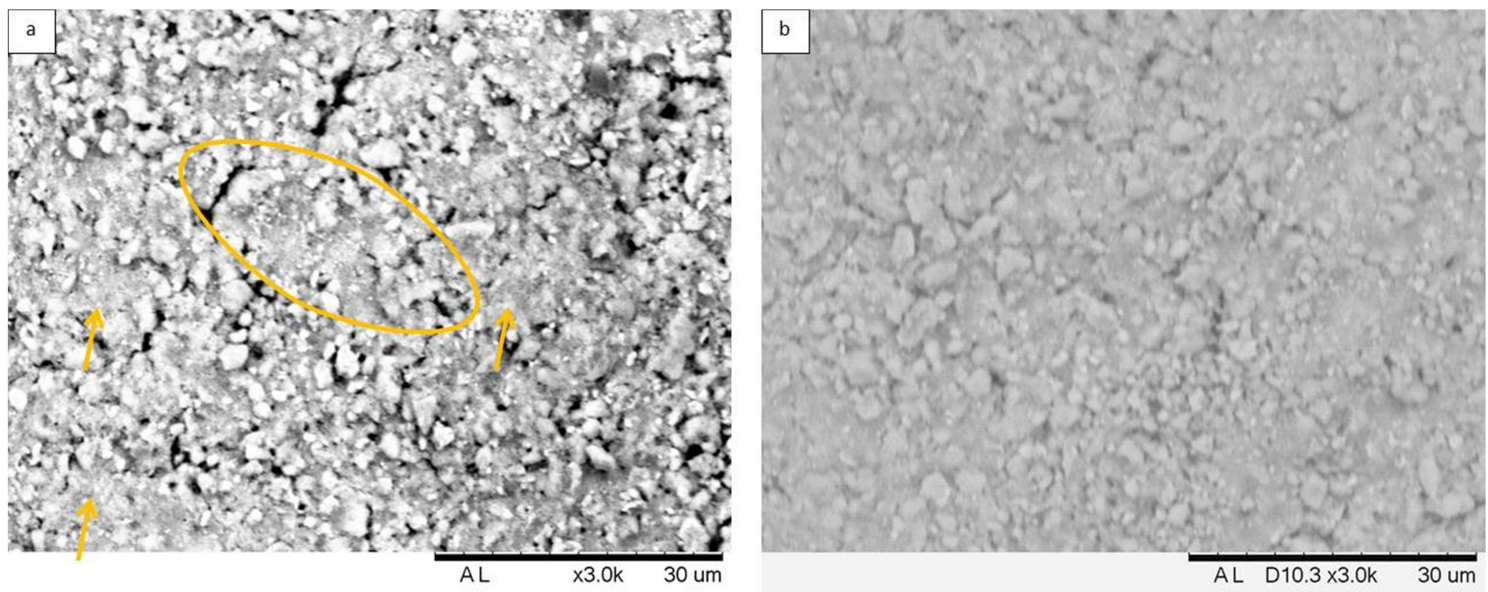

Figura 5-20 - Microscopia eletrônica de varreduras da amostra 5F. (a) Região irradiada; parâmetros de irradiação Fluência de $120 \mathrm{~J} / \mathrm{cm}^{2}, \mathrm{~V}=250 \mathrm{~mm} / \mathrm{min}$ e Número de incidência igual a 8. (b) Região não irradiada.

Pode-se observar por meio das micrografias a amostra 2F apresentadas na Figura 5-18 que o aumento do número de incidência do laser para 4 provocou na região irradiada agregação das partículas gerando regiões contínuas (não podendo distinguir as partículas), porém, foram geradas trincas no recobrimento.

Nas micrografias da amostra 4F apresentadas na Figura 5-19, em que o número de incidência do laser foi igual a 6 , observa-se que também há uma agregação das partículas e a densificação de algumas regiões com a presença de trincas.

Nas micrografias da amostra 5F apresentadas na Figura 5-20, em que o número de incidência do laser foi igual a 8. Também é possível observar que há presença de regiões densas, porém essa densificação não é contínua, como identificado na figura pelas setas em amarelo.

Assim, pode-se dizer que o aumento do número de incidência do laser ocasionou maior agregação das partículas, provocando a densificação, porém a curto alcance.

Na Figura 5-21 e Figura 5-22 estão apresentadas as microscopias eletrônicas de varredura das amostras $8 G$ e $9 G$ do teste 5 de irradiação que foram produzidas tendo em vista o comportamento constatado no parágrafo anterior referente ao teste 4 . Nestas figuras são feitas as comparações entre a amostra irradiada e a não irradiada. 

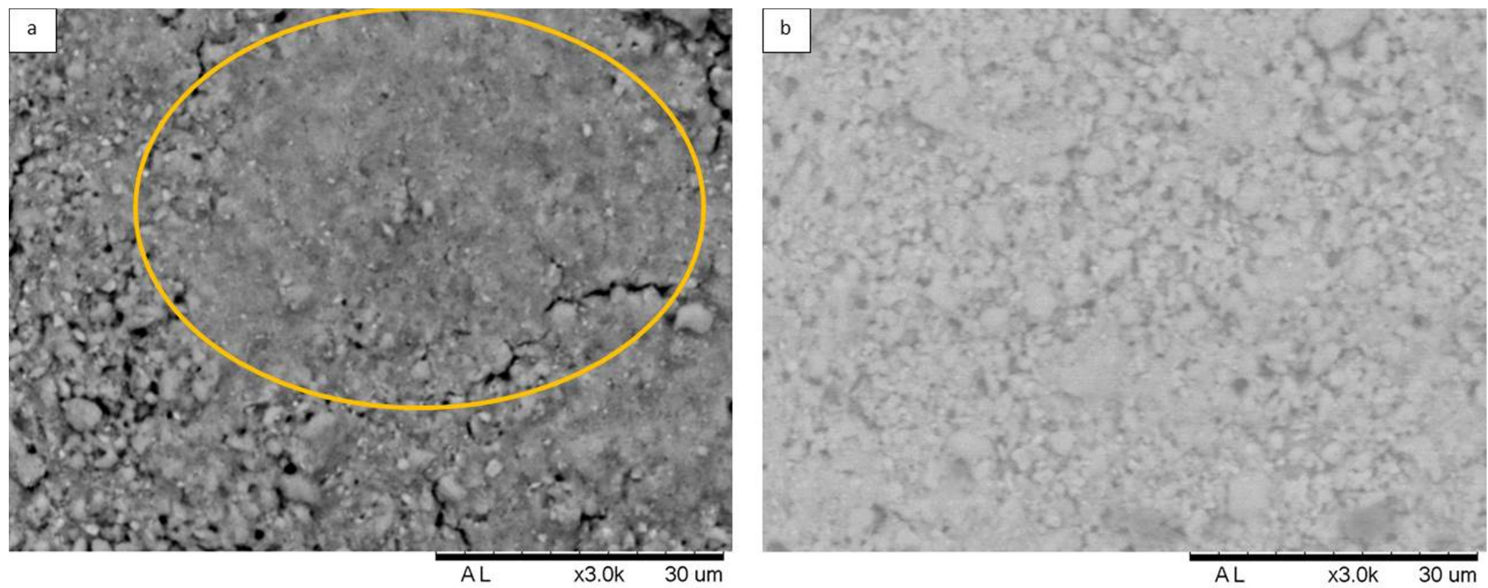

Figura 5-21 - Microscopia eletrônica de varreduras da amostra 8G. (a) Região irradiada; parâmetros de irradiação Fluência de $120 \mathrm{~J} / \mathrm{cm}^{2}, V=250 \mathrm{~mm} / \mathrm{min}$ e Número de incidência igual a 15. (b) Região não irradiada.
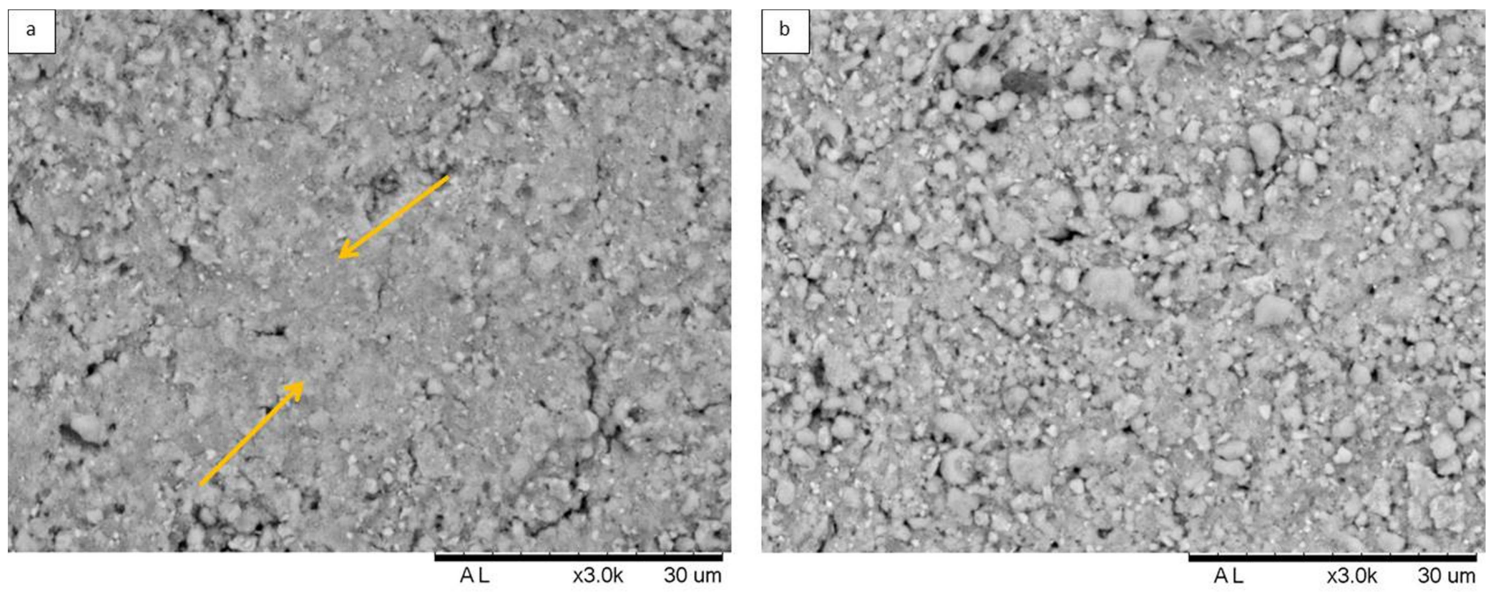

Figura 5-22 - Microscopia eletrônica de varreduras da amostra 9G. (a) Região irradiada; parâmetros de irradiação Fluência de $120 \mathrm{~J} / \mathrm{cm}^{2}, V=250 \mathrm{~mm} / \mathrm{min}$ e Número de incidência igual a 27. (b) Região não irradiada.

Observa-se que tanto para amostra $8 \mathrm{G}$ quanto para a amostra $9 \mathrm{G}$ (Figura 5-21 e Figura 5-22) a presença de regiões bastante densas, indicando que certamente houve a sinterização desta região, porém assim como nas amostras $2 \mathrm{~F}, 4 \mathrm{~F}$ e $5 \mathrm{~F}$ não acontece a sinterização de todo o recobrimento, compreendendose que para os parâmetros de fluência, velocidade de varredura e número de incidência do laser a sinterização acontece heterogeneamente.

Certamente, para as amostras em que foi possível constatar a sinterização de regiões isoladas, aconteceu a sinterização em fase líquida pelo 
mecanismo de fusão parcial das partículas proposto por Karapatis. Sendo o recobrimento constituído apenas por zircônia, não há a possibilidade de sinterização em fase líquida com a presença de ligante, como mostrado por German, assim como também não é possível sinterização no estado sólido uma vez que interação do laser com o material é muito rápida, não havendo tempo para que ocorra difusão $[47,46]$.

Nos casos em que houve o surgimento de trincas após a irradiação com laser De acordo com Mercelis e Kruth, estas trincas são ocasionadas pelo estresse residual proveniente do gradiente térmico que são inerentemente presentes em processamento a laser, sendo o TGM, sigla em inglês que significa mecanismo de gradiente de temperatura, o responsável por gerar esse estresse residual. Sendo que neste mecanismo há a expansão do material durante o aquecimento e a contração quando há o resfriamento. Como o resfriamento e o aquecimento é muito rápido, aparecem as trincas [60].

$\mathrm{Na}$ Figura 5-23 estão apresentados os difratogramas de raios $\mathrm{x}$ das amostras 2F, 4F e 5F análise de fases e na Figura 5-24 apresenta-se o difratograma de raios $\mathrm{x}$ destas mesmas amostras comparados aos difratogramas da cerâmica sinterizada e ao do pó de $\mathrm{ZrO}_{2}$.

$\mathrm{Na}$ Figura 5-25 estão apresentados os difratograma de raios $\mathrm{x}$ das amostras 8G e 9G com a análise de fases e na Figura 5-26 apresenta-se o difratograma destas mesmas amostras comparados aos difratogramas da cerâmica sinterizada e ao do pó de $\mathrm{ZrO}_{2}$. 


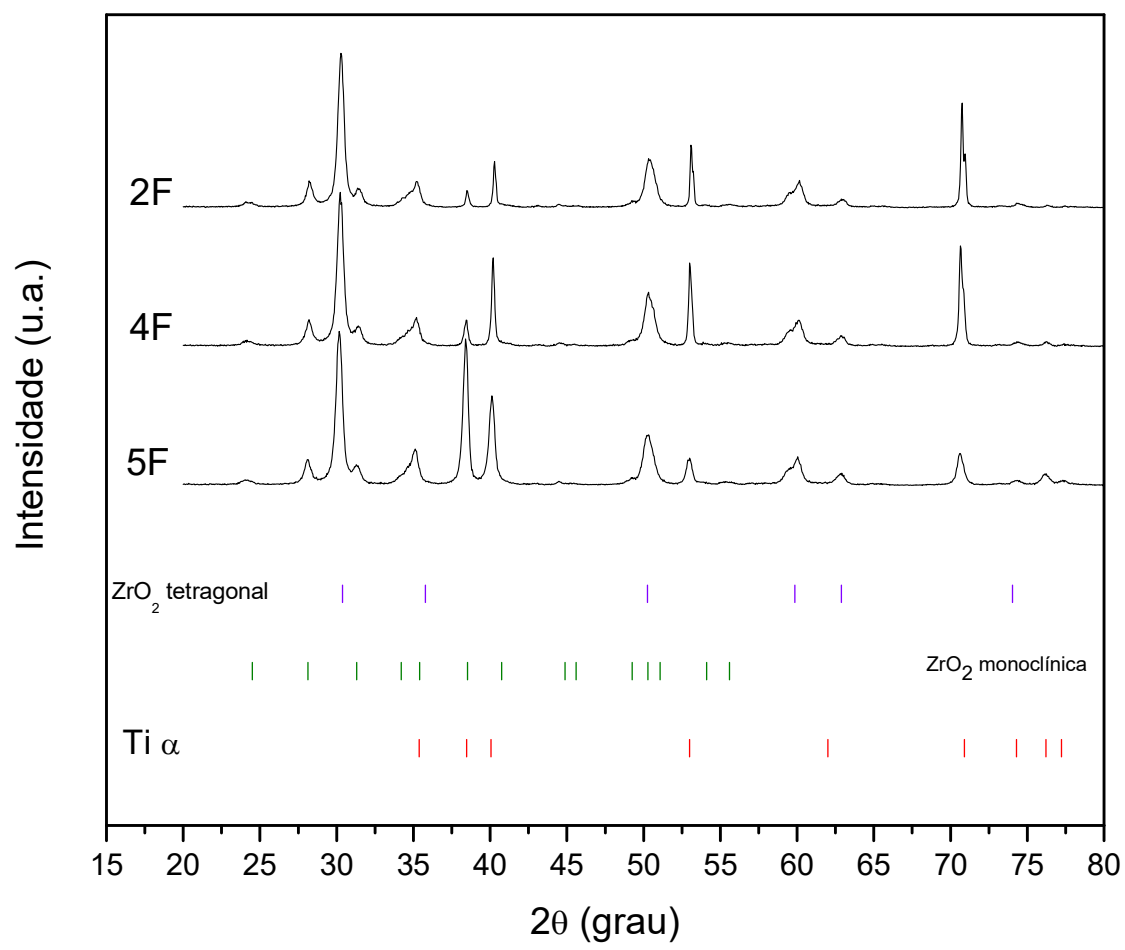

Figura 5-23 - Difratograma de raios $\mathrm{x}$ das amostras $2 \mathrm{~F}, 4 \mathrm{~F}$ e $5 \mathrm{~F}$ irradiadas com laser de $\mathrm{Nd}: \mathrm{YAG}$.

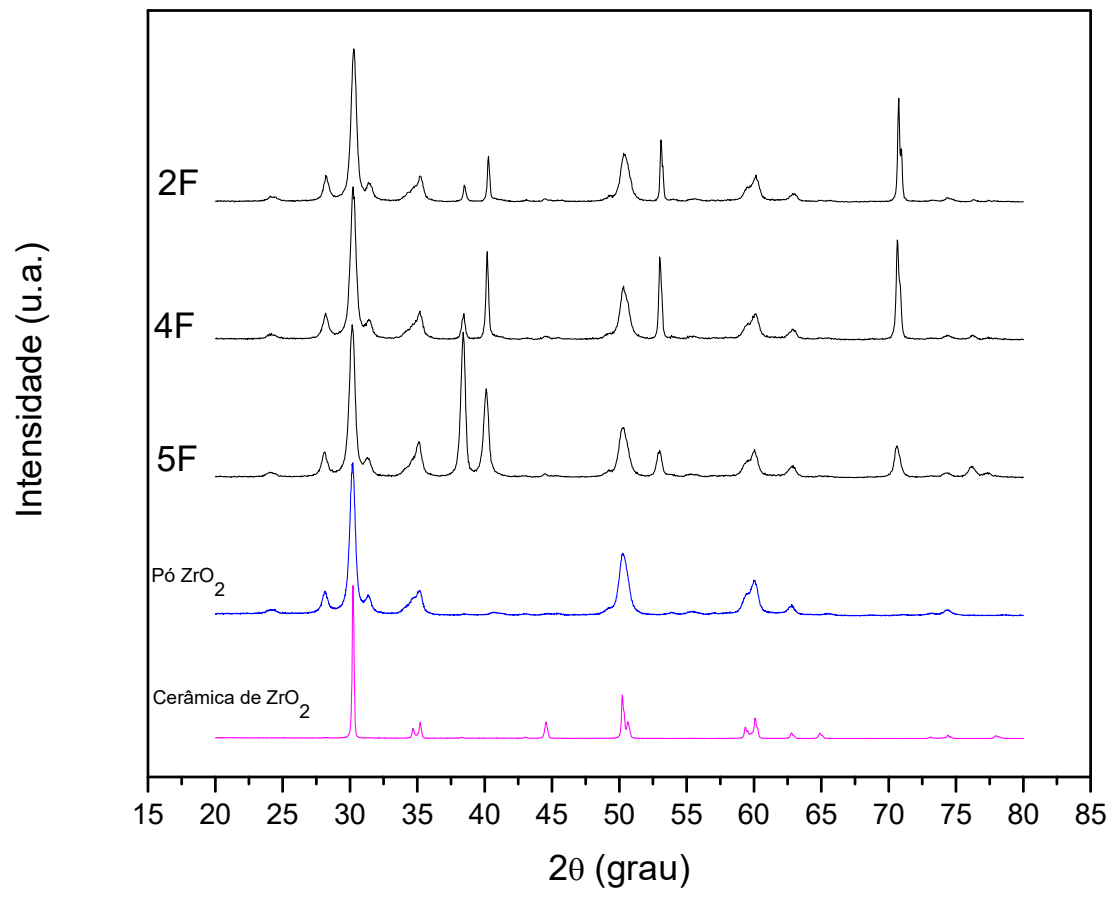

Figura 5-24 - Difratograma de raios $\mathrm{x}$ das amostras 2F, 4F e 5F irradiadas com laser Nd:YAG comparados ao da cerâmica sinterizada e ao do pó de $\mathrm{ZrO}_{2}$. 


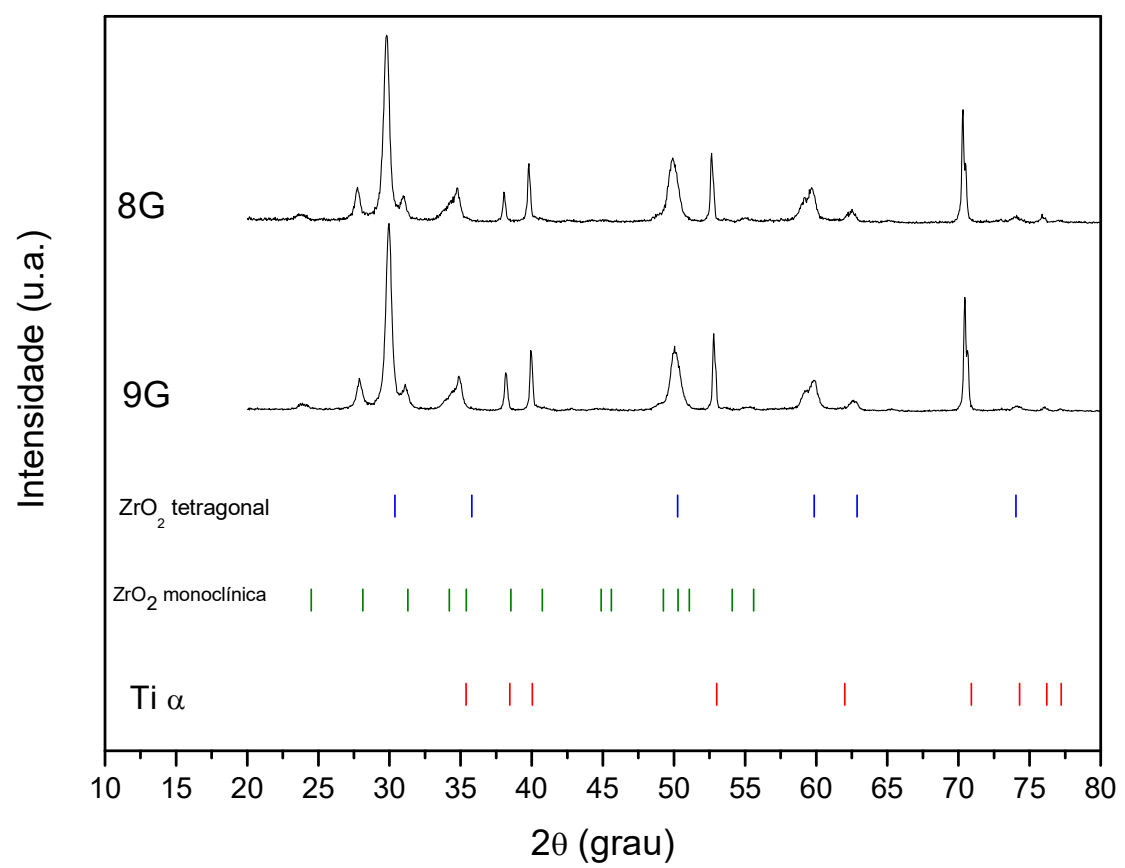

Figura 5-25 - Difratograma de raios $x$ das amostras $8 G$ e $9 G$ irradiadas com laser de Nd:YAG.

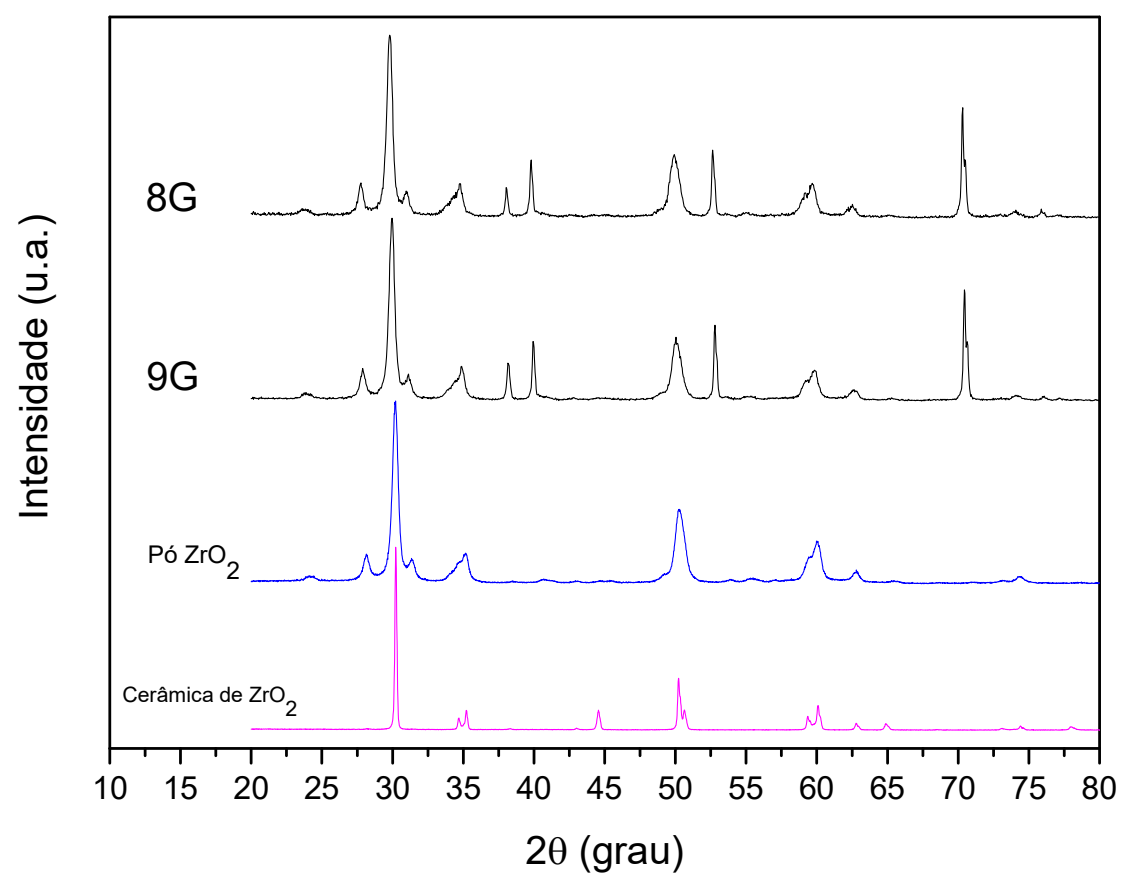

Figura 5-26 - Difratograma de raios $x$ das amostras $8 G$ e $9 G$ irradiadas com laser $\mathrm{Nd}$ :YAG comparados ao da cerâmica sinterizada e ao do pó de $\mathrm{ZrO}_{2}$.

Para todas as amostras são observados picos referentes ao Ti-alfa de acordo com a ficha do ICSD 89-2762, originados da placa usada para deposição. 
Observam-se também os picos referentes às fases tetragonal e monoclínica da zircônia de acordo com as fichas do ICSD 80-784 e 70-2491 respectivamente originados do recobrimento. Dessa maneira o mecanismo de sinterização por indução química, proposto por Klocke e Wirtz também pode ser descartado, uma vez que não há a formação de uma fase cristalina diferente [43]. Observa-se também, que para a amostra $5 \mathrm{~F}$ houve uma inversão na relação de intensidade para os picos referentes ao titânio na posição de $38^{\circ}, 40^{\circ}, 53^{\circ}$ e $71^{\circ}$ e também alargamento desses picos, se comparados aos das amostras $2 \mathrm{~F}$ e $4 \mathrm{~F}$. Sendo isto um indício de que o feixe de laser, para o número de incidência igual a 8 , interagiu com a superfície do substrato ocasionando alteração na orientação cristalográfica na superfície do metal.

Por meio da comparação entre os difratogramas das amostras irradiadas, do pó e da cerâmica sinterizada, observa-se que os picos de difração das amostras irradiadas assemelham-se mais com os picos de difração do pó do que com o da cerâmica sinterizada, fato que é confirmado com as microscopias que sugerem que a sinterização ocorre de maneira bastante heterogênea, apresentando regiões não sinterizadas.

$\mathrm{Na}$ Figura 5-27, Figura 5-28 e Figura 5-29 apresentam-se as micrografias obtidas por MEV dos riscos feitos no ensaio de Scratch da amostra não irradiada (6G), amostra $8 G$ e amostra $9 G$ respectivamente. Observa-se que para a amostra não irradiada, no risco em que foi aplicada a carga variável de 0,5 $\mathrm{N}$ a $3 \mathrm{~N}$ (Figura 5-27 (a) e (b)), o indentador apenas compactou o material depositado não provocando a remoção do recobrimento, sinal de que a camada depositada a verde era porosa e macia, ao passo que para o risco feito aplicandose a carga variável de 0,5 N a $5 \mathrm{~N}$ (Figura 5-27 (c) e (d)) o indentador também provoca a compactação do material depositado em praticamente toda a extensão causando a remoção apenas no fim do risco. Observa-se que tanto para as amostras $8 G$ e $9 G$ houve uma resistência maior ao risco, evidenciada pela remoção de partes do recobrimento à medida que se aumentava a carga aplicada. Como para a amostra não irradiada houve a compactação e para as duas amostras irradiadas observou-se a resistência ao risco, isso seria um indicio de regiões mais densas e melhor aderidas ao substrato para as amostras irradiadas. 
Obtendo-se a distância a partir da qual o recobrimento começava a ser arrancado pelo indentador, a extensão do risco e a variação de carga para cada risco, foi possível calcular a força de resistência ao risco para cada situação. Para as amostras $8 \mathrm{G}$ e $9 \mathrm{G}$ a força média de resistência foi em torno de 0,8 $\mathrm{N}$.
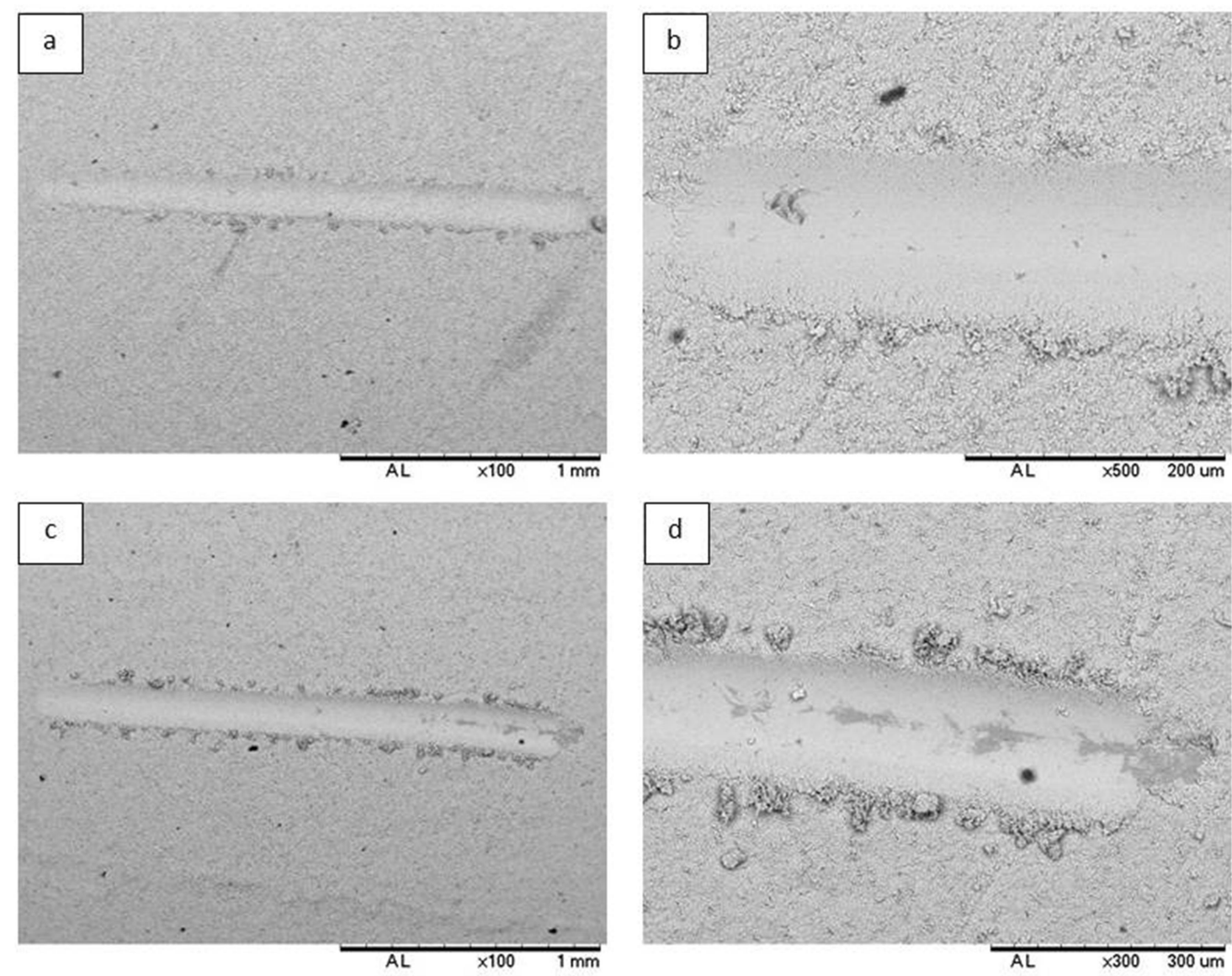

Figura 5-27 - Micrografia obtida por MEV da amostra não irradiada em que foi realizado o Scratch com pré-carga de $0,5 \mathrm{~N}$, risco de $2 \mathrm{~mm}$ e velocidade de 0,06 $\mathrm{mm} / \mathrm{s}$. (a) e (b) carga variável de $0,5 \mathrm{~N}$ a $3 \mathrm{~N}$; (c) e (d) carga variável de $0,5 \mathrm{~N}$ a 5 $\mathrm{N}$. 

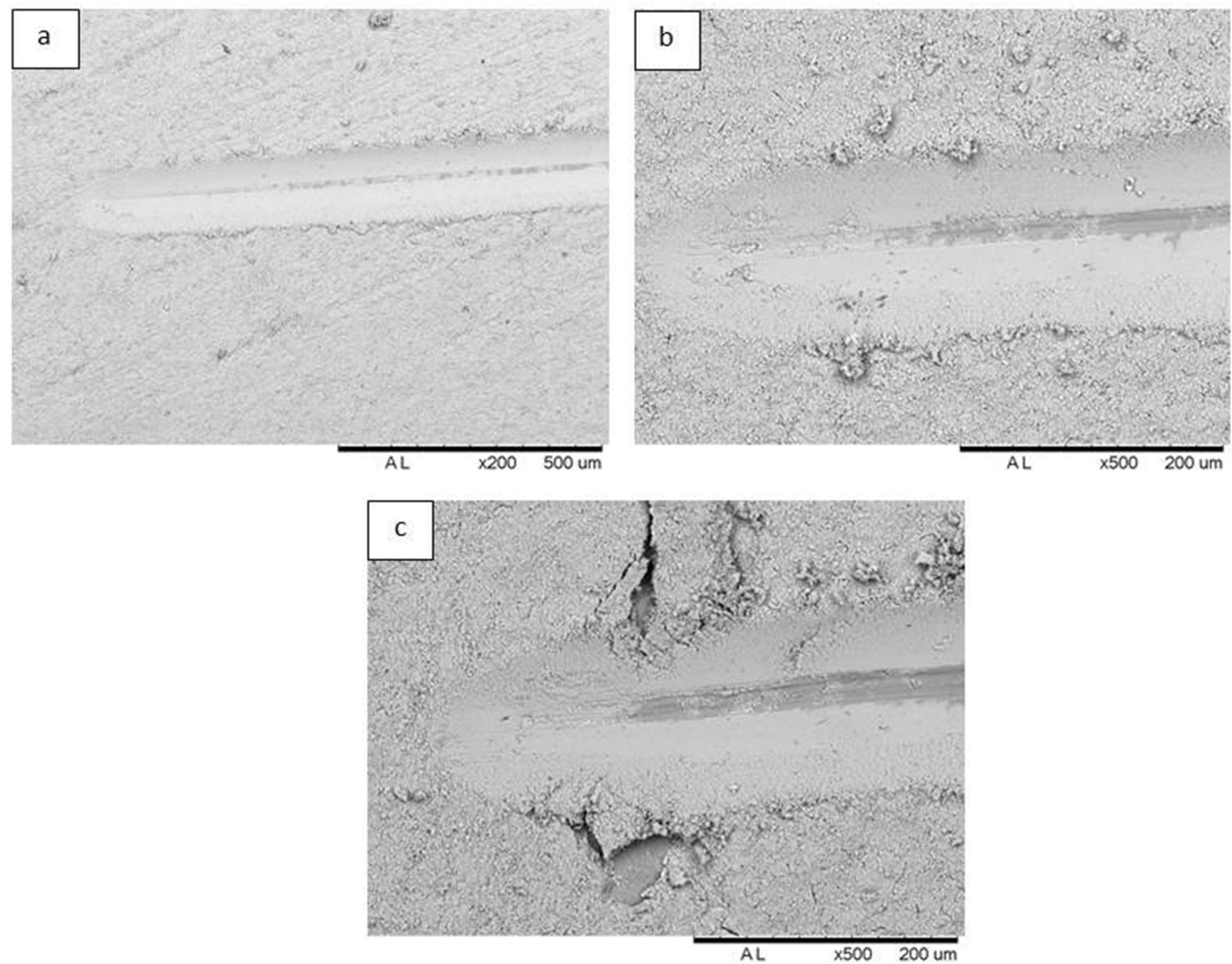

Figura 5-28 - Micrografia obtida por MEV da 8G irradiada com fluência de 120 $\mathrm{J} / \mathrm{cm}^{2}, \mathrm{~V}=250 \mathrm{~mm} / \mathrm{min}$ e Número de incidência igual a $15 \mathrm{em}$ que foi realizado o scratch com pré-carga de $0,5 \mathrm{~N}$ com risco de $2 \mathrm{~mm}$ e velocidade de $0,06 \mathrm{~mm} / \mathrm{s}$ (a) carga variável de $0,5 \mathrm{~N}$ a $2 \mathrm{~N}$ (b) carga variável de $0,5 \mathrm{~N}$ a $3 \mathrm{~N}$ e (c) carga variável de $0,5 \mathrm{~N}$ a $5 \mathrm{~N}$. 

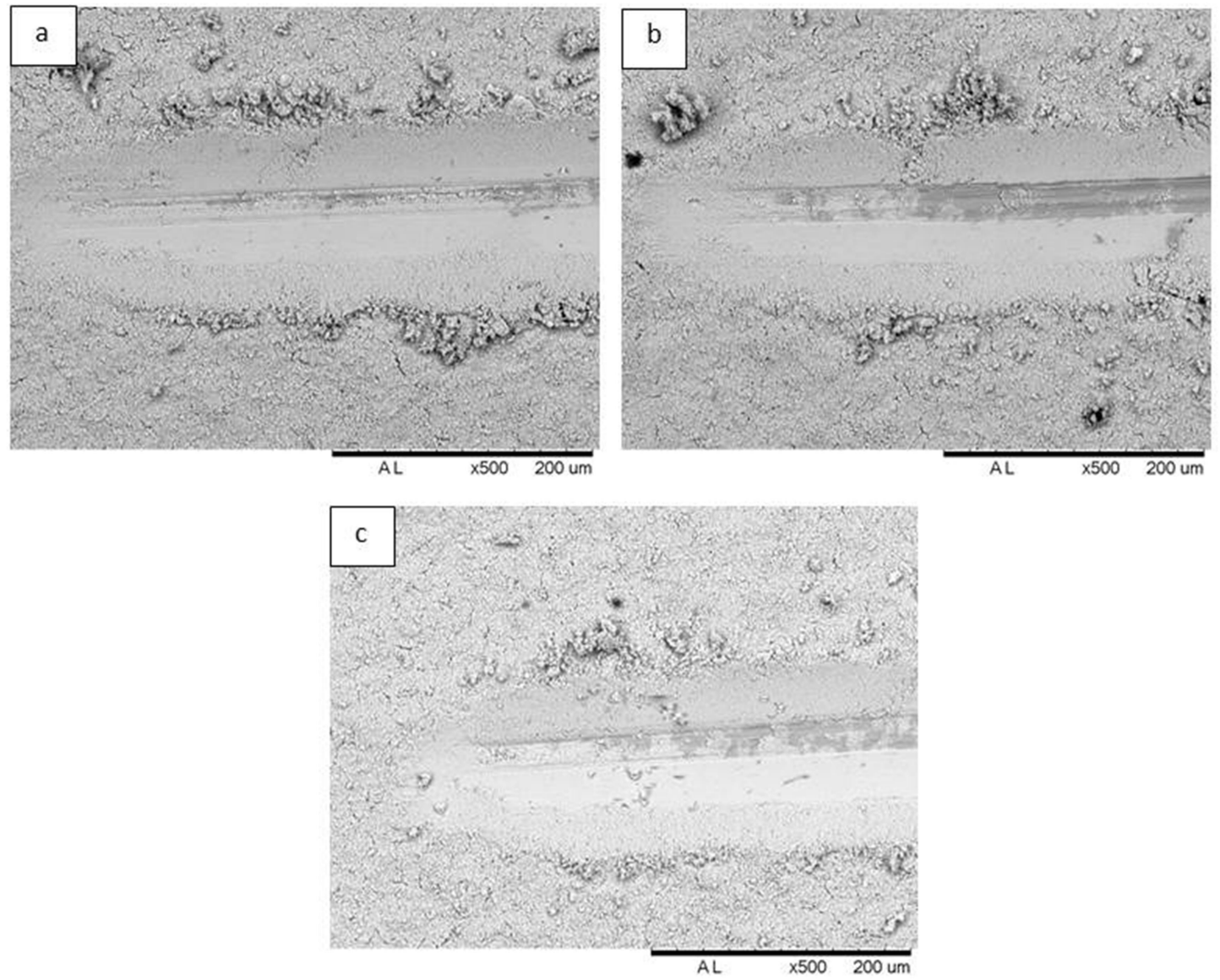

Figura 5-29 - Micrografia obtida por MEV da 9G irradiada com fluência de 120 $\mathrm{J} / \mathrm{cm}^{2}, V=250 \mathrm{~mm} / \mathrm{min}$ e Número de incidência igual a $27 \mathrm{em}$ que foi realizado o scratch com pré-carga de $0,5 \mathrm{~N}$ com risco de $2 \mathrm{~mm}$ e velocidade de $0,06 \mathrm{~mm} / \mathrm{s}$ (a) carga variável de $0,5 \mathrm{~N}$ a $2 \mathrm{~N}$ (b) carga variável de $0,5 \mathrm{~N}$ a $3 \mathrm{~N}$ e (c) carga variável de $0,5 \mathrm{~N}$ a $5 \mathrm{~N}$. 


\section{CONCLUSÕES}

Os resultados desta dissertação mostraram a eficiência da deposição eletroforética para a obtenção de filmes de 3YTZP em titânio metálico, desde que otimizadas a escolha do sistema de solventes utilizado na suspensão e as condições de processo. Mostraram também a influência da irradiação a laser para promover a sinterização, levando em consideração os parâmetros de irradiação.

Com as análises de difração de raios $\mathrm{x}$ assim como as micrografias do pó calcinado a $800^{\circ} \mathrm{C}$ por 1 hora foi possível concluir que estes estavam adequados para o uso na EPD, uma vez que apresentavam em grande parte estrutura cristalina tetragonal, de grande importância para a resistência mecânica da zircônia e também partículas de forma mais alongada com sessão transversal de aproximadamente $10 \mathrm{~nm}$ e comprimento de $100 \mathrm{~nm}$.

Quanto à cerâmica sinterizada, as análises de difração de raios $\mathrm{x}$ das mostraram que após a sinterização foi identificada apenas a fase tetragonal, fundamental para a resistência mecânica da cerâmica. E por meio do estudo de densificação, verifica-se $94,4 \%$ da densidade teórica com relação a zircônia sinterizada, valor que foi confirmado pelas micrografias de fratura que revelaram poros existentes na estrutura, justificando essa considerável diferença entre a densidade teórica e real.

Os resultados da análise de difração de raios $x$ das placas usadas como substrato para EPD mostraram que eram constituídas de titânio comercialmente puro com presença apenas da fase $\alpha$.

Com os resultados de rugosidade total feito nas chapas de titânio atacadas quimicamente com ácido sulfúrico $\left(\mathrm{H}_{2} \mathrm{SO}_{4}\right) 50 \%$ em volume e outro com solução de ácido nítrico $\left(\mathrm{HNO}_{3}\right) 25 \%$ em volume, com tempo de ataque de 10 segundos e 30 segundos para cada, mostraram que o ataque mais adequado para promover a ancoragem das partículas de 3YTZP foi o realizado com ácido sulfúrico a 10 segundos, levando em consideração que a rugosidade total deve ser menor que a espessura mínima de filme pretendido para apenas algumas camadas de partículas de pós se aderirem à cavidade.

Quanto à deposição eletroforética as suspensões à base de acetona proporcionaram filmes mais heterogêneos, bastante rugosos, ao passo que as suspensões a base de acetilacetona proporcionaram filmes mais homogêneos 
devido à maior estabilidade da suspensão. Quanto aos parâmetros de processo, da análise das micrografias foi possível observar que de modo geral os melhores filmes foram os obtidos com menores diferenças de potencial (em temos) que resultaram em depósitos de menor espessura, sendo estes mais homogêneos e livres de trincas. Levando a conclusão de que das suspensões usadas a que se mostrou mais adequada a EPD foi a de acetilacetona pura para $40 \mathrm{~V}$ a 20 segundos.

Para a irradiação com laser, do primeiro teste de irradiação, com base nas microscopias obtidas, pôde-se determina que a fluência mais adequada para dar continuidade aos ensaios é de $120 \mathrm{~J} / \mathrm{cm}^{2}$, o que corresponde a uma distância $Z$ de $5 \mathrm{~mm}$, além de velocidade de varredura de $250 \mathrm{~mm} / \mathrm{min}$. Determinou-se também que para o demais testes havia a necessidade de ajustar-se o número de incidência dos laser, sendo feitos, então, ensaios com número de incidência com 2, 4, 6, 8, 15 e 27 . Pôde-se observar que com aumento do número de incidência havia maior aproximação da condição de sinterização, porém a sinterização aconteceu de forma heterogênea, de modo que se puderam observar regiões sinterizadas e não sinterizadas, por meio da microscopia eletrônica de varredura. O que também foi comprovado por meio da técnica de difração de raios $x$, em que o difratograma das amostras irradiadas assemelhava-se mais com o difratograma do pó e não com o da cerâmica.

Pode-se concluir-se com o estudo realizado que existe a possibilidade de alcançar-se a sinterização a laser de filmes cerâmicos de zircônia depositados em titânio, porém ainda há a necessidade de mais estudos relacionados aos parâmetros do laser para que se consiga alcançar a condição ideal de sinterização, evitando uma série de defeitos, como o surgimento de trincas nos filmes depositados e também para que a sinterização ocorra de forma homogênea. 


\section{SUGESTÕES PARA TRABALHOS FUTUROS}

Realizar mais testes de irradiação dos filmes cerâmicos de zircônia depositados em titânio usando-se o laser pulsado de Nd:YAG, mantendo-se a fluência e velocidade já determinados neste trabalho, porém justando-se o número de incidência para que obtenha-se uma condição ideal de sinterização.

Fazer também os testes de irradiação dos filmes cerâmicos de zircônia depositados sobre titânio utilizando o laser contínuo de $\mathrm{CO}_{2}$. 


\section{REFERÊNCIAS}

1 ANANTH, H.; KUNDAPUR, V.; MOHAMMED, H.S.; ANAND, M.; AMARNATH, G.S.; MANKAR, S.; A Review on Biomaterials in Dental Implantology. Internatlonal journal of Blomedlcal Science. v.2, n.3, p. 113-120, setembro de 2015.

2 Titanium Processing, Encyclopedia Britannica, 13 Mar. 2014. Disponível em <http://academic-ebbritannica.ez67. periodicos.capes.gov.br/levels/collegiate/print/article/titaniumprocessing/110675> Acessado em 22 Jun. 2017.

3 LEYENS, C.; PETERS, M. Titanium and Titanium Alloys. Fundamentals and Applications. Köln: Dgm, 2003.

4 FERNANDES, Viviane Kettermann; MARTENDAL, Caroline Pereira. Titânio e suas 2016.2 Disponível em: <http://engenheirodemateriais.com.br/tag/alotropia-do-titanio/>. Acesso em: 22 jun. 2017.

5 GEETHA, M.; SINGH, A.K.; ASOKAMANI, R.; GOGIA. A.K.; Ti based biomaterials, the ultimate choice for orthopaedic implants - A review. Progress In Materials Science, [s.I.], v. 54, n. 3, p.397-425, 2009

6 AMERICAN SOCIETY FOR TESTING AND MATERIALS. Standard Specification for Unalloyed Titanium, for Surgical Implant Applications, United States, 2013 (ASTM F67).

7 WEISS, I.; SEMIATIN S.L.. Thermomechanical processing of beta titanium alloys - an overview. Materials Science and Engineering, v.243, p.46-65, 1998.

8 RODRIGUEZ, J.A.; GARCIA, J.C.; ALONSO, E.; HAMZAOUI, Y.; RODRIGUEZ, J.M.; URQUIZA, G.. Failure probability estimation of steam turbine blades by enhanced Monte Carlo Method. Engineering Failure Analysis, [s.I.], v. 56, p.8088, 2015. 
9 GURRAPPA, I.; GOGIA, A.K. High performance coatings for titanium alloys to protect against oxidation. Surface and Coatings Techmology, v.139, p. 216-217, 2001.

10 WELSCH G.; KAHVECI, A.I. Oxidation of high- temperature intermetallics In: Grobstein, T.; Doychak, J. (eds.). Oxidation behavior of titanium aluminide alloys. Warrendale: PA, 1988. cap.3, p.167-174.

11 AMANO, K. Thermal barrier coating. U.S. Patent n. 4,774,150, 27 set. 1988.

12 SCHULZ, U.; FRITSCHER, K.; LEYENS, C. Two-source jumping beam evaporation for advanced EB-PVD TBC systems. Surface and Coatings Technology, v.133-134, p.40-48, 2000.

13 Heydecke G, Kohal R, Glaser R. Optimal esthetics in single-tooth replacement with the re-implant system: a case report. Int J Prosthodont. 1999; 12(2):184-9 Epub 1999/06/18.

14 HUNG, K.; LO, S.; SHIH, C.; YANG, Y.; FENG, H.; LIN, Y. Titanium surface modified by hydroxyapatite coating for dental implants. Surface And Coatings Technology, [s.I.], v. 231, p.337-345, 2013.

15 FINET, B.; WEBER, G.; CLOOTS, R. Titanium release from dental implants: an in vivo study on sheep. Materials Letters, v. 43, n. 4, p.159-165, 2000.

16 HAHN, R.B. Zirconium and Hafnium. In : Kulthoff IM, Elving P. Treatise on analytical Chemistery. Part II, 5, Analytical Chemistery of elements. New York: Interscience. p.61-138, 1961.

17 SILVA, M. B. F. da. Zircônio. 2001.

18 LAZAR, D. R. R. Avaliação da influência de elementos de terras raras pesadas na microestrutura e nas propriedades mecânicas e elétricas de cerâmicas de zircônia - ítria. 2002 Tese (doutorado) - Instituto de Pesquisas Energéticas e Nucleares - IPEN - São Paulo, 2002.

19 GARCIA, R. H. L.; USSUI, V.; LIMA, N. B.; MUCCILLO, E. N. S.; LAZAR, D. R.R. Physical properties of alumina/yttria-stabilized zirconia composites with improved microstructure. Journal. Alloys Compounds. 486, 747-753 2009). 
20 LAZAR, D.R.R.; BOTTINO, M.C.; ÖZCAN, MVALANDRO, L.F.; AMARAL, R.; USSUI, V.; BRESSIANI, A.H.A..Y-TZP ceramic processing from coprecipitated powders: A comparative study with three commercial dental ceramics. Dental Materials, [s.I.], v. 24, n. 12, p.1676-1685, 2008.

21 PICONI, C.; MACCAURO, G.. Zirconia as a ceramic biomaterial. Biomaterials, 20(1):1-25, 1999.

22 HANNINK, H.J.R.; KELLY, M.P.; MUDDLE, C.B. Transformation Toughening in Zirconia-Containing Ceramics. Journal of the American Ceramic Society, v.83, p.461-487, 2000.

23 KELLY, J.; DENRY, I. Stabilized zirconia as a structural ceramic: An overview Dental Materials, [s.I.], v. 24, n. 3, p.289-298, 2008.

24 STAPPER, G., BERNASCONI, M., NICOLOSO, N.; PARRINELLO, M. Ab initio study of structural and electronic properties of yttria-stabilized cubic zirconia. Physical Review B. n.59, 797-810 1999.

25 SEVILLA, P.; SANDINO, C.; ARCINIEGAS, M.; MARÍNEZ-GONIS, J.; PEREIRE, M.; GIL, F.J..Evaluating mechanical properties and degradation of YTZP dental implants. Materials Science And Engineering: C, [s.I.], v. 30, n. 1, p.14-19, 2010.

26 NETTLESHIP, I.; STEVENS, R. Tetragonal zirconia polycrystal (TZP) - A review. International Journal of High Technology Ceramics. 3, p.1-32 1987.

27 GARVIE, R.C.; HANNINK, RH.; PASCOE, R.T. Ceramic steel? Nature; 258:703-4, 1975.

28 FERRARI, B.; MORENO, R. EPD kinetics: A review. Journal Of The European Ceramic Society, [s.I.], v. 30, n. 5, p.1069-1078, 2010.

29 CORNI, I.; RYAN, M.P.; BOCCACCINI, A.R.. Electrophoretic deposition: From traditional ceramics to nanotechnology. Journal Of The European Ceramic Society, [s.I.], v. 28, n. 7, p.1353-1367, 2008. 
30 HAMAKER, H.C. Formation of deposition by electrophoresis. Trans Farady Society. V.36:279-8, 1940.

31 BACCACCINI, A.R; ZHITOMIRSKY, I. Application of electrophoretic and electrolytic deposition techniques in ceramics processing. Current Opinion In Solid State And Materials Science, Londres, v. 6, p.251-260, 2002.

32 BESRA, L.; ZHA, S.; LIU, M. Preparation of NiO-YSZ/YSZ bi-layers for solid oxide fuel cells by electrophoretic deposition. Journal Of Power Sources, [s.I.], v. 160, n. 1, p.207-214, 2006.

33 KAWAKAMI, R.; ITO, K.; SATO, Y.; MORI, Y.; ADACHI, M.; YOSHIKODO, S..Evaluation of $\mathrm{TiO}_{2}$ Nanoparticle Thin Films Prepared by Electrophoresis Deposition. Key Engineering Materials, [s.I.], v. 485, p.165-168, 2011.

34 ANANTH, K.P.; SUGANYA, S.; MANGALARAJ, D.; FERREIRA, J.M.F.; BALAMURUGAN, J.M.F. Electrophoretic bilayer deposition of zirconia and reinforced bioglass system on Ti6Al4V for implant applications: $A n$ in vitro investigation. Materials Science And Engineering: C, [s.I.], v. 33, n. 7, p.41604166, 2013.

35 GUO, F.; SHAPIRO, I.P.; XIAO, P. Effect of $\mathrm{HCl}$ on electrophoretic deposition of yttria stabilized zirconia particles in organic solvents. Journal Of The European Ceramic Society, v. 31, n. 14, p.2505-2511, 2011.

36 ARUNA, S.T.; RAJAM, K.S.. A study on the electrophoretic deposit ion of 8YSZ coating using mixture of acetone and ethanol solvents. Materials Chemistry And Physics, v. 111, n. 1, p.131-136, 2008.

37 FERRARI, B.; MORENO, R.. The conductivity of aqueous $\mathrm{Al}_{2} \mathrm{O}_{3}$ slips for electrophoretic deposition. Materials Letters, [s.I.], v. 28, n. 4-6, p.353-355, 1996.

38 KRÜGER, H. G.; KANOTE, A.; SCHINDLER, U.;JERN, H.; BOCCACCINI, A. Composite ceramic-metal coatings by means of combined electrophoretic deposition and galvanic methods. Journal Of Materials Science, [s.I.], v. 39, n. 3, p.839-844, 2004. 
39 WANG, Y.; LEU, I.; HON, M.. Kinetics of Electrophoretic Deposition for Nanocrystalline Zinc Oxide Coatings. Journal Of The American Ceramic Society, [s.I.], v. 87, n. 1, p.84-88, 2004.

40 ZHITOMIRSKY, I; GAL-OR, L. Electrophoretic deposition of hydroxyapatite. Journal Of Materials Science Materials In Medicine, [s.l.], v. 8, n. 4, p.213-219, 1997.

41 QIAN, B.; SHEN, Z. Laser sintering of ceramics. Journal Of Asian Ceramic Societies, [s.l.], v. 1, n. 4, p.315-321, 2013.

42 WANG, X.; XIÃO, P.; SCHIMIDT, M.; LI, L.. Laser processing of yttria stabilised zirconia/alumina coatings on Fecralloy substrates. Surface And Coatings Technology, [s.I.], v. 187, n. 2-3, p.370-376, 2004.

43 Klocke, F. and Wirtz, H. (1997), "Selective laser sintering of ceramics", Proc. Int. Conf. Laser Assisted Net Shape Engineering

44 KRUTH, J-p.; MERCELIS, P.; VAERRENBERGJ, J.V.;FROYEN, L.; ROMBOUTS, M. Binding mechanisms in selective laser sintering and selective laser melting. Rapid Prototyping Journal, [s.I.], v. 11, n. 1, p.26-36, 2005.

45 SCHUEREN, B. V.D.. Basic contributions to the development of the selective metal powder sintering process. 1996. Tese (pós-doutorado), K.U.Leuven, Engienniring. Faculty, Belgium.

46 GERMAN, R.M. Liquid phase sintering. New York: Plenum Press, 1985.

47 KARAPATIS, P. A sub-process approach of selective laser sintering. 2002. Tese (pós-doutorado) , Escola Politécnica Federal de Lausana.

48 Nd:YAG laser, Physics and radio electronics. Disponível em http://www.physics-and-radio-electronics.com/physics/laser/ndyaglaser.html .acessado em 06 de julho de 2017. 
49 PASCHOTTA, R. YAG lasers em Encyclopedia of Laser Physics and Technology, edição de outubro de 2008. Disponível em https://www.rpphotonics.com/yag lasers.html. Acessado em 06 de julho de 2017.

50 OpenSPIM - Theorical Basics. Gausian Beams optics. Disponível em http://openspim.org/SPIM_Optics_101/Theoretical_basics\#Gaussian_Beam_Optic s. Acessado em 22 de agosto de 2017.

51 PASCHOTTA, R. Gaussian beams em Encyclopedia of Laser Physics and Technology, edição de outubro de 2008. Disponível em https://www.rpphotonics.com/gaussian_beams.html. Acessado em 07 de Julho de 2017

52 AMERICAN SOCIETY FOR TESTING AND MATERALS. Standard Test Methods for Apparent Porosity, Water Absorption, Apparent Specific Gravity, and Bulk Density of Burned Refractory Brick and Shapes by Boiling Water. West Conshohocken, PA, 2000.

53 ALBAYRAK, O.; EL-ATWANI, O.; ALTINTAS, S.. Hydroxyapatite coating on titanium substrate by electrophoretic deposition method: Effects of titanium dioxide inner layer on adhesion strength and hydroxyapatite decomposition. Surface And Coatings Technology, [s.I.], v. 202, n. 11, p.2482-2487, 2008.

54 RAD, A.T.; SOLATI-HASHJIIN, M.; OSMAR, N.A.A.; FAGHIHI, S.. Improved bio-physical performance of hydroxyapatite coatings obtained by electrophoretic deposition at dynamic voltage. Ceramics International, [s.I.], v. 40, n. 8, p.12681$12691,2014$.

55 SATO, N.; KAWACHI, M.; NOTO, K.; YOSHIMOTO N.; YOSHIZAEA, M. Effect of particle size reduction on crack formation in electrophoretically deposited YBCO films. Physic C: Superconductivity, v.357-360, p.1019-1022, 2001.

56 BESRA, L; LIU, M. A review on fundamentals and applications of electrophoretic deposition (EPD). Progress In Materials Science, v. 52, p.1-61, 2007.

57 POWERS, R.W. The electrophoretic forming of beta-alumina ceramic. Journal Electrochemical Society , p.122:482-6, 1975. 
58 BASU, R.N.; RANDALL, C. A.; MAYO, M.J.. Fabrication of Dense Zirconia Electrolyte Films for Tubular Solid Oxide Fuel Cells by Electrophoretic Deposition. Journal Of The American Ceramic Society, v. 84, n. 1, p.33-40, 2001.

59 SAVALANI, M M; HAO, L; A HARRIS, R. Evaluation of $\mathrm{CO}_{2}$ and Nd: YAG Lasers for the Selective Laser Sintering of HAPEX®. Proceedings Of The Institution Of Mechanical Engineers, Part B: Journal of Engineering Manufacture, v. 220, n. 2, p.171-182, 2006.

60 MERCELIS, P; KRUTH, J.. Residual stresses in selective laser sintering and selective laser melting. Rapid Prototyping Journal, v. 12, n. 5, p.254-265, 2006. 